\title{
Camp Maxey IV Archaeological Testing of Six Sites, Lamar County, Texas
}

Richard B. Mahoney

Steve A. Tomka

Raba Kistner

Jason D. Weston

Raymond P. Mauldin

Center for Archeological Research, University of Texas at San Antonio

Follow this and additional works at: https://scholarworks.sfasu.edu/ita

Part of the American Material Culture Commons, Archaeological Anthropology Commons, Environmental Studies Commons, Other American Studies Commons, Other Arts and Humanities Commons, Other History of Art, Architecture, and Archaeology Commons, and the United States History Commons

Tell us how this article helped you.

This Article is brought to you for free and open access by the Center for Regional Heritage Research at SFA ScholarWorks. It has been accepted for inclusion in Index of Texas Archaeology: Open Access Gray Literature from the Lone Star State by an authorized editor of SFA ScholarWorks. For more information, please contact cdsscholarworks@sfasu.edu. 


\section{Camp Maxey IV Archaeological Testing of Six Sites, Lamar County, Texas \\ Creative Commons License \\ (C) $(1) \Theta$}

This work is licensed under a Creative Commons Attribution-NonCommercial 4.0 International License 


\section{Camp Maxey IV}

\section{Archaeological Testing of Six Sites, Lamar County, Texas}

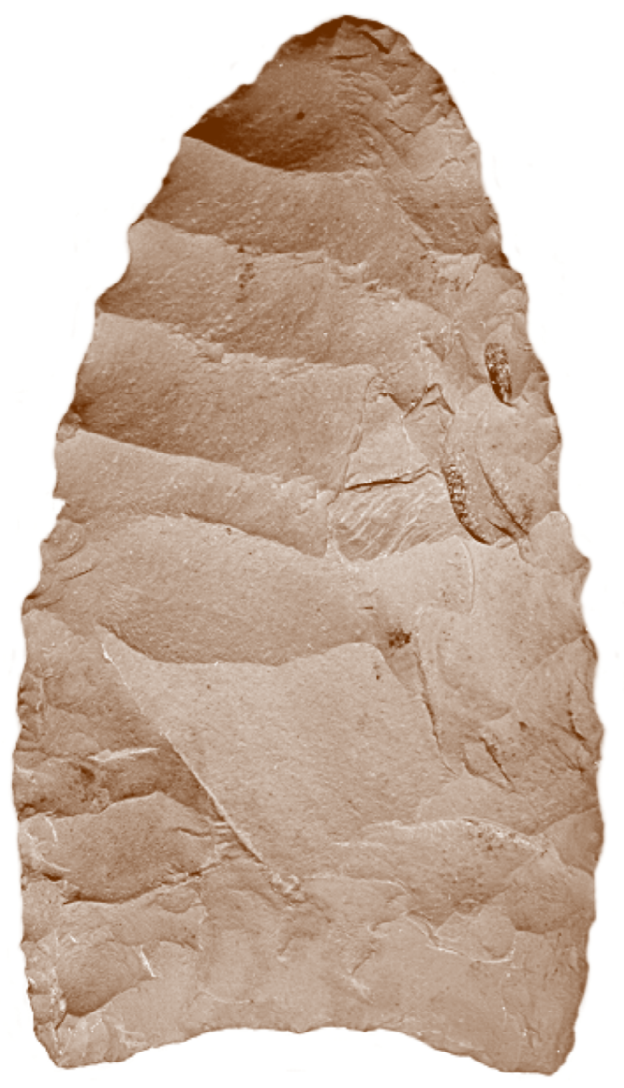

by

Richard B. Mahoney, Steve A. Tomka, Jason D. Weston, and Raymond P. Mauldin

with contributions by

Rick C. Robinson and Marybeth S. F. Tomka

Center for Archaeological Research The University of Texas at San Antonio Archaeological Survey Report, No. 326 2002

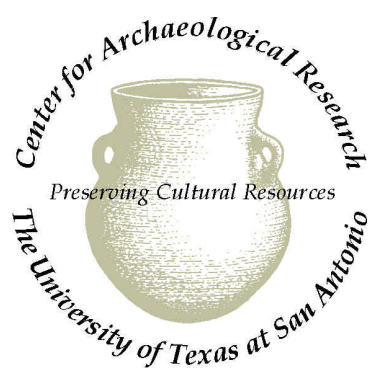




\title{
Camp Maxey IV \\ Archaeological Testing of Six Sites, Lamar County, Texas
}

\author{
by \\ Richard B. Mahoney, Steve A. Tomka, \\ Jason D. Weston, and Raymond P. Mauldin \\ with contributions by \\ Rick C. Robinson and Marybeth S. F. Tomka
}

Texas Antiquities Committee Permit No. 2180

Steve A. Tomka

Principal Investigator

Prepared for:

Adjutant General's Department of Texas Directorate of Facilities and Engineering Environmental Branch, Austin, Texas http://www.agtx-ev.pollution.org

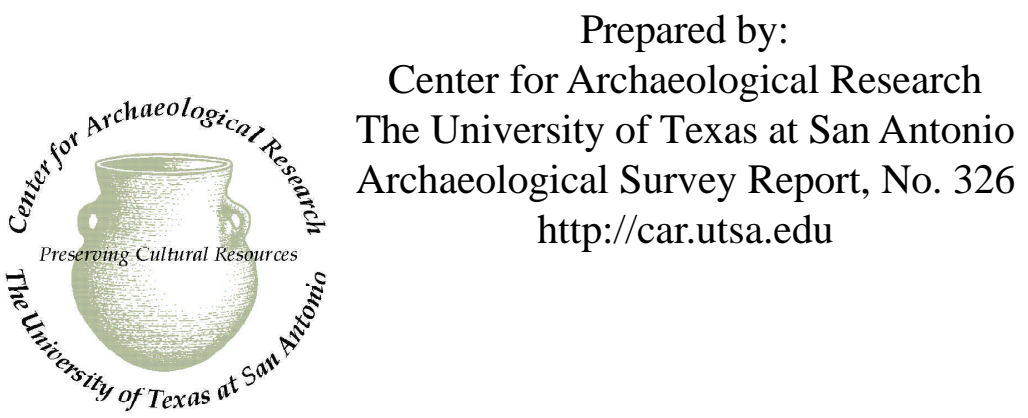

(C)opyright 2002 
The following information is provided in accordance with the General Rules of Practice and Procedure, Chapter 41.11 (Investigative Reports), Texas Antiquities Committee:

1. Type of investigation: Testing

2. Project name: Camp Maxey IV, Archaeological Testing of Six (6) Sites

3. County: Lamar

4. Principal investigator: Steve A. Tomka

5. Name and location of sponsoring agency: Texas Army National Guard, Cultural Resources, P.O. Box 5218, Austin, TX 78763-5218

6. Texas Antiquities Permit No.: 2180

7. Published by the Center for Archaeological Research, The University of Texas at San Antonio, 6900 N. Loop 1604 W., San Antonio, Texas 78249-0658, 2002

A list of publications offered by the Center for Archaeological Research is available. Call (210) 458-4378; write to the Center for Archaeological Research, The University of Texas at San Antonio, 6900 N. Loop 1604 W., San Antonio, Texas 78249-0658; e-mail to car@lonestar.utsa.edu; or visit CAR's web site at http://car.utsa.edu. 


\begin{abstract}
From June 14 through July 4, 2001, the Center for Archaeological Research of The University of Texas at San Antonio conducted National Register of Historic Places eligibility testing of six prehistoric archaeological sites (41LR190, 41LR194, 41LR196, 41LR200, 41LR258, and 41LR259) at Camp Maxey, Lamar County, Texas, under contract with the Texas Army National Guard. The investigations were conducted under Texas Antiquities Permit No. 2180. The Phase II testing fieldwork consisted of the excavation of twelve backhoe trenches and nineteen 1 x 1-m test units across the sites to investigate significant cultural deposits encountered during the previous survey phase. In concert with the archaeological field investigations, lithic and native ceramic analyses and magnetic sediment susceptibility studies were performed to aid in the determination of site integrity and eligibility.

The synthesis of these analyses has provided adequate data to determine temporal integrity and recommendation of National Register eligibility for site 41LR190. Further cultural resources investigations in the form of Phase III data recovery excavations are thus recommended for this site prior to proposed development. Conversely, due to lack of significance criteria, sites 41LR194, 41LR196, 41LR200, 41LR258, and 41LR259 are recommended as ineligible for inclusion in the National Register and require no further cultural resources investigations.
\end{abstract}




\section{Camp Maxey IV: \\ Archaeological Testing of Six Sites, Lamar County, Texas}

\section{Contents}

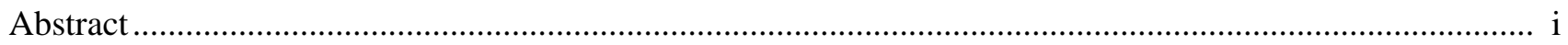

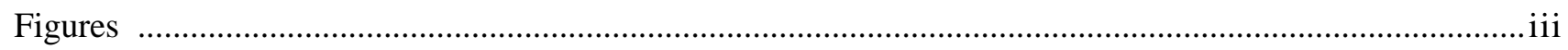

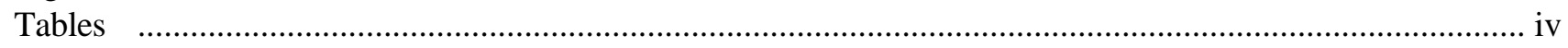

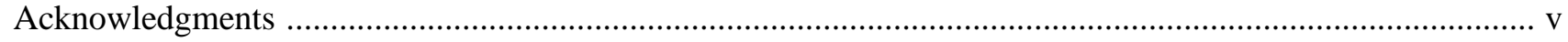

Chapter 1: Introduction

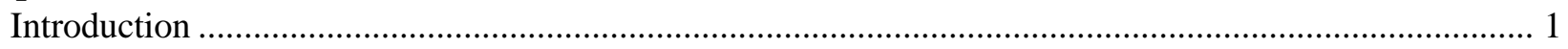

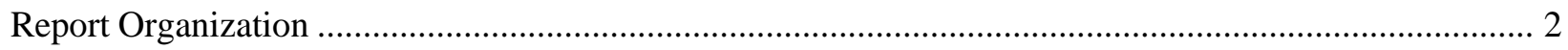

Chapter 2: Environmental Setting

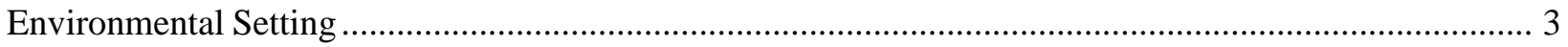

Chapter 3: Cultural Setting

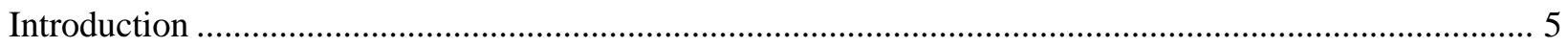

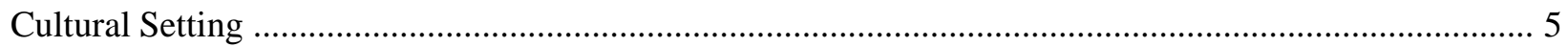

Chapter 4: Archaeological Background

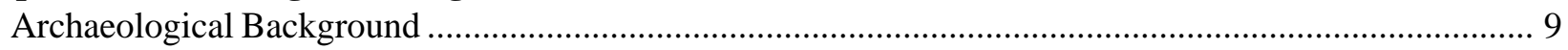

Chapter 5: Methodology

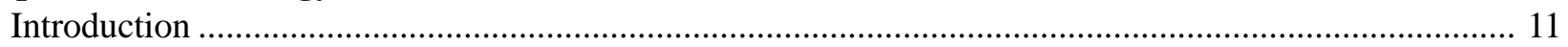

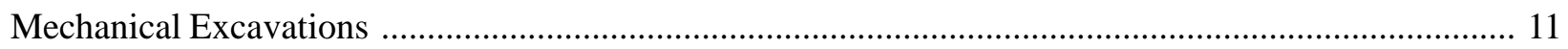

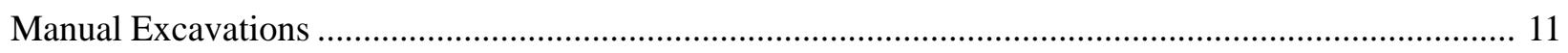

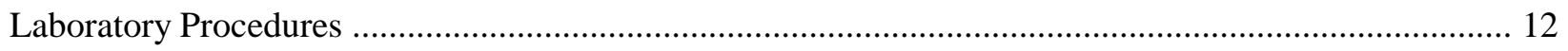

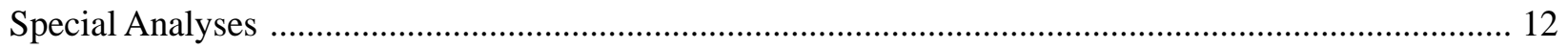

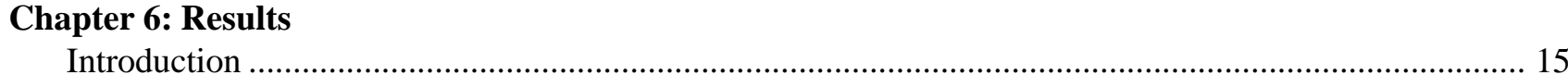

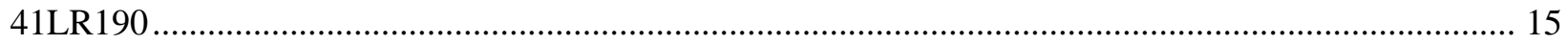

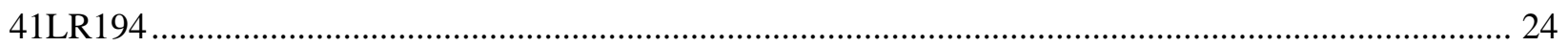

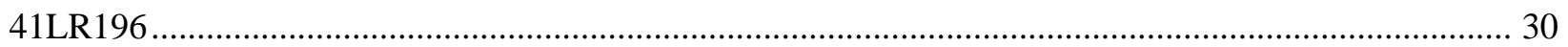

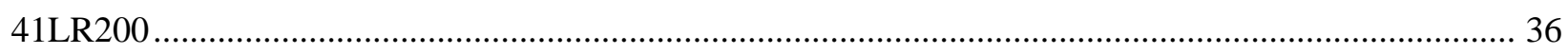

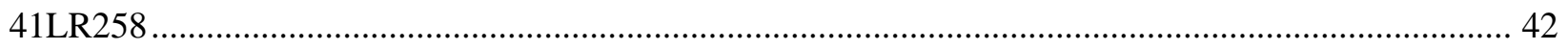

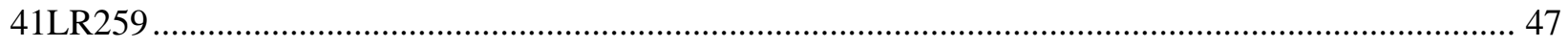

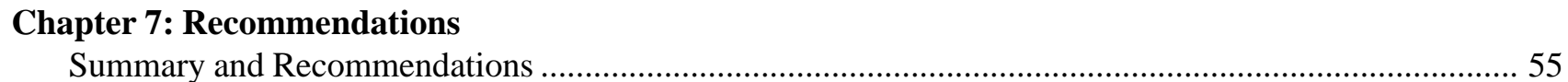

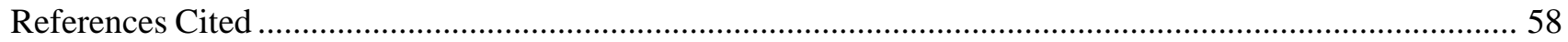

Appendix A: Magnetic Sediment Susceptibility Testing

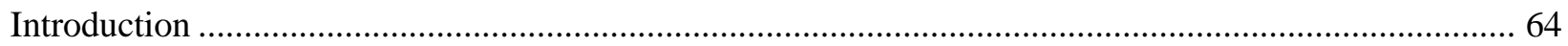

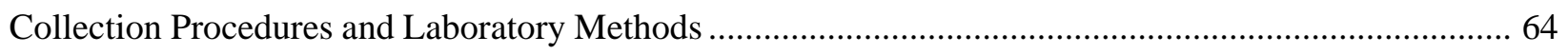

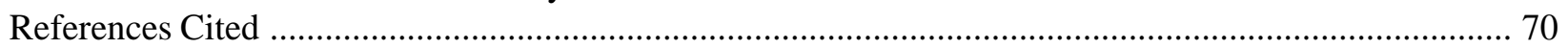




\section{Figures}

Figure 1. General location of Camp Maxey in Lamar County, northeast Texas........................................... 1

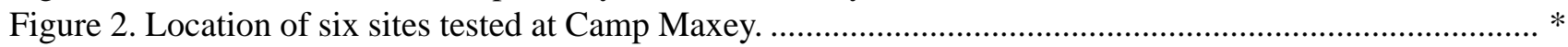

Figure 3. Site map of 41LR190 showing the location of all units excavated on site. .................................. 16

Figure 4. Profiles of five test units excavated at 41LR190 ............................................................... 17

Figure 5. Profiles of three backhoe trenches excavated at 41LR190 ...................................................... 18

Figure 6. Plan view of Feature 3, Test Unit 5 (Level 7, 60-70 cm bs), 41LR190..................................... 19

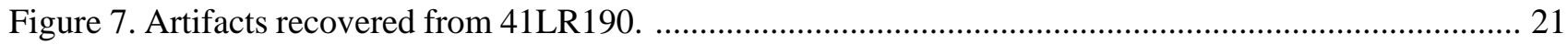

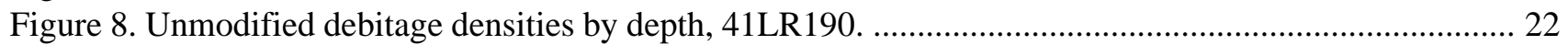

Figure 9. Plot of mass specific sediment susceptibility values for Test Unit 5, 41LR190. ......................... 25

Figure 10. Site map of 41LR194 showing the location of all units excavated on site. .............................. 26

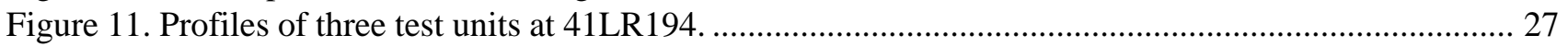

Figure 12. Profiles of three backhoe trenches excavated at 41LR194 ..................................................... 28

Figure 13. Unmodified debitage densities by depth, 41LR194. .............................................................. 30

Figure 14. Site map of 41LR196 showing the location of all units excavated on site. ................................ 31

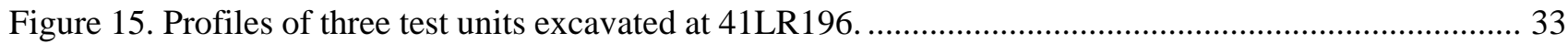

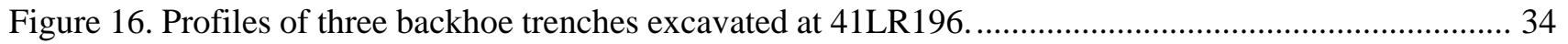

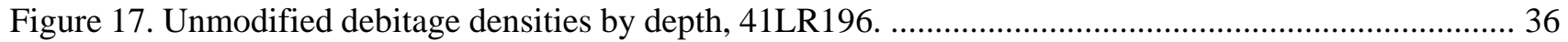

Figure 18. Site map of 41LR200 showing the location of all units excavated on site. ................................ 37

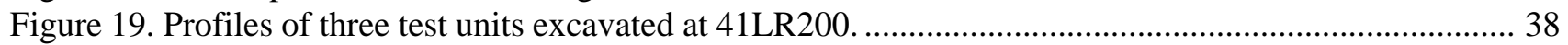

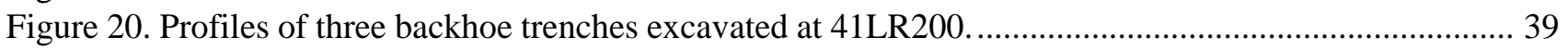

Figure 21. Unmodified debitage densities by depth, 41LR200. .............................................................. 41

Figure 22. Plot of mass specific sediment susceptibility values for Test Unit 2, 41LR200. ....................... 42

Figure 23. Site map of 41LR258 showing the location of all units excavated on site. ................................ 43

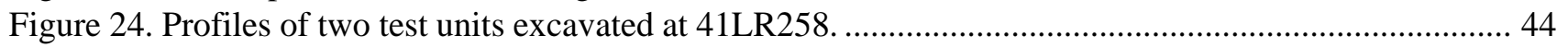

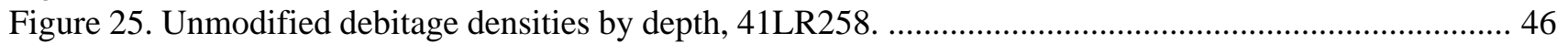

Figure 26. Plot of mass specific sediment susceptibility values for Test Unit 2, 41LR258. ...................... 47

Figure 27. Site map of 41LR259 showing the location of all units excavated on site. ................................. 48

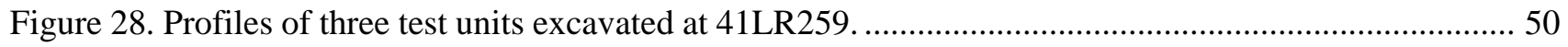

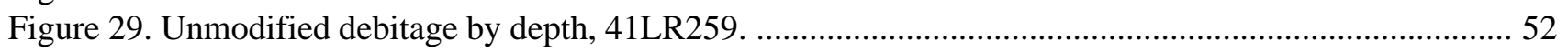

Figure 30. Plot of mass specific sediment susceptibility values for Test Unit 2, 41LR259........................ 53

* Figure located in pocket at back of report. 


\section{Tables}

Table 1. Potential to address research issues and NRHP eligibility of tested sites at Camp Maxey ............... 56

Table A-1. Magnetic sediment susceptibility data for a variety of substances ........................................... 65

Table A-2. Presence/absence of cultural material and sediment susceptibility scores for 41BR473 ..............65

Table A-3. Sediment susceptibility data for four sites at Camp Maxey ..................................................... 67 


\section{Acknowledgments}

The staff at the Center for Archaeological Research (CAR) wish to thank the Camp Maxey Facility Manager, Sgt. Linda Surber, and Sgt. Norman Nicholson for their support during the fieldwork. They allowed us access to the facility and aided with logistics. Shellie Sullo-Prewitt, Cultural Resources Manager at Camp Mabry, and the staff at the Adjutant General's office in Austin, provided logistical support. Also, we greatly appreciate Ms. Sullo-Prewitt's dedication to the preservation of cultural resources on the facility, and her interest in the pursuit of scientific research in Caddo archaeology. With each passing day, we learn more about the prehistory of the facility and region.

We would like to thank the owner and staff at the Victorian Inn for their hospitality. Similarly, Bob and Brian, backhoe operators from J.D. Mickel Construction, deserve a great deal of thanks for their hard work and skill in not losing any backhoes in the loose sands of Camp Maxey.

The crew of the Maxey IV project, led by Richard Mahoney, consisted of: Cory Broehm, Jennifer Logan, Sylvia Reyna, Rick C. Robinson, Bryant Saner, John Spencer, and Carol Villalobos. All of these individuals deserve many thanks for their hard work and dedication to proper archaeological methods and techniques. Many thanks also are due to the CAR staff, including Raymond P. Mauldin, Bruce Moses, Richard Young, Marybeth Tomka, Maryanne King, and Johanna Hunziker for their hard work that made possible the completion of the project. The site and project maps, the accuracy of the data, and the overall outstanding quality of the report are due to their hard work. Raymond P. Mauldin carried out the soil susceptibility study. Rick C. Robinson and Jason D. Weston carried out the unmodified debitage analysis, while Marybeth Tomka conducted the ceramic analysis of the native wares and oversaw the curation preparation of the project-related materials. Finally, none of it could have been possible without the help of the large number of laboratory staff that washed, cataloged, and prepared for curation the collection of artifacts from the project. 



\section{Chapter 1: Introduction}

\section{Introduction}

The Center for Archaeological Research (CAR) of The University of Texas at San Antonio conducted National Register of Historic Places (NRHP) testing at six sites within the Camp Maxey training facility during June and July 2001. Camp Maxey is located in the northern portion of Lamar County and is depicted in Figure 1. The project was conducted under contract with the Texas Army National Guard (TXARNG). The purpose of the investigations was to assess, through excavation of backhoe trenches and test units, the NRHP eligibility of the six prehistoric archaeological sites, 41LR190, 41LR194, 41LR196, 41LR200, 41LR258, and 41LR259, determined potentially eligible during previous survey efforts (Lyle et al. 2001). The Texas Antiquities Permit Number (2180) originally assigned to the most recent CAR survey project (Lyle et al. 2001) is retained for the current testing phase through an extension of contractual obligations through TXARNG, with Dr. Steve A. Tomka continuing to serve as Principal Investigator.

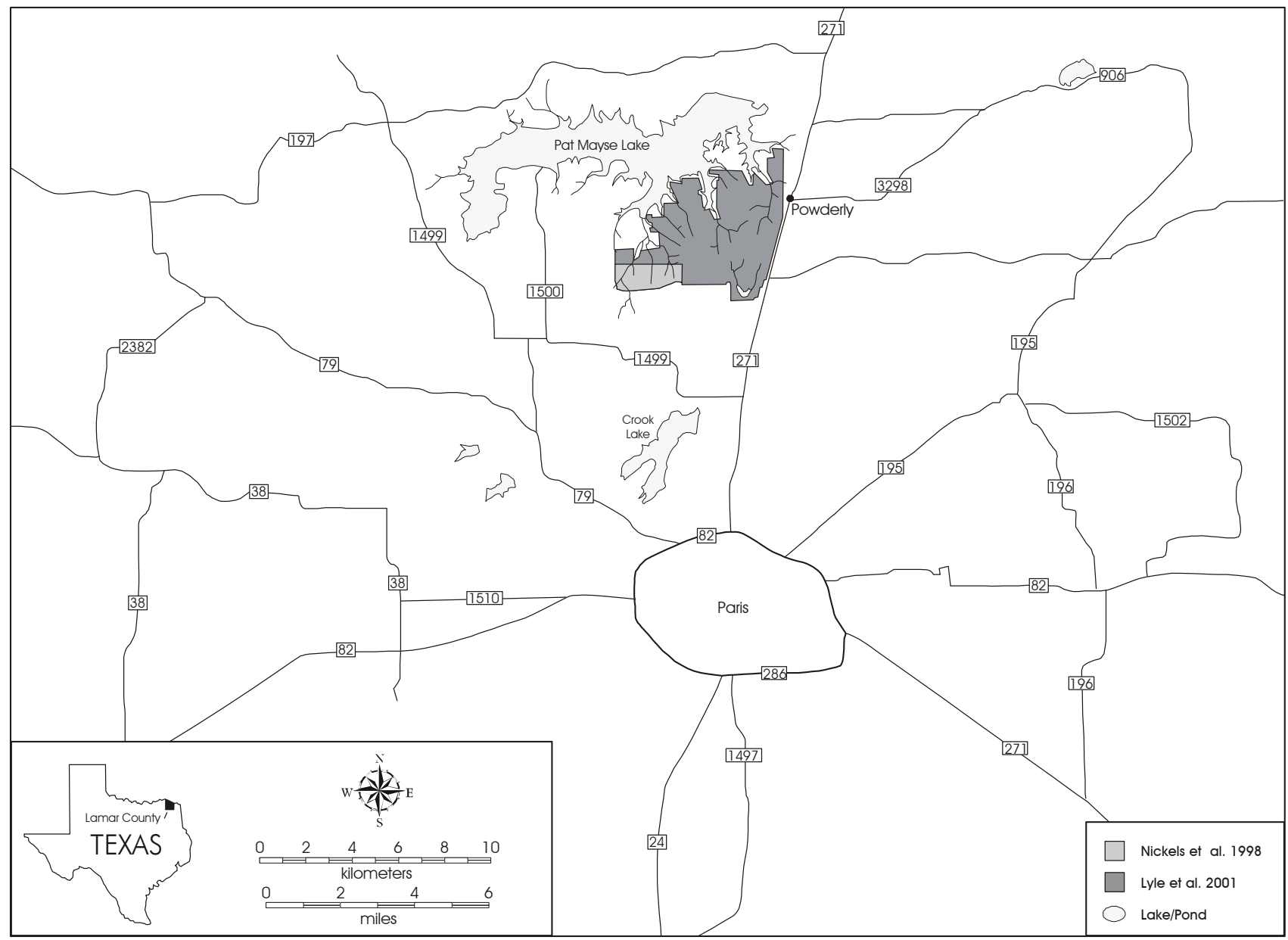

Figure 1. General location of Camp Maxey in Lamar County, northeast Texas. Note two previous CAR survey areas within the facility. 


\section{Report Organization}

As the Camp Maxey project has been expanded to include both survey and testing efforts under the original contract, a series of volumes will report the results of the survey and various testing phases of investigations. While each volume serves as a standalone document, settings chapters such as Environmental Setting, Cultural Setting, and Archaeological Background will not be replicated in as great detail in subsequent volumes. The interested researcher is referred to Camp Maxey II: A 5,000 Acre Cultural Resource Survey of Camp Maxey, Lamar County, Texas (Lyle et al. 2001) for a more in-depth discussion of these aspects of the Camp Maxey training facility.

This report is composed of seven chapters and one appendix. Following this introductory chapter, the Environmental Setting chapter will discuss the general physical environment encountered within the project area. The third chapter, Cultural Setting, provides a brief overview of the cultural prehistory and history of the region. Chapter Four, Archaeological Background, presents previous archaeological investigations within the region and an overview of previously recorded sites. The fifth chapter, Methodology, describes, in detail, the field and laboratory methodologies employed during the investigations, special analyses, and curatorial requirements. Chapter 6, Results, will discuss the results from the field and laboratory investigations on a site-by-site basis. The final chapter, Recommendations, presents recommendations for NRHP eligibility and, where warranted, for further work. Appendix A, Magnetic Sediment Susceptibility Testing, presents supporting data for the site assessments.

The Camp Maxey facility map with site locations is not included in the text but is located in a pocket at the back of this report. A copy of the map may be obtained by writing to AGTX-EV, Cultural Resources, P.O. Box 5218, Austin, TX 78763-5218. 


\section{Chapter 2: Environmental Setting}

Camp Maxey is located in the north-central portion of Lamar County, Texas, approximately $9.7 \mathrm{~km}(6 \mathrm{mi})$ north of the city of Paris. The project area is bound to the north by Pat Mayse Reservoir; to the east by US HWY 271; to the south by Gate Two County Road; and to the west by unimproved pastureland. In its current state, the training facility occupies approximately 6,400 ac $(2,590 \mathrm{ha})$, far less than the original 70,000 ac $(28,329$ ha) allocated by the federal government in 1942.

The extant, remnant portion of Camp Maxey is wholly contained within the Post Oak Savannah vegetation region, with a relative diversity of flora. Oak woodlands atop upland sandy and loamy soils predominate throughout the project area, with intermittent prairies of little bluestem comprising a majority of the remainder of the project area. Persimmon and winged sumac seem to occur in greatest densities along the border of the prairies and intersecting riparian zones of intermittent tributaries and perennial streams. Riparian zones of water oak/elm border the numerous second and third order tributaries that dissect the training facility draining into Pat Mayse Reservoir.

The reservoir was constructed from Sanders Creek, a tributary of the Red River, in 1967 following authorization from the Flood Control Act of 1962; Project Document HD 71, 88th Congress, 1st Session. According to U.S. Army Corps of Engineers (COE) station data, the reservoir occupies 7,680 ac $(3,108 \mathrm{ha})$ at the top of the flood control pool (460.5 ft [140.4 m] above mean sea level [AMSL]) with an approximate 182,940 ac-ft ( 225-billion liter) capacity. Construction of the reservoir subsumed roughly ten percent of the original acreage of the training facility, including some of the more intensive live-round munitions activity areas.

According to recent Soil Conservation Service (SCS) soil survey maps of the project area, Camp Maxey is located within the Whakana-Porum series of moderate to well-drained upland loamy soils (Ressel 1979).
Within this series occur several soil map units as defined by the 1974 soil survey. A majority of the prehistoric sites at Camp Maxey occur on WhakanaPorum complex or Whakana fine sandy loams. These soils generally exhibit slow to moderate permeability with moderate to rapid runoff, providing severe water erosion potential (Ressel 1979).

Numerous natural springs and seeps were encountered within the bounds of the training facility. While historic wells within the vicinity have probably reduced the resources of the springs and seeps, prehistoric occupation proximity to these natural features would have been preferred. Magnitude ranges from slow, barely noticeable seeps to active, swift-flowing springs of cold, clear water.

Landform elevations range from $140 \mathrm{~m}$ (460 ft) to 171 $\mathrm{m}(560 \mathrm{ft})$ AMSL throughout the project area. All six of the tested sites occur within the $149 \mathrm{~m}$ (490 ft) to 159 m $(520 \mathrm{ft})$ AMSL elevation range. The sites occupy ridges adjacent moderate to very steep ravines. This distributional pattern is most likely associated with proximity to potable water in the form of seeps, springs, or intermittent streams. 



\section{Chapter 3: Cultural Setting}

\section{Introduction}

Geographically, Camp Maxey is situated in the extreme northeast corner of Texas (see Figure 1) immediately north of the juncture of the Post Oak Savannah and Blackland Prairie vegetation subregions. The general region of the project area is bordered to the west by the Southern Plains, to the north by the Ouachita province, to the southwest by the Edwards Plateau, and to the south by the West Gulf Coastal Plain. It is the proximity to these various ecotones and physiographic provinces that provides for the influence of various adaptation patterns, patterns of mobility, and/ or external cultural influences.

\section{Cultural Setting}

\section{Paleoindian}

The Paleoindian period is conceptually that era in prehistory wherein humans first entered the New World during the latter part of the Pleistocene geologic epoch. Due to the frequent location of isolated finds of Paleo-era projectile points and the infrequent encounter of dense occupational features, it is inferred that these peoples were highly mobile, nomadic hunters and opportunistic gatherers. Without certainty, it is possible that the cultures of this era were specialized exploiters of the dwindling population of the now extinct megafauna that once roamed the North American continent.

With some variation, the Paleoindian period for this region is generally agreed to have begun approximately 12,000 years ago and terminated roughly 9,000 to 8,000 years ago, sometime during the Early Holocene climatic interval (Johnson and Goode 1994; Perttula 1999; Schambach 1998; Wood 1998). However, Girard (2000:7) argues that the Paleoindian period for northwest Louisiana occurs from 12,000 BP until 10,000 BP. The termination for this period, relative to conventional Texas chronologies (however slightly varied they may be) is quite premature, and Girard (2000:8) qualifies this discrepancy due to the fact that "archaeologists in Texas do not routinely calibrate radiocarbon dates." Granted, the primary reference Girard cites (Collins 1995) does not use calibrated dates; however, the periods of Collins' chronology do not differ markedly from those espoused by Johnson and Goode (1994), which are based upon calibrated dates utilizing the methodology of Stuvier and Reimer (1993).

Regardless the chronology of choice, the Paleoindian period is divided technologically into early and late phases. The early phase is characterized by the presence of primarily fluted projectile points (i.e., Clovis and Folsom) produced of non-local materials. The exotic stone tools recovered from these early sites further suggest a high-mobility culture. The late phase of the Paleoindian period is regionally characterized by dart points, such as San Patrice and Dalton, consisting primarily of local materials (Schambach 1998). The presence of woodworking tools, such as the Dalton adze, in association with these new variant dart points suggests a slightly more sedentary culture than its predecessor.

\section{Early Archaic}

The Archaic Era represents the following ca. 6,000 to 6,500 years of prehistory for this region and is subdivided into three separate periods: Early, Middle, and Late. Environmentally, this era commences just before the onset of the Middle Holocene geologic epoch, a time of "oscillating" conditions beginning at a moderate climate, trending toward a dry extreme, and returning to moderate conditions throughout the entirety of the era (Collins 1995; Johnson 1995). Culturally, the development of the Archaic within this region and, more specifically within the Plains margin proper, may have been attributable to Late Paleoindian plainsmen exploiting the woodland-prairie margin and interacting with woodland cultures during times of drought (Johnson 1989). 
Early Archaic manifestations within the region include the apparent onset of sedentary subsistence indicated by the diversity of recovered artifact assemblages at numerous sites (e.g., Girard 2000; Wyckoff 1984). Specifically, woodworking tools, such as adzes and wedges, become more common, as well as abraders and scrapers. The Conly site in northwestern Louisiana exhibited excellent preservation of faunal remains including mussel shell, bone, snail, and crawfish exoskeletons (Girard 2000:63). Additionally, Girard (2000:63) cites the presence of burned rock, grinding stones, pounding tools, an axe, various bifaces, and bone tools as further indicators of a more diversified pattern of subsistence.

\section{Middle Archaic}

The relatively brief Middle Archaic period represents the final years of the Middle Holocene and can be viewed as a transitional time for the prehistoric peoples of the region. During the early part of this period, bison are present along the bordering plains and prairie regions after a nearly three millennia hiatus (Dillehay 1974). Their appearance is short-lived, however, and by approximately 5200 вр bison once again disappear from the faunal assemblage of the Southern Plains and adjoining prairie margin. The continuance and massive proliferation of relative sedentism and/or specific exploitation of localized natural resources is evidenced by the continued occupation and re-occupation of preferred landforms (e.g., Girard 2000:8). Johnson and Goode (1994:28) also point to the specialization of targeting specific natural resources, possibly xerophytic plants. These characteristics, in response to an increasingly drier environment (c.f. Bousman 1998; Johnson 1995), would form the basis for the transformation in the overall stylistic tradition to that of the Late Archaic.

\section{Late Archaic}

The Late Archaic period represents the final three millennia of the Archaic Era, from approximately 4200 BP to 1200 вP (Johnson and Goode 1994:29) and roughly coincides with the commencement of the Late Holocene. Within northeast Texas, the Woodland, preCaddoan culture introduces a new aspect to this generally accepted time of pre-ceramic, dart and atlatl using inhabitants of the state. Crude ceramics alongside smaller dart points typical of the Late Archaic period are diagnostic of this Woodland period.

Adaptation to a relatively dry climate with low precipitation and high temperatures appears to mark the beginning of the period, with bison reappearing in the faunal assemblage following a hiatus of over one thousand years (Dillehay 1974). Despite these xeric conditions, human population seems to have increased within the region (Prewitt 1985). Adaptation to this changing environment is best shown in Prewitt's (1981) discussion of the Uvalde and Twin Sisters Phases for central Texas. During this time, burned rock middens and similar burned rock scatters are abandoned. Diagnostics of this period are usually encountered stratigraphically above the underlying middens and scatters.

Floodplain-focused adaptation during this time is evident in various sites adjacent to the region (Girard 2000:9; Mahoney and Tomka 2001). Environmental changes can be cited as determinate factors in settlement patterns during this time. During and prior to this period, streams exhibited various stages of aggradation and stabilization. These dynamic changes are evidenced in the extant location of occupation sites in relation to streams and their current location topographically. The further analysis of this proximic location can be instrumental in determining the spatial relationship between site locations relative to the former meander of the associated stream.

The commencement of the Late Archaic I phase relative to the project area is characterized by a generally xeric environment probably correlative with the Dry Edwards Interval to the west and southwest. Palynological evidence from the Boriak bog (Lee County, Texas) and the Weakly bog (Leon County, Texas) reveals relatively low arboreal canopy cover; indicating a predominant grassland environment for these adjoining regions (Bousman 1998:Figure 7). Johnson and Goode (1994:34-35) propose that, due to the xeric conditions experienced by the peoples of the Late Archaic I period, burned rock middens proliferate for the processing of semi-succulents. Additionally, the period is further defined by the projectile-point styles of the Bulverde, Pedernales, Marshall, Montell, and Castroville (Johnson and Goode 1994:Figure 2). 
Johnson and Goode (1994:37) suggest eastern (United States) religious influences, manifest in the form of various burial practices, as one of the primary indicators of the Late Archaic II phase. The continuum of the trend toward a mesic environment can also be attributable to this period change. While a definitive date cannot be placed upon the abandonment of burned rock middens, Johnson and Goode (1994) note that these feature types are generally associated with the Late Archaic I phase, and the absence thereof denotes the beginning of the Late Archaic II phase. Typical projectile-point styles of this phase include, in progressive order, Marcos, Ensor, Frio, Darl, and Figueroa (Johnson and Goode 1994:Figure 2).

\section{Woodland}

Unique to characteristic Caddoan areas in northeast Texas, the Woodland period encompasses the latter 1,300 years of the traditionally accepted Late Archaic period in other Texas temporal chronologies (25001200 BP). Within the Caddoan area, this period basically subsumes the Late Archaic II phase, described above. This pre-Caddoan, ceramic culture is distinctive of northeast Texas archaeology. Artifact assemblages consist primarily of later, smaller Gary dart points to early expanding stem arrow points and early, sandy paste ware ceramics. As stated above, most ceramic cultures within Texas are associated with the Late Prehistoric. Here, Archaic-era dart points are encountered alongside ceramic vessels and associated sherds. This coincidence provides evidence for a continuum of native technology. While the advent of ceramics in concert with the occurrence of the bow and arrow in the remainder of the state signifies the onset of the Late Prehistoric period, the advent of ceramics alone indicates the Woodland period.

\section{Caddoan}

Transition from the Late Archaic, and more specifically from the Woodland, to the Caddoan is arguably accepted to occur with the advancement in technology from hunting techniques utilizing the atlatl and dart to utilization of the bow and arrow alongside the beginning of horticultural and, later, agricultural groups. Additionally, the occurrence of Caddoan-specific ceramic vessels generally denotes this change of periods. The Caddoan period is here defined as the time frame of approximately 1200 BP until European contact, roughly 300 вр within this region.

Explicit subdivisions of the Caddoan era have been established in recent years to better define the technological advancement of these peoples (e.g., Story 1990). The following timeline, adapted from Kenmotsu and Perttula (1993), provides a general synopsis of horticultural and agricultural advancements:

Formative Caddoan (A.D. 800-1000)

Onset of horticulture, but hunting and gathering still play an important role in subsistence.

Early Caddoan (A.D. 1000-1200)

Formal horticulture to the beginnings of agriculture. Hunting continues, but gathering becomes less important.

Middle Caddoan (A.D. 1200-1400)

Intensive agriculture and hunting predominate subsistence. Foraging does not appear to be a pivotal activity in the subsistence base.

Late Caddoan (A.D. 1400-1680)

Intensive agriculture, specifically maize, predominates the diet, as evidenced in skeletal pathologies. Less effort seems to be placed on hunting.

In the central Texas region, bordering to the west and southwest of the Caddoan area, Prewitt (1981:Figure 3) identifies the initial succeeding Late Prehistoric phase as the Austin Phase, occurring from the termination of the Late Archaic II until approximately 650 BP. This phase would generally be coeval with the Formative and Early Caddoan cultures. Aside from the aforementioned changes in technology, Prewitt (1981:74) ascribes only a slight increase in the dependence upon hunting as a means of subsistence and a marked increase in the occurrence of "true cemeteries" as an indicator of period change.

The succeeding central Texas Late Prehistoric phase, the relatively short-lived Toyah phase, as defined by Prewitt (1981), is characterized by the "dramatic" shift in subsistence from hunter-gatherer to that of an economy based primarily on hunting. This phase would generally be coeval with the Middle and Late 
Caddoan cultures. Based upon data from Dillehay (1974), bison once again appear in the faunal assemblage of archaeological sites within central Texas. An intermediate shift to a generally dry, mesic environment is attributed to this influx of ungulate dependence (Johnson 1995). The material culture of this time-period appears to reflect subsistence based upon the procurement of bison in the form of various stone tools utilized for bison procurement and processing, such as Edwards, Perdiz, and Scallorn arrow points, along with various scrapers and other stone tools. 


\section{Chapter 4: Archaeological Background}

Professional archaeological investigations begin in the Lamar County region with the 1931 University of Texas excavations at the Sanders Farm Site (41LR2) in the far northwestern portion of Lamar County (Jackson et al. 2000). Later that year, the university also conducted limited test excavations at 41LR1, the Womack Site (Harris et al. 1965). The remainder of the earlier sites, primarily mound and/or burial sites, recorded by R. K. Harris throughout the mid-twentieth century were subsequently assigned current trinomials (41LR3-41LR9).

The impending construction of Pat Mayse Reservoir on Sanders Creek necessitated archaeological surveys that resulted in the recordation of an additional 23 trinomials in Lamar County. Sites 41LR10 through 41LR21 were recorded during the Texas Archeological Salvage Project (TASP) immediately prior to commencement of construction on March 9, 1965 (Shafer 1965). In 1967, the Archeological Salvage Project of Southern Methodist University conducted limited test excavations of sites recommended by Shafer (1965:38) for more intensive cultural resource investigation and also conducted further survey, locating an additional eleven sites (Lorrain and Hoffrichter 1968).

Various other universities and state agencies conducted survey and testing in Lamar County over the following three decades. Southern Methodist University conducted two phases of cultural resource surveys in Lamar County in the early 1970s. Both phases focused on the proposed Big Pine Lake project in the eastern portion of Lamar County and western portion of Red River County. Fifty-three archaeological sites were recorded in Lamar County during the two phases of survey (Hyatt and Mosca 1972). In the late 1970s and early 1980s, the Texas Department of Water Resources (now, Texas Water Development Board) recorded six sites during reconnaissance work for utility easements in the city of Reno, west of Paris (Fox 1979, 1981). North Texas State University (now, University of North Texas), Institute of Applied Sciences conducted various surveys in Lamar County throughout the late 1970s and 1980s. These surveys were primarily for the development of utility easements (e.g., Perttula and Nathan 1988) and yielded the discovery of 37 additional sites. The State Department of Highways and Public Transportation (now, Texas Department of Transportation) conducted Phase II testing on two prehistoric sites (41LR58 and 41LR92) east and south of the project area, respectively, concluding neither eligible for inclusion in the National Register of Historic Places (Luke 1978; Young 1984). Additionally, the Texas Archeological Society conducted their 1991 field school at the Ray Site, located along Nolan Creek, east of the current project area.

Prior to CAR's various survey and testing efforts, only limited cultural resources investigations had been conducted within the confines of the training facility. Survey for a utility easement resulted in the recordation of two historic (41LR138 and 41LR139) and one disturbed prehistoric lithic quarry site (41LR137) within Camp Maxey (Corbin 1992). During the 1990s, the Adjutant General's Department of Texas (AGD) conducted three limited pedestrian surveys within the facility, locating four historic sites (41LR14541LR148) that predate the military era (AGD 1993, 1997; Sullo and Stringer 1998). 



\section{Chapter 5: Methodology}

\section{Introduction}

The field methodology employed is based, in part, upon the results from the previous survey efforts (Lyle et al. 2001). These survey efforts generally defined areas of artifact densities within each recorded site that would condition subsequent placement of backhoe trenches and associated test units. Backhoe trenching and/or manual excavation of test units were conducted at each site.

Upon completion of investigations at each site, a Global Positioning System (GPS)-based site map was produced. Subsequent to the field investigations, each map was downloaded from the GPS unit and rendered by the drafting department at CAR, and reproductions are included in this report.

\section{Mechanical Excavations}

Twelve backhoe trenches were excavated among the sites investigated. This method of testing has become relatively commonplace in archaeological investigations and serves not only to prospect for cultural deposits and features, but also to provide a comparative view of the stratigraphy to be encountered during subsequent manual excavations. The machine employed for the current investigations was a Case 580 Super K tractor equipped with a Construction King Extend-AHoe arm attachment and 24" bucket. Typically, a cleanout plate is welded to the teeth of the bucket for archaeological trenching in order to produce a cleaner view of trench floors, however, due to the abundant root systems encountered, and occasional gravel deposits and ferruginous sandstone formations, this method proved counterproductive to trenching efforts, and a standard, toothed bucket was utilized.

The strategy employed for placement and excavation of backhoe trenches was to explore the apparent densest portion of each site, based upon survey-phase shovel test data. Specifically, the trenches were excavated adjacent to the most productive shovel tests in order to further investigate temporally diagnostic cultural material and/or investigate possible features. Shovel tests were considered "productive" based upon the presence of diagnostic artifacts or density of artifacts, suggestive of a nearby feature or cultural midden.

The excavation of each trench was closely monitored for impact to potential intact features or significant deposits. The excavated material was observed and all cultural material was collected and maintained with the backhoe trench provenience. Each backhoe trench profile was described on a unique form.

\section{Manual Excavations}

\section{Test Units}

A total of 19 test units was excavated during the current testing efforts. Test units per site varied from two to five based upon site size, distribution of cultural material, and density of cultural material. An average of approximately three test units per site was deemed adequate to assess NRHP site eligibility and determine whether further mitigative efforts are warranted.

When feasible, test units were placed immediately adjacent to backhoe trenches, with a unit wall sharing an associated backhoe trench wall. This method allowed for a more efficient means of excavation by permitting the excavator to view the various strata to be encountered during manual excavation. In addition, the physical demands of manual excavation are lessened as the excavator may dig while standing inside the relatively shallow $(\sim 1 \mathrm{~m})$ trench. This positioning permits greater leverage using hand tools, as opposed to excavation of a stand-alone unit not adjoining a backhoe trench.

All horizontal proveniences were maintained in $1 \mathrm{~m}^{2}$ levels, with large (ca. $>5 \mathrm{~cm}$ ) in situ burned rock, large $(\mathrm{ca} .>3 \mathrm{~cm})$ artifacts, and temporally diagnostic 
artifacts point provenienced whenever possible. Vertical excavation levels did not exceed $10 \mathrm{~cm}$ in thickness. Arbitrary $10 \mathrm{~cm}$ levels were maintained until the basal clayey substrate was encountered. All excavated sediments and soils were dry-screened through 1/4" mesh hardware cloth. The excavation results of each level were recorded on a unique form, including provenience data, soil data, artifactual material recovered, inclusions, disturbances, and a sketch of features (if any) encountered. Upon completion of each unit excavation, wall profiles were photographed and accurately depicted on archival quality graph paper.

All cultural material encountered during excavation was collected and recorded on field forms relative to their encountered provenience. Various samples were collected in the field to provide relevant data. These included the collection of all snail shell, faunal, and other ecofactual material observed. Soil samples were collected from throughout the vertical column at select sites and from each feature encountered. These samples will be used for soil susceptibility, macrobotanical (flotation), and microbotanical (e.g., pollen, phytoliths) analyses.

\section{Laboratory Procedures}

Upon completion of each 10-day session, all recovered artifacts and special samples along with the associated paperwork were submitted to the laboratory at CAR for processing and temporary curation. Artifact processing consisted of washing, a general category sort, cataloging, and entry into a standardized database. Subsequent to this initial laboratory processing, the various artifact categories were submitted to specialists for analyses. Following the formal analyses, the results were then incorporated into the database for final curation.

After completion of the reporting for the current project, and in preparation for future work, the artifacts and records from the sites tested during this project and the previous survey were pulled. The survey artifacts and records will be curated at the Texas Archeological Research Laboratory (TARL) with the associated records and recovered artifacts from the testing effort. Any recataloging or reanalysis of material that results in different data than that presented herein will be documented both on the artifact tags and in the accompanying records.

Final curatorial processing was conducted in accordance with 36 CFR 79 (Curation of Federally Owned and Administered Archaeological Collections), and other proprietary standards espoused by the Texas Archeological Research Laboratory, the permanent curatorial facility for the Camp Maxey project.

\section{Special Analyses}

\section{Native Ceramics}

Analysis of the Camp Maxey IV ceramics is consistent with the methods described in Nickels et al. (1998) and Lyle et al. (2001). That is, the sherd and vessel analysis is based on differences in paste and temper, the type of sherd (i.e., rim, body, or base), the rim and lip form (cf. Brown 1996:Figure 2-12), decoration (if present), decorative element (if identifiable), surface treatment (smoothing, burnishing, or polishing [see Rice 1987]), and oxidation patterns (cf. Teltser 1993). Sherd cross sections were inspected macroscopically and with a 10x hand lens to determine the character of the paste and its inclusions. Determining the firing atmosphere- the conditions of temperature, duration of firing, clays with different organic contents, or the amount of oxygen available at the time of firing-is based on the identification of the firing core in the sherd cross sections and the identification of oxidation patterns as defined in Teltser (1993:535-536 and Figure 2).

\section{Lithics}

In order to provide continuity in the analysis phase during the process of NRHP eligibility determination, all lithics recovered during the previous CAR survey (Lyle et al. 2001) at sites that are the focus of this subsequent testing, underwent reanalysis. Lithic analysis was divided into two equally important categories, tools and debitage. Tools are classified as intentionally modified and/or utilized lithics that range from formal, typed dart and arrow points to expedient, edge 
modified flakes used to scrape or cut. Debitage is classified as the by-product of tool preparation, tool manufacture, or tool rejuvenation. Metric traits, as well as macroscopic and low-power microscopic morphological characteristics were recorded for each of the debitage and the tools recovered during the two CAR investigations.

\section{Soil Susceptibility}

Numerous soil samples were recovered from the sites during the current investigations to test for magnetic sediment susceptibility. The process of measuring the change in magnetic susceptibility of the sediments involves collecting small soil samples at regular intervals throughout the vertical column of a test unit, backhoe trench, or shovel test. The potential change in value of the samples can indicate an increase or decrease in the amount of organic material through the various horizontal levels. Ideally, these peaks in magnetic susceptibility will correspond to an increase in artifact densities.

Samples recovered from the selected units were placed in plastic bags and stored in the controlled laboratory at CAR until analysis was performed. Prior to analysis, all sediment samples were air dried on a non-metallic surface. After drying, the samples were then ground to a uniform grain size using a ceramic mortar and pestle. This was done to standardize particle size and make the material both easier to handle and pack into sample containers. The ground samples were placed into a MS2B Dual Frequency Sensor that, in conjunction with a MS2 Magnetic Susceptibility Meter, provided the magnetic susceptibility of each sample. The results of these analyses are presented in Appendix A. 



\section{Chapter 6: Results}

\section{Introduction}

This chapter provides a detailed discussion of each site investigated during the current testing phase (Figure 2, in pocket at back of report). Results of applicable special analyses are presented on a site-bysite basis, including an assessment of the temporal affiliation of the sites and intra- and/or inter-site comparisons, where applicable. Cultural material recovered from each site is incorporated into the descriptive text to provide a better understanding of the assemblages.

\section{LR190}

\section{Description}

This site is located in the north-central portion of the survey area (Figure 2) bordering a moderate probability area but found within a low probability setting. The site is situated atop an upland landform of Woodtell series loams at 146-152 m (480-500 ft) AMSL. The vegetation community consists of the Quercus stellata-Quercus marilandica-(Carya texana) (post oak-blackjack oak-[black hickory]) Woodland class, affording roughly five percent ground surface visibility. The site is approximately $22,715 \mathrm{~m}^{2}$ in area. Historic cultural materials are scattered on the surface along an old east-west running county road. These materials are indicative of a probable historic house site, and the site itself is a multicomponent site with both historic and prehistoric components.

\section{Excavations and Stratigraphy}

During the 1999-2000 site discovery and documentation phase, 20 shovel tests (STs) were dug on site (Figure 3). Of these, 15 contained cultural materials. Prehistoric materials including chipped lithics and firecracked rock were present in 14 of the STs. Chipped lithic artifacts were recovered in 10 of the STs. Prehistoric materials extended to a depth of at least 80 $\mathrm{cm}$ below surface (bs) and approximately 70 percent of the lithic debris was from $0-40 \mathrm{~cm}$ bs. The total prehistoric artifact density during testing was 3.86 per positive shovel test.

During the 2001 site testing activities three backhoe trenches (BHTs) and five $1 \times 1$-m test units (TUs) were excavated on site (Figure 3 ). The terminal depths of the five hand-excavated units varied based on the depths of the red sandy clay substrate (Figure 4). In each unit, excavations halted once this red sandy clay was penetrated to a depth of at least $3-5 \mathrm{~cm}$. In general, excavations stopped in the mottled yellowishbrown sand and red clay loam. This mottled zone appeared to be sitting on top of a more homogeneous red clay loam. In a few instances, excavations penetrated into this clay loam but no artifacts were encountered in this matrix. The depth of the mottled sandy clay loam varied from about $42 \mathrm{~cm}$ bs (TU 3), to about $69 \mathrm{~cm}$ bs (TU 5). The more homogenous red clay loam was penetrated in TUs 1, 3, 4 and 5. It was encountered at about $55 \mathrm{~cm}$ bs in TU 1, between 42 $48 \mathrm{~cm}$ bs in TU 3, at a depth of about $75 \mathrm{~cm}$ bs in a portion of TU 4, and at $92-98 \mathrm{~cm}$ bs in TU 5 .

Distinguishing stratigraphic and/or pedogenic zones within the test units was difficult. Often, the differences consisted of variations in shades of yellowishbrown sand and slight changes in the sand and clay constituents through the profile (Figure 4). The greatest number of strata were noted in TU 1 with the remaining units containing relatively massive undifferentiated sandy matrix with only few and very subtle differences throughout the profiles. Rodent burrows and root disturbances were common in the units.

The three backhoe trenches were each five meters long and were excavated to a depth of between 95 (BHT 3) to $150 \mathrm{~cm}$ bs (BHT 1). The mechanical excavations were halted either in the homogenous red clay loam or the mottled sand and clay loam (Figure 5). The more 


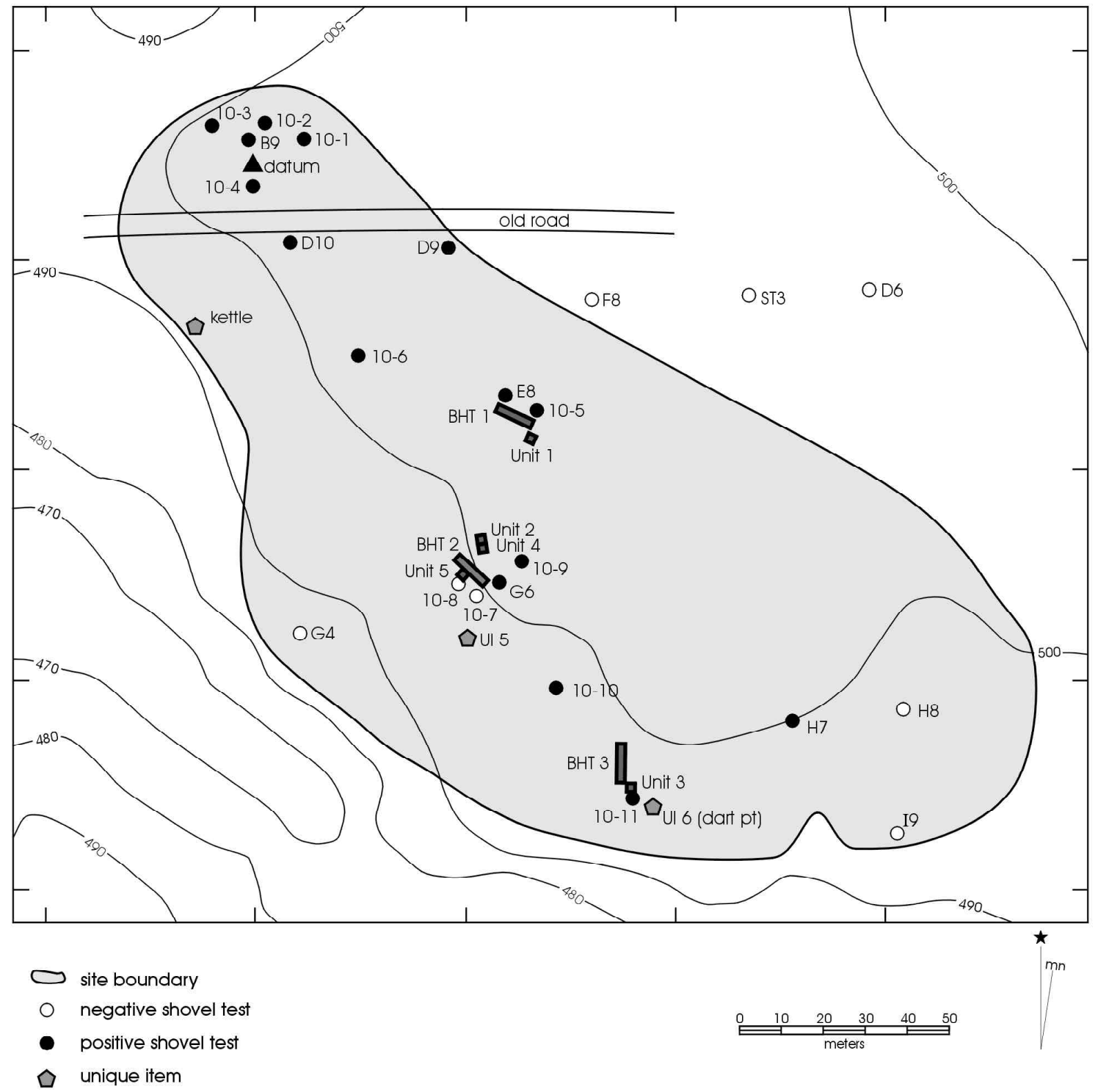

Figure 3. Site map of 41 LR190 showing the location of all units excavated on site.

notable feature of BHT 3 was the heavily root disturbed sandy loam stratum extending to a depth of $70-73 \mathrm{~cm}$ bs. The west wall profile of BHT 2 clearly indicates a zone of burned rock ranging from about 65 to $95 \mathrm{~cm}$ bs within the yellowish-brown sandy loam. The depth of this zone corresponds to the depth of a well defined burned rock feature (see following section) identified in TU 5, excavated adjacent to BHT 2.

\section{Features}

Three features, consisting of clusters of burned rock, were identified at site 41LR190. They are concentrated in the center of the site in the vicinity of BHT 2. Although burned rock was encountered in TUs 1 and 3 as well, the quantities were significantly smaller and no clusters were identified. 


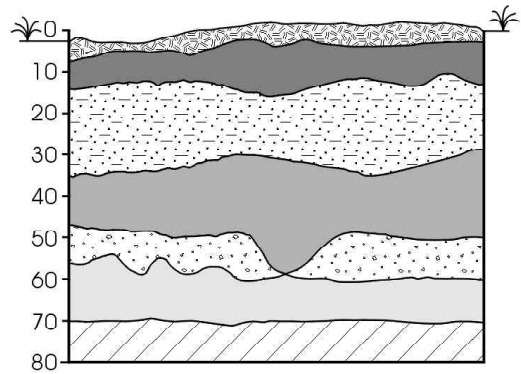

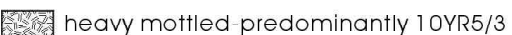
sand with some 10YR5/8 clayey sand 10YR5/8 sand

$\because 710 Y$ Y $5 / 7$ sand

$\square$ lightly mottled-predominantly 1 OYR5/7 sand with some $10 Y R 5 / 8$ clayey sand

$\therefore \because$ heavy mottled - 1 OYR5/7 sand with $50 \%$ 1OYR5/8 clayey sand

$5 Y R 4 / 6$ clay

unexcavated

41LR190 Unit 1 South Wall Profile
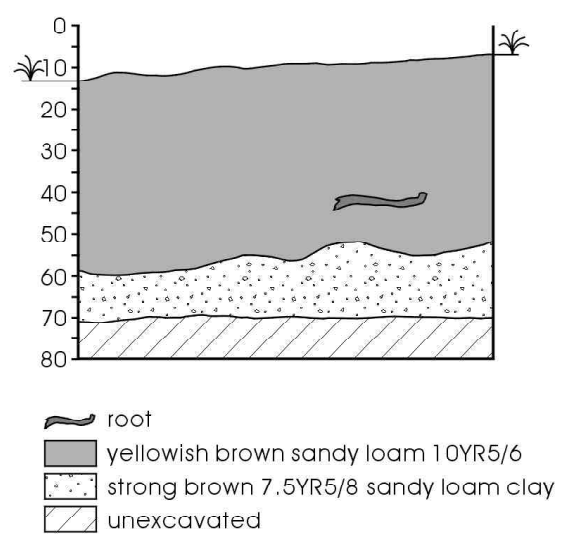

41 LR1 90 Unit 2 North Wall Profile Feature 1

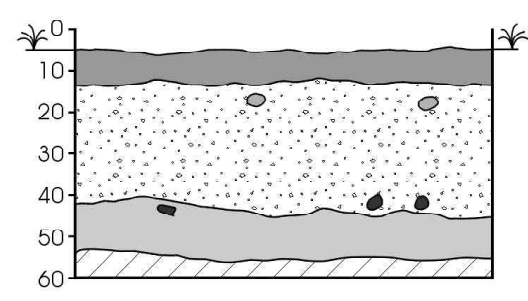

41LR190 Unit 3 North Wall Profile organic 10YR3/2

sandy loam 10 OYR5/8

clay/loam 5 YR4/6

unexcarated

$\longrightarrow$ burrow

- root

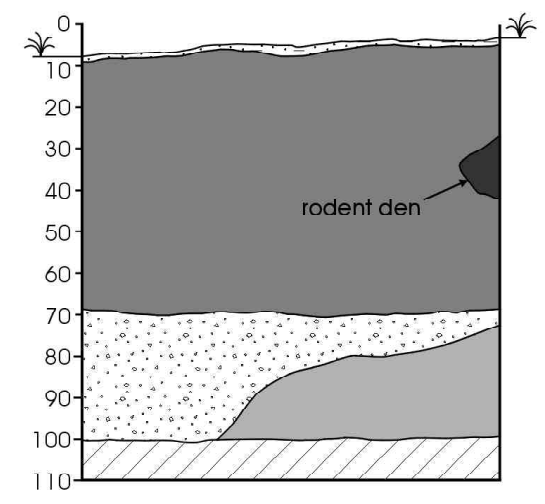

$\therefore$ numus

yellowish brown sandy loam

$\because \because$ mottled sandy loam and red clay loam

red clay loam

$\square$ unexcavated

\section{LR190 Unit 4 West Wall Profile} Feature 2

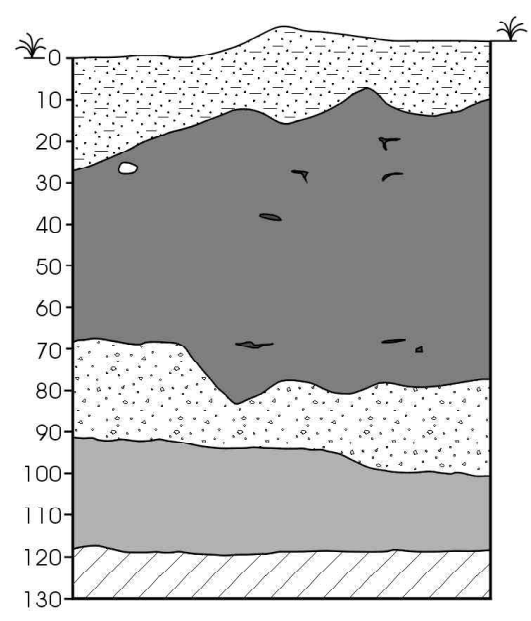

$\because$ yellowish brown sandy loam

$\square$ yellowish brown sandy loam mottled light brown

$\because \because$ yellowish brown sandy mottled yellowish red clay yellowish red sandy clay slightly compacted

$Z$ unexcavated

$\sim$ roots

$\bigcirc$ burned rock

41 LR1 90 Unit 5 North Wall Profile Feature 3

Figure 4. Profiles of five test units excavated at 41LR190. 


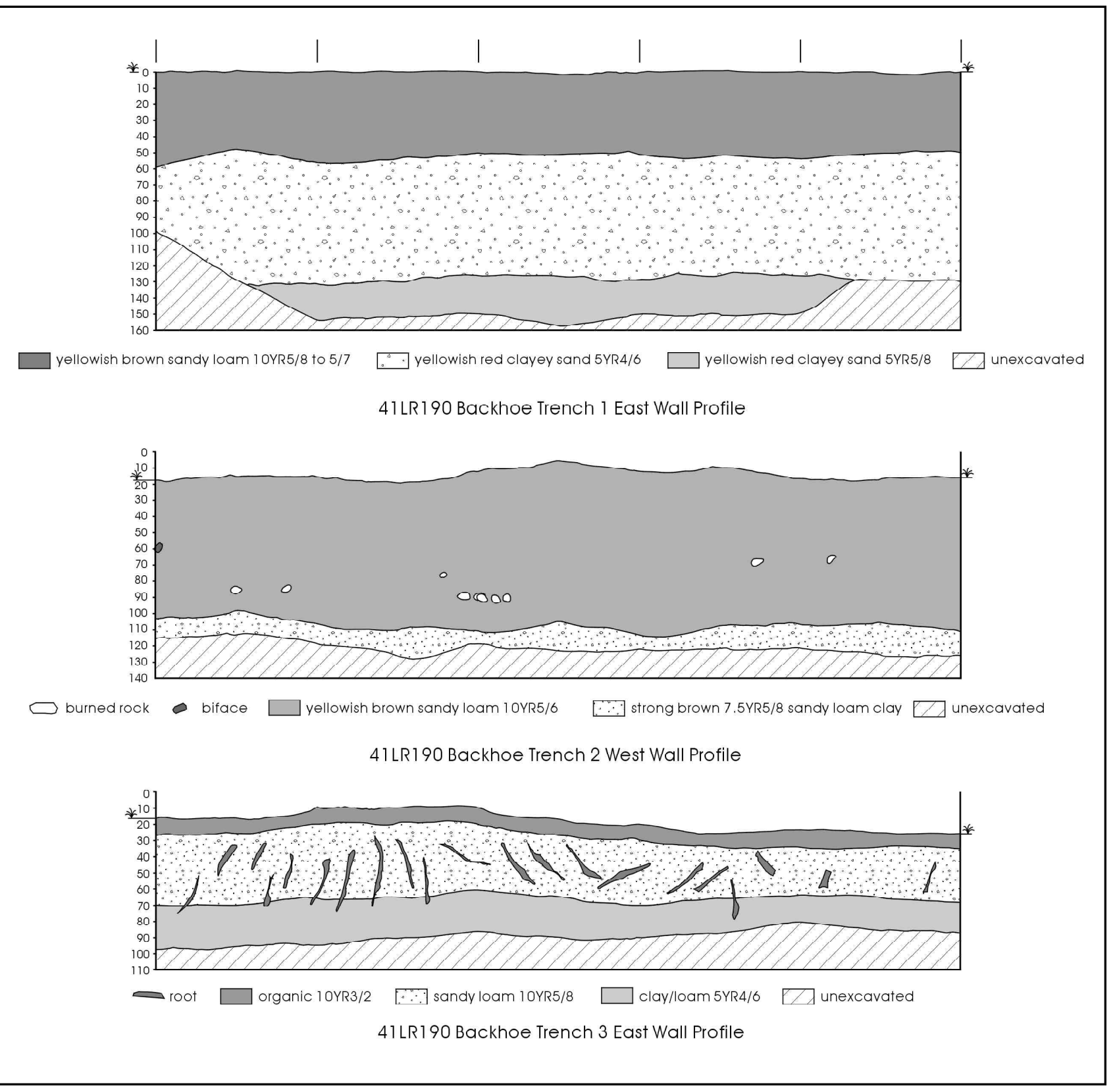

Figure 5. Profiles of three backhoe trenches excavated at 41LR190.

\section{Feature 1}

A cluster of burned rocks encountered within Level 3 $(20-30 \mathrm{~cm} \mathrm{bs})$ of TU 2 was recorded as Feature 1. The feature consists of burned sandstone with associated burned soil and charcoal. A total of 82 pieces of burned rock, weighing 1,399 $\mathrm{g}$ was part of the feature. The feature appears to have been a surface hearth with no indication of vertical depth. However, two biface fragments were recovered immediately beneath the feature in Level 4. Artifact density dramatically decreased with the excavation of subsequent levels, and no artifacts were encountered below Level 7 . A sparse amount of charcoal was collected from the feature. 


\section{Feature 2}

A small cluster $(\sim 30 \mathrm{~cm}$ in diameter) of burned rocks encountered in TU 4 was recorded as Feature 2. The top elevation of the highest rock was $60 \mathrm{~cm} \mathrm{bs}$, while the bottom elevation of the lowest rock was $74 \mathrm{~cm}$ bs. The individual burned rocks encountered within the feature ranged from $25-70 \mathrm{~mm}$ in diameter and consisted of quartzite. A total of 13 pieces of burned rock, weighing $1,503.5 \mathrm{~g}$ was part of the feature. A single charcoal sample, a charred nut fragment, was recovered from the feature (Field Sack no. 82).

\section{Feature 3}

A dispersed scatter of burned quartzite encountered within Levels 7 through 9 of TU 5 was recorded as Feature 3 (Figure 6). All quartzite nodules measured between $30-70 \mathrm{~mm}$ in diameter. A total of 284 pieces of burned rock, weighing $8,240.75 \mathrm{~g}$, was part of the feature. The feature began in Level 7 and ended in Level 9 at a depth of approximately $90 \mathrm{~cm}$ bs. A single Gary dart point was recovered in Level 9 of the unit. Since it extends through three levels (Levels 7, 8, and 9 ) it is likely that the feature was a basin-shaped pit, although no changes in soil color or texture were noted during the excavation. Four charcoal samples were taken from within the feature.

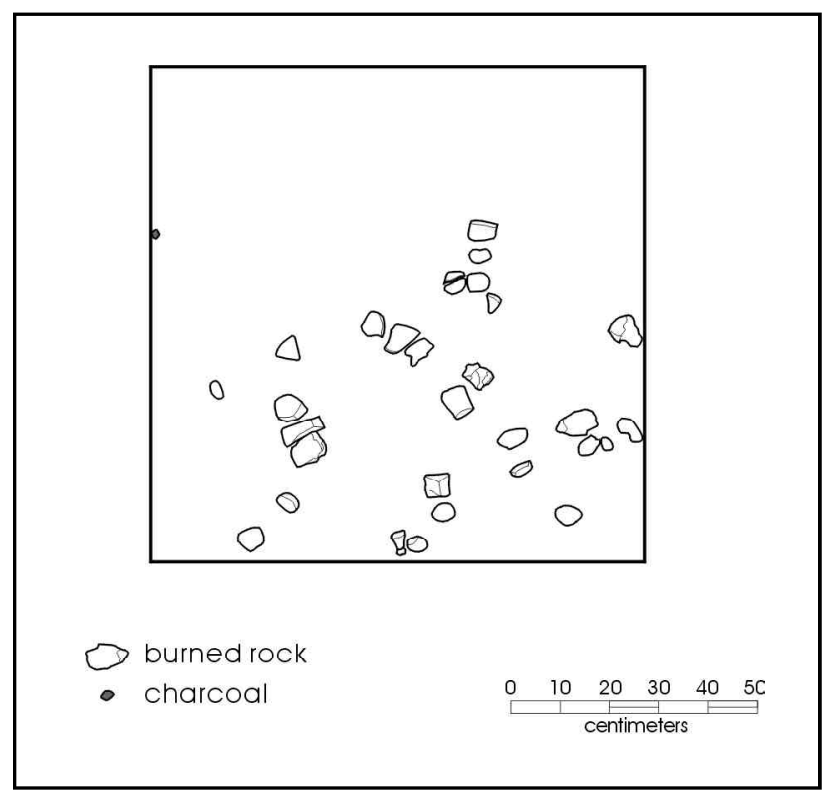

Figure 6. Plan view of Feature 3, Test Unit 5 (Level 7, 60-70 cm bs), 41LR190.

\section{Artifacts Recovered}

A total of 1,494 artifacts was recovered from excavations at the site. Of these, $76(5 \%)$ came from survey and the remainder $(n=1,416,95 \%)$ came from testing. Prehistoric artifacts constitute the bulk of the collection $(n=1,455,97 \%)$, although a few $(n=35,3 \%)$ historic artifacts were found during both phases of work at the site. In addition to these artifacts, four pieces of natural ocher from TUs $2 \quad(n=2)$ and five $(n=2)$, ranging from Level $3(n=3)$ to Level $8(n=1)$ in depth, were recovered. Finally, 12 charcoal samples were collected from TUs $2(n=2), 3(n=2)$, $4(n=1)$, and $5(n=7)$ ranging in depth from $0-10$ to $100-110 \mathrm{~cm}$ bs.

\section{Prehistoric Artifacts}

An overall total of 889 chipped lithic artifacts was recovered from the site during the two phases of work. The majority $(\mathrm{n}=856,96 \%)$ consist of debitage, although miscellaneous bifaces also are relatively numerous $(n=15,2 \%)$. The remainder of the lithic artifacts consist of projectile points $(\mathrm{n}=10,1 \%)$, cores $(\mathrm{n}=6,1 \%)$, a hammerstone, and an expedient knife.

The second most common prehistoric artifact class is fire-cracked rock (FCR). A total of 514 FCR was recovered with 379 derived from the three burned rock features (Features 1, 2, and 3) encountered at the site.

\section{Chipped Lithics}

\section{Tools and Cores}

A total of 26 chipped lithic tools, six cores, and a hammerstone were recovered from the site. Of these only two (dart points) came from the 1999 survey project (Lyle et al. 2001:122-123). Ten (38\%) of the 26 chipped lithic artifacts are projectile points, 15 $(58 \%)$ are miscellaneous bifaces, and one is an expedient knife on a small flake.

Of the 10 projectile points, seven are typeable specimens while two are untypeable distal fragments and one is an untypeable medial fragment. Eight (80\%) of 
the dart points are of locally-available reddish-brown and/or gray quartzite. One of the specimens is of a wellsilicified petrified wood, and one is of a locally available yellow chert. The two dart points recovered during survey came from the surface of the site, one at ST H7 and the other southwest of ST G-6. Both were recovered during survey and site recording. The first dart point (UI-6; lot no. 55; Figure 7a) is a contracting stem Gary, var. Camden made from a heat-treated coarsegrained quartzite; the tip has been snapped off. It is 29 $\mathrm{mm}$ in width, $6.1 \mathrm{~mm}$ in thickness, and has a $15.2 \mathrm{~mm}$ stem width. The second dart point (UI-5; lot no. 54; Figure 7b), probably of Late Archaic age, has a broad parallel stem, convex base, and minimal barbs. It is also made of a heat-treated coarse-grained quartzite, and measures $48 \times 30.5 \times 9.4$ mm in length, width, and thickness; the stem width is $21 \mathrm{~mm}$.

Of the five typeable points recovered during testing, two are Gary dart points. One of the Gary specimens is a classic contracting stem fragment broken in the vicinity of the neck (lot no. 256-4). It is made of locally available yellow chert. The second specimen is a heat-spalled fragment missing a portion of its stem and one shoulder (lot no. 289-4; Figure 7c). It is made of local fine-grained quartzite and appears to fit in the kaufman variety defined by Johnson (1962:161-163) from the Yarbrough site. The two Gary points were recovered from TUs 1 and 5, Levels 1 and 9, respectively. Of the three remaining specimens one has a parallel stem and a convex base (lot no. 284-5; Figure 7d). It fits the Kent type, quinlan variety (Johnson 1962:168), and is made of red fine-grained quartzite of local origin. It appears to have been broken in manufacture. The final two typeable specimens (lot nos. 285-3 and 281-3; Figure 7e-f) also fit in the Kent type and probably represent the phalba variety defined by Johnson (1962:168) from the Yarbrough site. One (lot no. 281-3) is complete, the other was broken in manufacture. The three Kent points came from TU 5, Levels 2, 5, and 6. The three untypeable fragments came from TU 2, Level 5 [n=2], and TU 3, Level 3.

Thirteen of the 15 bifaces from the site are of fine-grained quartzite and represent primarily early $(n=6)$ to middle $(n=7)$ reduction stage specimens. One of the remaining specimens is of fine-grained chert of yellowish-tan color, the other is of ferruginous sandstone. Six of the 13 quartzite bifaces are distal fragments, four are proximal specimens, one is a medial fragment, and two are complete. All of the fragments were broken in manufacture. The two complete specimens also are manufacture failures discarded due to failure to thin the blanks. Nine of the 13 appear to have been heat-treated. The chert biface is a complete specimen $(55 \times 30 \times 14 \mathrm{~mm})$. It also is a middle-reduction stage manufacture failure discarded due to failure to thin the blank. The final biface fragment is of dark gray ferruginous sandstone. It is an early reduction stage fragment broken during manufacture. Six of the bifaces are from TU 2, (Levels $1[n=1], 2$ $[n=1], 4[n=2]$, and $5[n=2])$, and four are from TU 5 (Levels $3[n=1], 5[n=1]$, and $10[n=2])$. Only three specimens are from TU 4 (Levels $4[n=1]$ and $9[n=2]$ ), and the remaining two are from BHT 2 (Level 5 and backdirt).

The single hammerstone measures $75 \times 48 \times 28 \mathrm{~mm}$ and comes from TU 2 (Level 3). Although it exhibits minimal battering, it further attests to the lithic reduction activities that were carried out on site. The lone expedient knife is a secondary flake of tan chert with use wear present on one edge. It comes from TU 5 (Level 1).

Four of the six cores are of locally available finegrained quartzite of yellowish-gray $(n=3)$ and purple color $(n=1)$. At least two of them represent tested nodules with only one flake removal per specimen. The other two have only two flake removals per specimen. Only one of the four quartzite cores is heat-treated. The remaining two cores are of locally available finegrained chert. Both exhibit four flake removals each. One is of yellow chert while the other is a mottled yellowish-brown color. Two cores each were recovered from three distinct test units. The specimens from TU 2 came from Levels 4 and 5, those from TU 3 were found in Levels 2 and 3, and the two from TU 5 were in Levels 4 and 5.

\section{Debitage}

During the spring of 2001 testing of 41LR190 a total of 826 pieces of debitage was recovered. In addition, 30 pieces were recovered during the 1999 survey (Lyle et al. 2001:123). The material types represented include two novaculite, two chalcedony, five silicified 


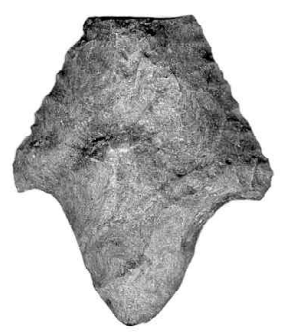

a

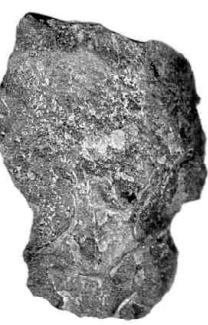

e

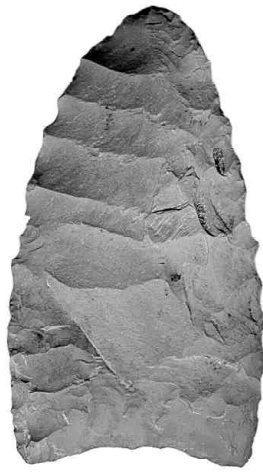

i

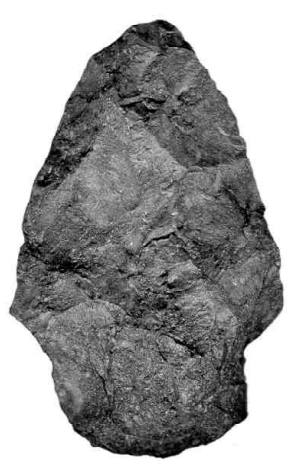

b

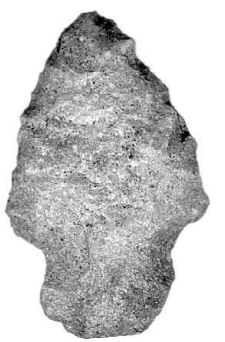

f

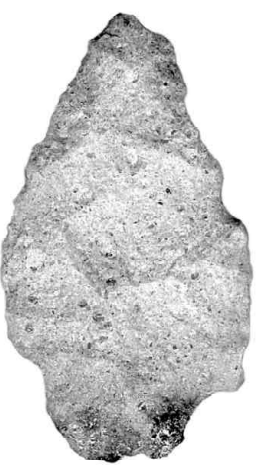

j

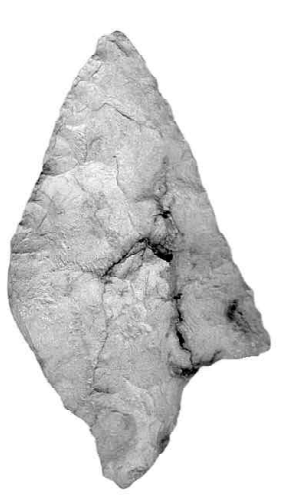

C

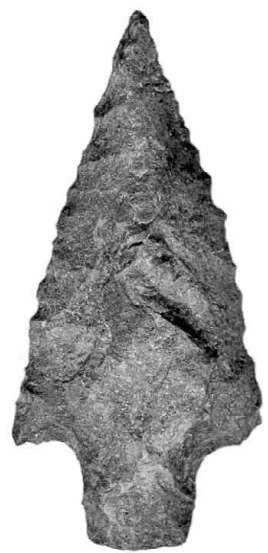

g

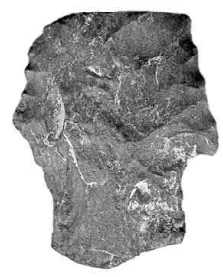

d

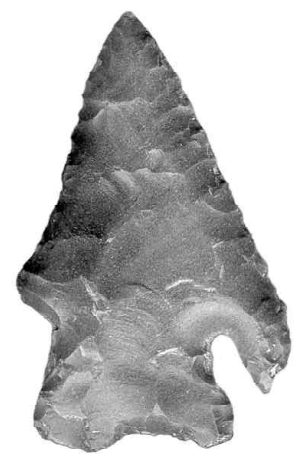

h

Figure 7. Projectile points recovered from Maxey IV sites. a) Gary [41LR190]; b) untyped parallel stem convex base [41LR190]; c) Gary [41LR190]; d-f) Kent [41LR190]; g) Kent [41LR196]; h) untyped expanding stem, concave base [41LR196]; i) Plainview preform [41LR259]; j) Kent preform [41LR259]. 
wood, six quartz, 25 silicified sandstone, 114 chert, and 702 quartzite debitage. The quartzite debitage is by far the most heavily relied upon material at this location. All materials are local except the novaculite. This material is commonly from the Ouachita Mountains in eastern Oklahoma and western Arkansas (Banks 1990). Heat-treating is evident only in the chert and quartzite materials. Heating has affected eight percent $(n=9)$ of the chert and 21 percent $(n=144)$ of the quartzite flakes. This indicates the heat-treating technique for improving the workability of raw materials was of low importance for the chert but moderately important for the quartzite.

Quartzite and chert are the most heavily utilized raw materials at the site. For this reason chert and quartzite are the focus of the debitage analysis. Out of the 114 chert flakes, 67 are decorticate ( $0 \%$ cortex), 30 are $1-50 \%$ cortex covered, 12 are $51-99 \%$, and five are $100 \%$ cortex covered primary flakes. The mean thickness to length ratio is .23. The 702 quartzite debitage consist of 407 decorticate flakes, 179 flakes with $1-50 \%$ cortex, 92 specimens with $51-99 \%$, and 24 primary flakes. The mean thickness to length ratio of the quartzite debitage is .24. Thickness to length ratios can be used to identify reduction stages, for example, a ratio of greater than .25 indicates an early reduction stage and a ratio of .15-.25 signals middle stage reduction and tool production. A ratio smaller than .15 is indicative of late stage reduction and tool rejuvenation (Robinson et al. 2001). Based on these figures, the main lithic activity at this site was middle stage reduction and tool manufacture.

The flake types present in the chert debitage are two angular debris, four biface manufacture flakes, 11 biface thinning flakes, one blade, 45 platform preparation flakes, and 51 indeterminate. The quartzite flakes consist of six angular debris, 37 biface manufacture flakes, 29 biface thinning flakes, one blade, 196 indeterminate, four notching flakes, 428 platform preparation flakes, and one uniface flake. The flake type comparisons support the indication that tool manufacture was the main activity at 41LR190.

Debitage was recovered from the surface to $120 \mathrm{~cm}$ bs (Figure 8). Three distinct peaks can be noted in the vertical distribution of debitage. The highest number of debitage occurs in Levels 2 and 3 and smaller peaks are evident in Levels 5 and 7. Finally, a small number of flakes, potentially representing a fourth peak, are present in Level 11.

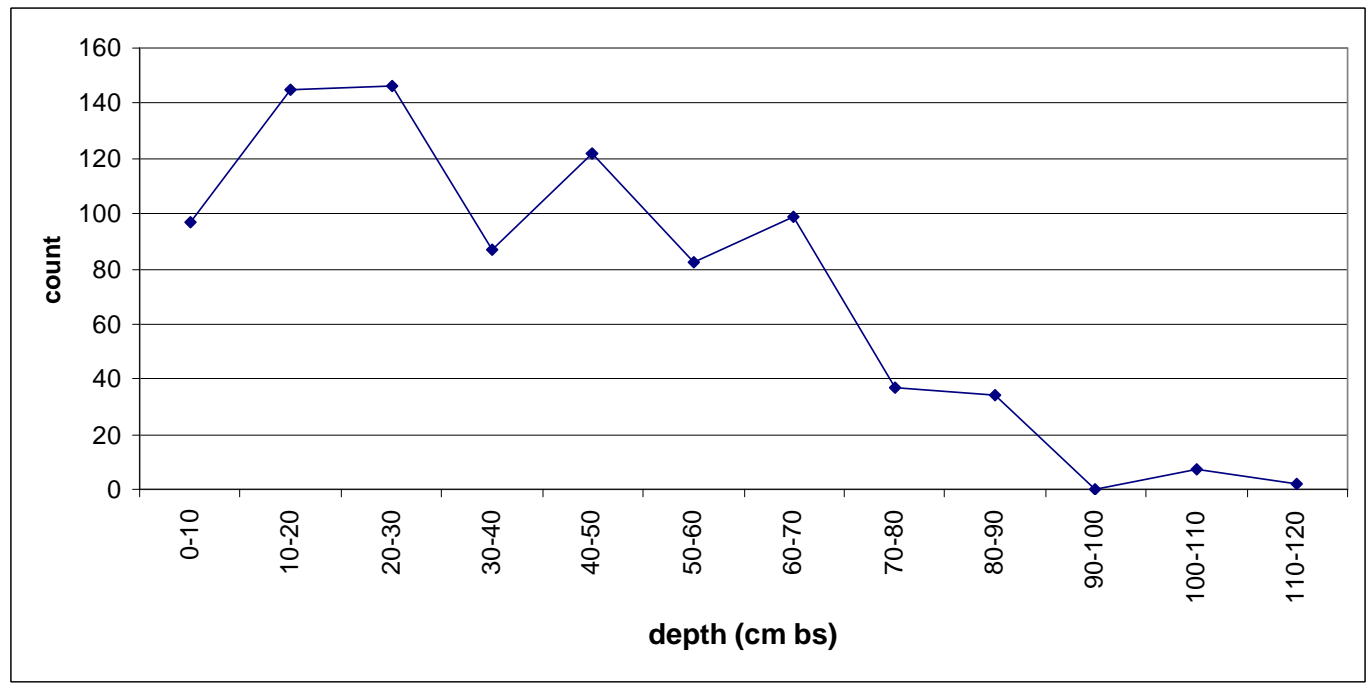

Figure 8. Unmodified debitage densities by depth, 41LR190. 


\section{Fire-cracked Rock}

A total of 18 FCR, weighing $389.6 \mathrm{~g}$, was recovered from nine shovel tests (STs 10-1, 10-9, 10-10, 10-11, 10-3, B-9, D-9, E-8, and G-6) dug during site discovery at 41LR190. Seven heat spalls were also recovered from six shovel tests (STs 10-5, 10-6, 10-9, 10-10, D-10, and G-6). The majority of these cultural materials were found between $0-60 \mathrm{~cm}$ bs, with only one heat spall found between $60-80 \mathrm{~cm}$ bs.

An additional 512 FCR, weighing 14,779.35 g, were collected from the five units. Of these, 379 amounting to a weight of $11,143.25 \mathrm{~g}$, came from three burned rock clusters identified as Features 1-3. A total of 284 $(8,240.75 \mathrm{~g})$ was collected from Feature 3, $82(1,399$ g) are from Feature 1, and only $13(1,503.5 \mathrm{~g})$ were part of Feature 2. By unit, TU 5 contained a total weight of 9,970.5 $\mathrm{g}(\mathrm{n}=258), \mathrm{TU} 4 \mathrm{had} 3,240.8 \mathrm{~g}$ $(\mathrm{n}=146)$, TU 3 had $13.65 \mathrm{~g}(\mathrm{n}=3)$, TU 2 had $1,456.8 \mathrm{~g}$ $(\mathrm{n}=94)$, and TU 1 had $97.6 \mathrm{~g}(\mathrm{n}=11)$.

\section{Charcoal Samples}

The twelve charcoal samples came from four of the five test units (TUs 2 [n=2], 3 [n=2], 4 [n=1], and 5 $[\mathrm{n}=7])$ and were collected from depths ranging from Level 1 to Level 11. The samples from TU 2 were collected between $20-50 \mathrm{~cm}$ bs and one of these was associated with Feature 1. The samples from TU 3 are from $20-40 \mathrm{~cm}$ bs. The single sample from TU 4 is from $60-70 \mathrm{~cm}$ bs and is a small burned hickory nut fragment that may have been associated with Feature 2 . The seven samples from TU 5 were collected from $0-110 \mathrm{~cm} \mathrm{bs}$, four of these samples are associated with Feature 3. Some of the charcoal recovered in the various samples appears to represent burned shell fragments.

\section{Historic Artifacts}

A total of 35 historic artifacts was recovered from the site. They came from six shovel tests (STs D-10, E-8, 10-6, 10-4, 10-2, and 10-11) and three of the five test units (TUs 1 [n=2], 2 [n=2], and 3 [n=7]). The testing phase artifacts were distributed between $0-40 \mathrm{~cm}$ bs, although during site discovery historic artifacts occurred as deep as $60 \mathrm{~cm}$ bs. The few historic artifacts include bottle and window glass fragments $(n=11)$, wire nails $(n=3)$, a brick fragment $(n=1)$, European ceramics $(n=10)$, unidentified metal fragments $(n=8)$, a military bullet, and a shotgun shell.

Some of the artifacts recovered can be helpful in estimating the dates of occupation of this site. Wire nails in combination with undecorated white earthenware can generally be securely dated to the post- 1900 period on Texas farm sites. Fragments of thin rusted metal cans probably represent the 1920 s to 1930 s when the modern "open top" sanitary can was first in use (The Encyclopedia Americana Volume V 1957:511). The glass fragments include olive green wine bottle glass, clear glass that could date to the 1930s, and part of the base of a brown snuff bottle-an interesting glimpse into the life of the occupants of the site. An anomaly on this location consists of two sherds of white earthenware, one with a hand painted design and one with a transfer pattern, which were made in England during the first half of the nineteenth century and would probably have come to Texas before the Civil War. These appear to be the only trace, recovered during this project, of the first settlers during the 1840s on what is now Camp Maxey.

\section{Mass Specific Soil Susceptibility}

Twenty-four soil samples from TU 5 were analyzed for magnetic soil susceptibility signatures. Table A-3 in Appendix A presents these raw data. As noted previously and as discussed in Appendix A, the magnetic susceptibility of sediment provides a measure of how easily that sample can be magnetized. Several processes can result in an increase in the susceptibility value within a given sediment sample. Of primary concern in the present context is the observation that sediments with high organic content tend to have elevated magnetic susceptibility values, probably as a function of the production of maghemite, an iron oxide, during organic decay (Reynolds and King 1995). Pedogenic processes, such as soil formation and weathering, as well as cultural processes, such as the production of ash and the concentration of other organic material on a living surface, will produce high magnetic susceptibility (MS) values. 
The top graph in Figure 9 presents the MS values for TU 5 by depth. Overall, the samples ranged from a low of 17.33 to a high of 35.19. An examination of the top graph in the figure suggests that two, and possibly three, peaks may be present, with the first occurring at between 42.5 and about $47.5 \mathrm{~cm}$ bs, a second peak between 65 and $70 \mathrm{~cm}$ bs, and a third, more distinct peak occurring between 95 and $100 \mathrm{~cm}$ bs. One, though by no means the only, interpretation of the changes in the values shown in the top graph is that three buried surfaces may be present.

Preliminary comparison of the debitage frequencies for this unit with the MS values suggests that the lowest peak $(95-100 \mathrm{~cm}$ bs) in the graph is not associated with any increase in artifacts. Of the 373 pieces of debitage recovered from this $1 \times 1-\mathrm{m}$ unit, only two were from level 10 (90-100 cm bs), and no debitage was present below $100 \mathrm{~cm}$ bs. The peak in MS values, then, probably represents a buried surface, but not one associated with human occupation, or one in which human occupation did not deposit lithic debitage.

The bottom graph in Figure 9 compares the number of artifacts for a given level with the MS values for the upper $90 \mathrm{~cm}$ of deposits within TU 5. Note that both data sets have been standardized for comparison. Examination of that graph suggests that peaks in the MS values have a rough correspondence with peaks in artifacts. The upper MS peak, between 42.5 and $47.5 \mathrm{~cm}$ bs, occurs in Level 5 (40-50 cm bs), a level that also had 60 pieces of debitage present. The second MS peak occurs in Level 7 (60-70 cm bs), where 86 pieces of debitage were recovered. The two debitage peaks are separated by Level 6, with only 34 items, and bracketed by Levels 4 and 8, with 29 and 25 pieces of debitage, respectively. The presence of both high MS values and high artifact totals suggest the possibility that within TU 5, two buried surfaces with associated artifacts are present. This possibility is strengthened by noting that the only feature in TU 5 was initially identified in Level 7.

\section{LR194}

\section{Description}

This site is located on the edge of a moderate probability area in the north-central portion of the facility, approximately 150-200 m east of a north-south running dirt road (Figure 2). The site is situated atop an upland landform of Whakana-Porum series loams at 155-158 m (510-520 ft) AMSL. The vegetation community consists of the Quercus stellata-Quercus marilandica-(Carya texana) Woodland class, providing roughly five percent ground surface visibility. The site is approximately $5,108 \mathrm{~m}^{2}$ in area.

\section{Excavations and Stratigraphy}

During the 1999-2000 site discovery and documentation phase, 13 shovel tests were excavated in this site (Figure 10), with eight producing cultural materials including burned nut shells in two tests. Seven of the eight shovel tests contained chipped lithic artifacts only. Material extended to a depth of at least $120 \mathrm{~cm}$ bs. The vertical distribution of artifacts suggested that there may be two prehistoric components buried in the landform, one between $0-40 \mathrm{~cm}$ bs $(\mathrm{n}=14$, or 41 percent of the artifacts), and the other between 60 $130 \mathrm{~cm}$ bs $(n=18$, or 53 percent of the artifacts). An unidentified piece of metal at a depth of $40-60 \mathrm{~cm}$ bs suggested the presence of a historic component, although a surface scatter of historic artifacts was not observed. The overall density of all prehistoric artifacts recovered during testing was 6.00 per positive shovel test.

During the 2001 site testing activities, three backhoe trenches and three $1 \times 1-\mathrm{m}$ test units were excavated on site (Figure 10). TU 1 was dug on the south-central portion of the site adjacent to BHT 1, while TUs 2 and 3 were excavated adjacent to BHTs 2 and 3, respectively, on the north-central portion of the site. 

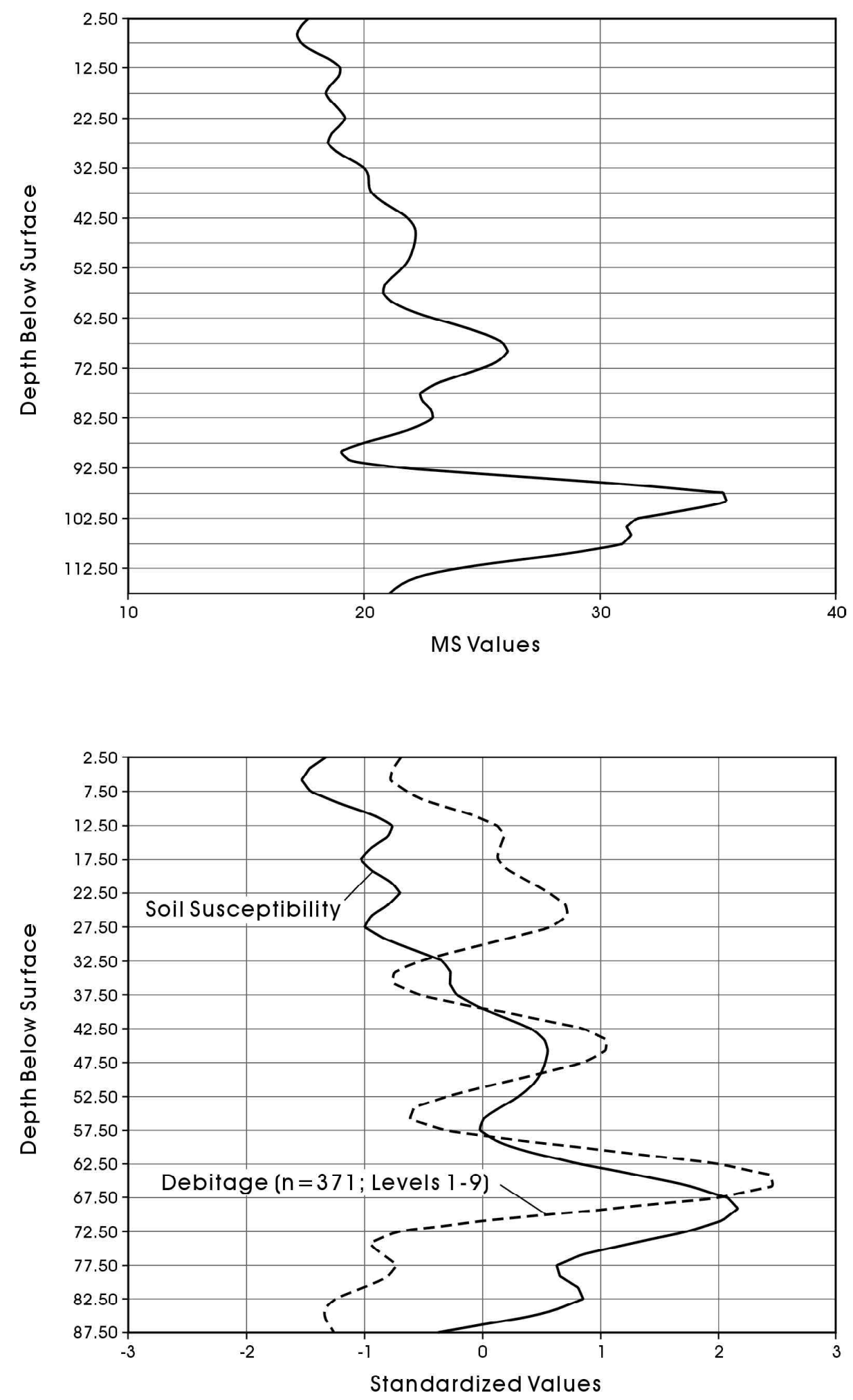

Figure 9. Plot of mass specific sediment susceptibility values for Test Unit 5, 41LR190. 


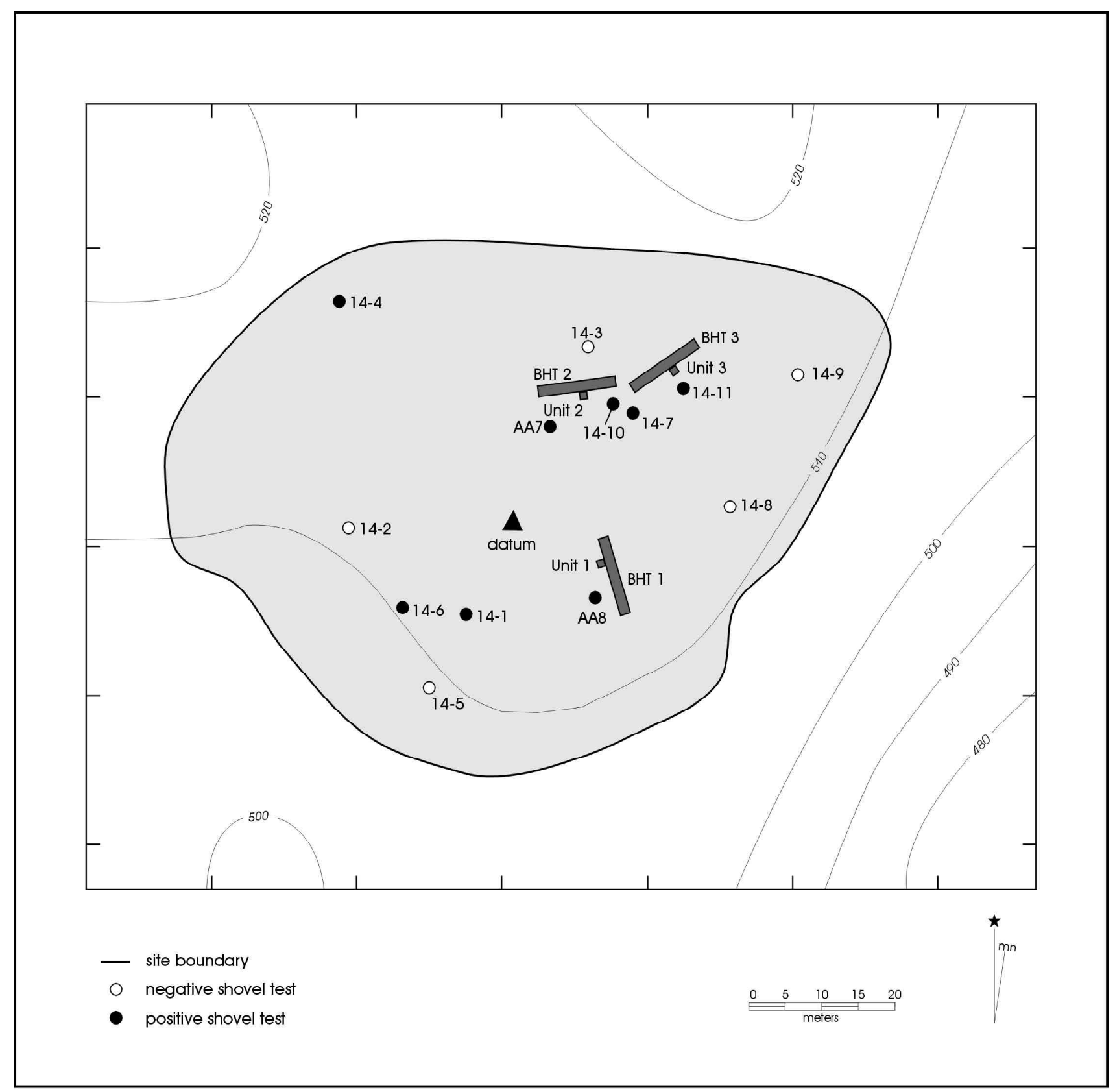

Figure 10. Site map of 41LR194 showing the location of all units excavated on site.

The terminal depths of the three hand-excavated units varied based on the depths of the mottled yellowishbrown sand and red clay loam (Figure 11). Based on excavation results from other sites at Camp Maxey (Lyle et al. 2001) this mottled zone appeared to be sitting on top of a more homogeneous red clay loam. The depth below surface of the mottled sandy clay loam varied from about $80 \mathrm{~cm}$ bs (TU 1), to about 130 $\mathrm{cm}$ bs (TUs 2 and 3). The stratum above this mottled zone was a relatively massive light brown sandy loam. None of the units were excavated to the depth at which the more homogenous red clay loam was to be encountered.

The three backhoe trenches were each five meters long and were excavated to a depth of between 165 (BHT 1) and $180 \mathrm{~cm}$ bs (BHT 3; Figure 12). The mechanical excavations were halted in the relatively homogeneous 


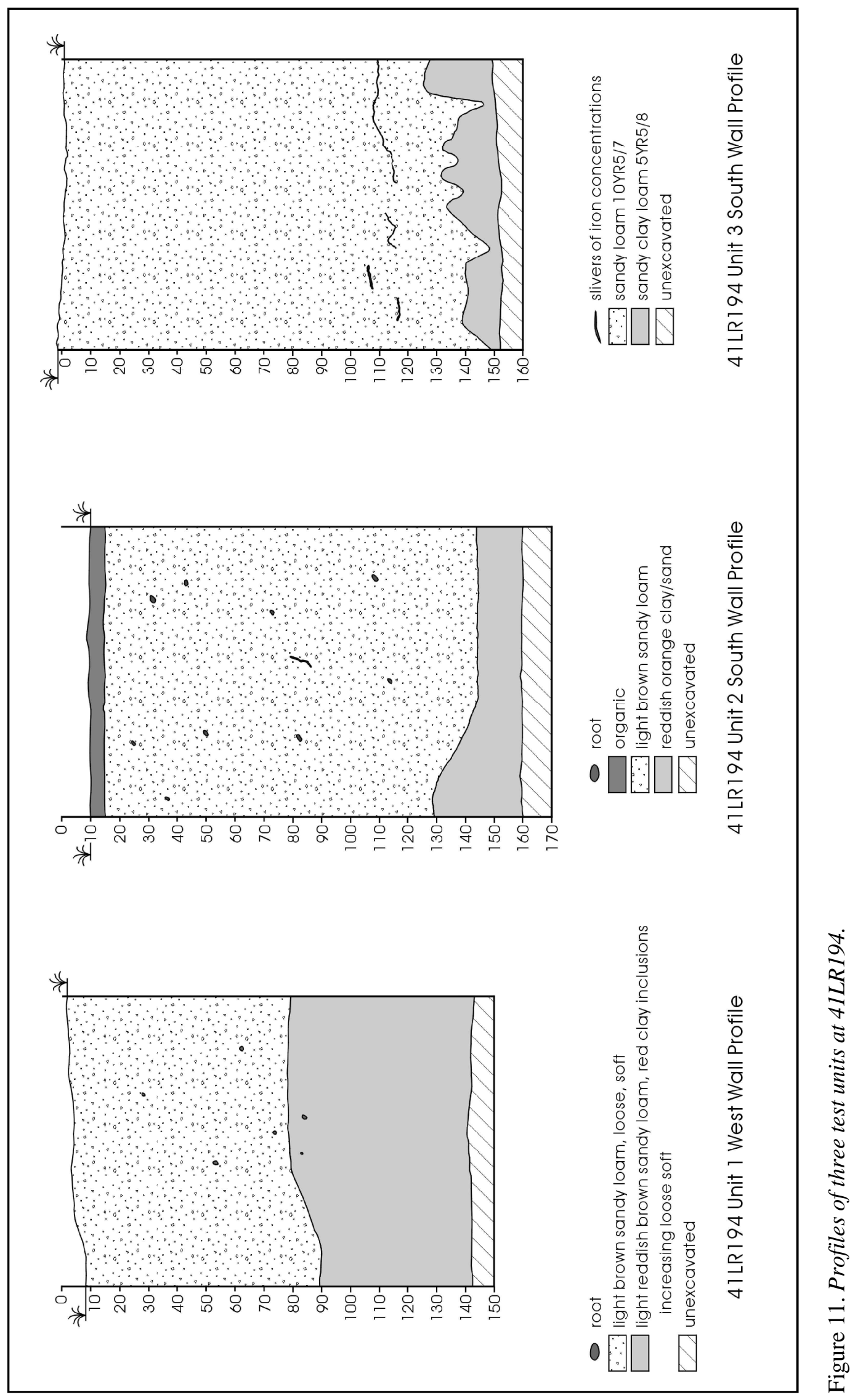




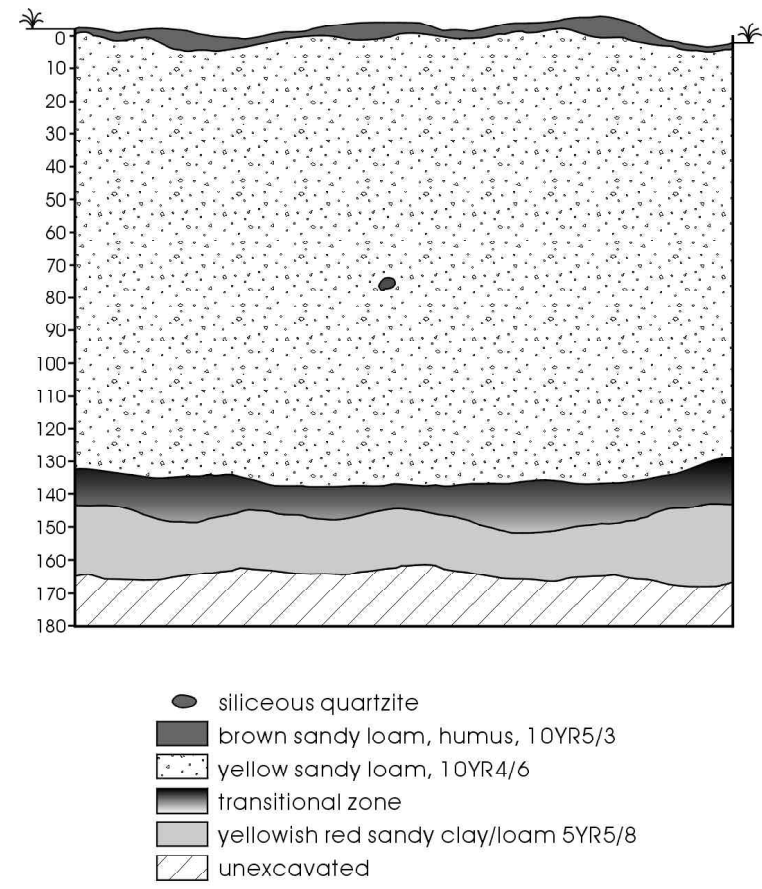

41 LR194 Backhoe Trench 1 North Wall Profile

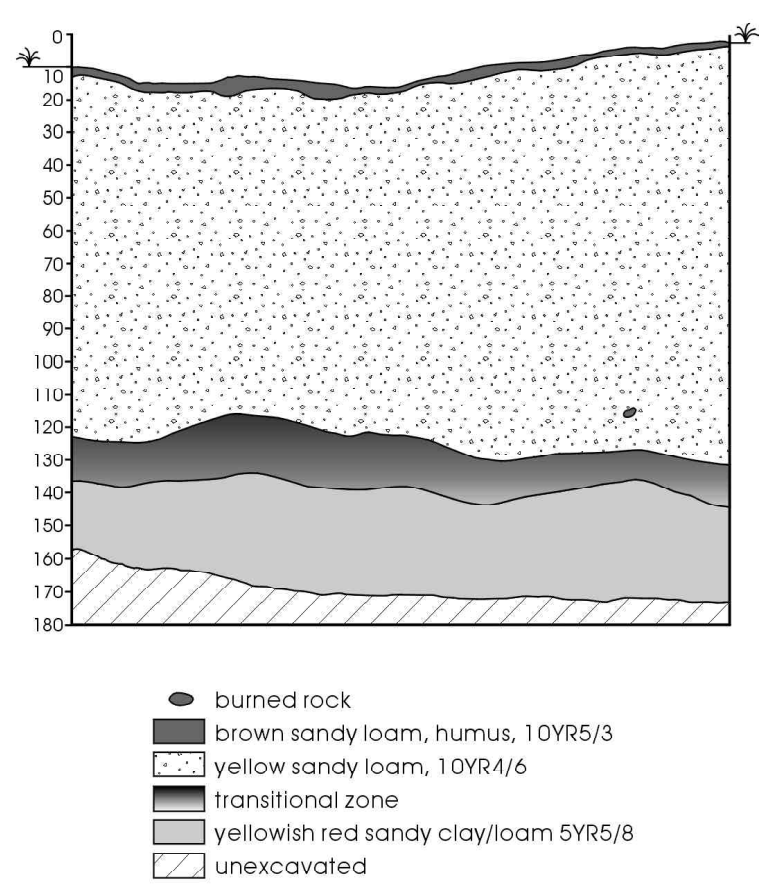

41 LR194 Backhoe Trench 2 North Wall Profile

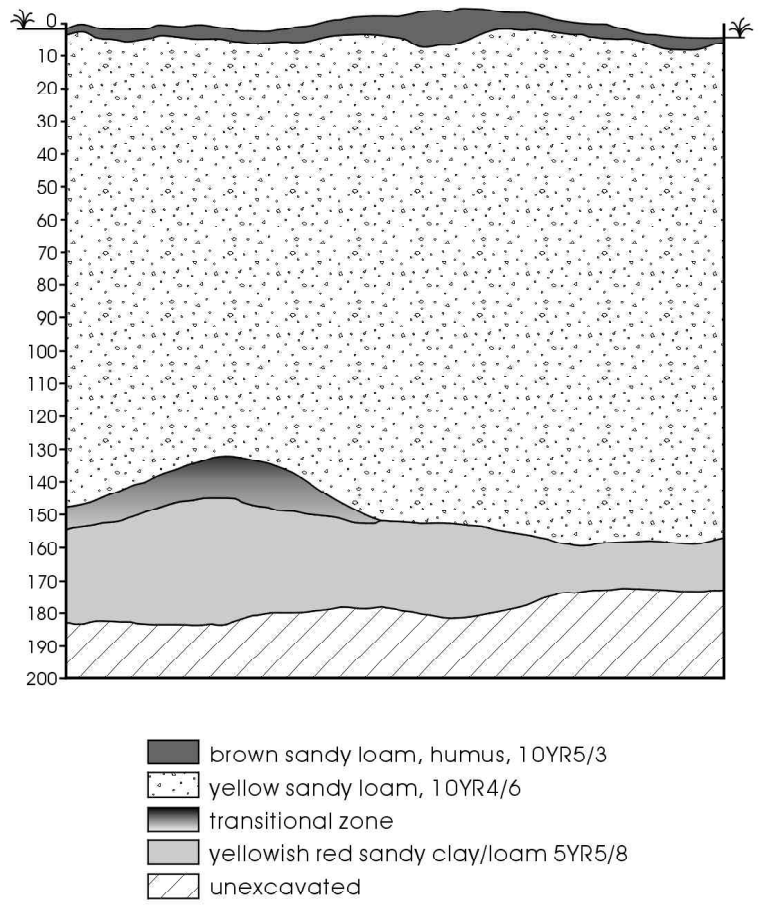

41LR194 Backhoe Trench 3 North Wall Profile

Figure 12. Profiles of three backhoe trenches excavated at 41LR194. 
and sterile yellowish-red clay loam that underlies cultural material bearing strata across the project area. Each BHT profile was overlain by a thin brown sandy loam, humus-containing, stratum. The thickest portion of each profile was the massive undifferentiated yellow sandy loam stratum that ranged from $110-130 \mathrm{~cm}$ in thickness. A $10-15 \mathrm{~cm}$ thick mottled sandy clay loam stratum forms the transition to the underlying homogenous red clay loam substrata in each BHT profile.

\section{Artifacts Recovered}

A total of 284 artifacts was recovered from excavations at the site. Of these, 41 (14\%) came from survey and the remainder $(n=243,86 \%)$ came from testing efforts at the site. An unidentified piece of metal and three military bullets are the only historic artifacts recovered from the site. The bullets are from TU 2 (Levels $7[n=1]$ and $8[n=2]$ ), while the unidentified metal fragment came from a shovel test during survey. Two other artifact categories are present, they are bone and charcoal. A single piece of heavily weathered bone was encountered in TU 3, Level 9. Given that the three bullets and the metal fragment are all likely to be military artifacts, no historic component was defined at 41LR194.

In addition to these artifacts, 21 charcoal samples were recovered from the site. Four of these came from survey shovel testing while the remaining samples were from site testing.

\section{Prehistoric Artifacts}

An overall total of 243 prehistoric artifacts was recovered from the site during the two phases of work. The majority $(\mathrm{n}=214,89 \%)$ consists of unmodified debitage. The single non-debitage chipped lithic artifact is a core. The second most common prehistoric artifact class consists of fire-cracked rock. A total of 28 pieces of fire-cracked rock was recovered from the site.

\section{Chipped Lithics}

\section{Tools and Cores}

No chipped lithic tools were recovered from the site. However, a single multidirectional chert core was found in TU 2, Level $11(100-110 \mathrm{~cm} \mathrm{bs})$. The core measures $37 \times 23 \times 13 \mathrm{~mm}$ and has seven removal scars.

\section{Debitage}

Archaeological excavations at 41LR194 recovered 214 pieces of debitage. Of these, 36 were recovered during the 1999 project survey (Lyle et al. 2001). Raw material types consist of three chalcedony, three silicified wood, four silicified sandstone, 10 novaculite, 95 chert, and 99 quartzite debitage. The novaculite is a non-local material commonly from the Ouachita Mountains in east Oklahoma and west Arkansas (Banks 1990). Heating affected 14 percent $(n=7)$ of the chert debitage and seven percent $(n=7)$ of the quartzite. Heat-treating for improved workability was likely of low importance at this site.

Dominating the raw materials are chert and quartzite. The chert debitage includes 66 decorticate flakes, 20 pieces with 1-50\% cortex, seven specimens with 51$99 \%$ cortex, and two primary flakes (100\% cortex). The mean thickness to length ratio is .18. The quartzite debitage contains 64 decorticate pieces, 19 flakes with $1-50 \%$ cortex, nine pieces with $51-99 \%$ cortex, and seven primary flakes. The mean thickness to length ratio for the quartzite is .29 . The thickness to length ratio of the chert (.18) suggests middle stage reduction and tool manufacture while the quartzite ratio (.29) indicates early stage reduction.

Flake types among the chert include one angular debris, eight biface manufacture flakes, seven biface thinning flakes, two blades, 39 indeterminate specimens, 37 platform preparation flakes, and one uniface flake. The quartzite debitage consists of four angular debris, seven biface manufacture flakes, one biface thinning flake, 32 indeterminate flakes, and 55 platform preparation flakes. This data is consistent with stone tool production. 


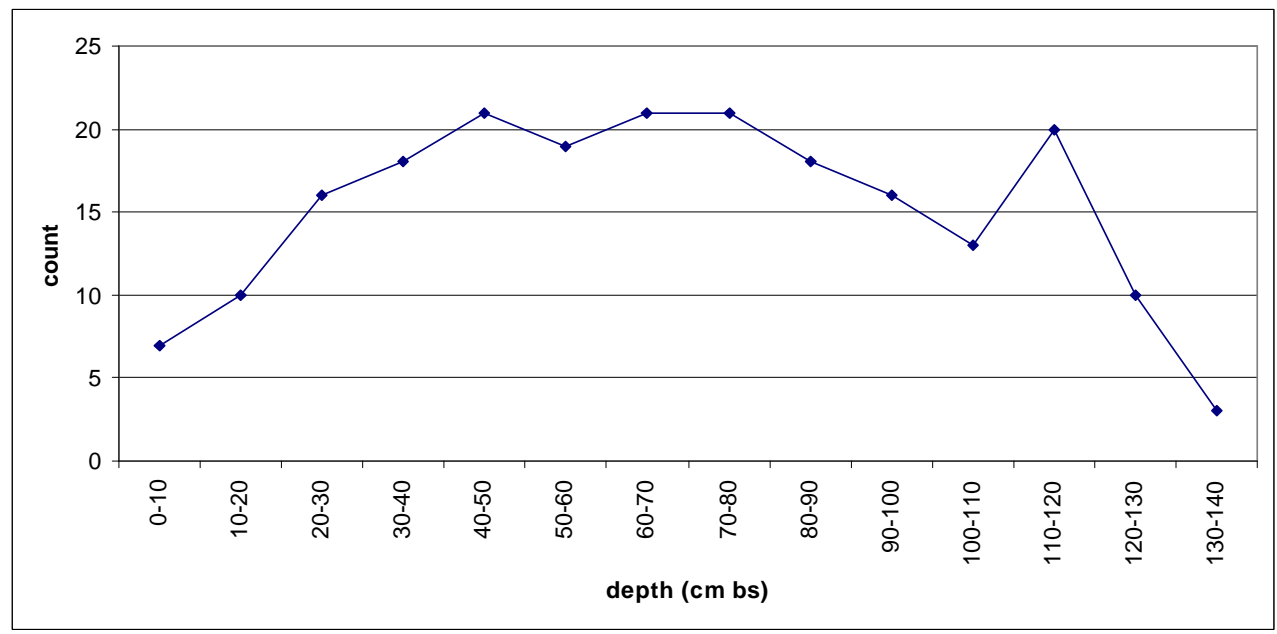

Figure 13. Unmodified debitage densities by depth, 41LR194.

Debitage was recovered from the surface down to 140 $\mathrm{cm}$ bs where excavation ceased. The density increases steadily from the surface to $50 \mathrm{~cm}$ bs (Figure 13). Debitage counts remain fairly consistent between 70 and $80 \mathrm{~cm}$ bs, accounting for 38 percent $(\mathrm{n}=82)$ of the total recovered. From 80 to $110 \mathrm{~cm}$ bs the count slowly drops off with a third spike occurring at 110-120 cm bs. Below $120 \mathrm{~cm}$ bs the density of debitage drops off sharply.

\section{Fire-cracked Rock}

Four pieces of FCR, weighing a total of $38.0 \mathrm{~g}$, were recovered between $40-120 \mathrm{~cm}$ bs in three STs (14-4, 14-10, and 14-11) during the survey and site recording. The 24 pieces found during testing came from Levels 4 through 13 . Test Unit 1 only had two pieces (Levels 9 and 10), while TU 2 had 10, and TU 3 had 12 pieces. All three units combined, the highest peaks in terms of FCR weight occur in Levels 6 (78.3 g, $\mathrm{n}=3)$ and $13(73.9 \mathrm{~g}, \mathrm{n}=3)$, with smaller peaks occurring in Levels 8 (29.6 g, $\mathrm{n}=4)$ and $12(31.2 \mathrm{~g}, \mathrm{n}=3)$. Only the Level 8 peak coincides with a peak in debitage counts.

\section{Charcoal Samples}

Site 41LR194 is one of the few Camp Maxey sites where charcoal was recovered during both initial site recording and testing. During initial site recording samples of carbonized plant remains were recovered from STs 14-7 $(n=2), 14-10(n=1)$, and 14-11 $(n=1)$. Seventeen additional charcoal samples were recovered during testing. They came from TUs $1(n=1), 2$ $(n=9)$, and $3(n=7)$ and were distributed from a depth of 10 to $150 \mathrm{~cm}$ bs. The single sample from TU 1 is from $70-80 \mathrm{~cm}$ bs. The samples from TU 2 are distributed from $10-140 \mathrm{~cm}$ bs, while those from TU 3 were collected from between $50-150 \mathrm{~cm}$ bs.

\section{LR196}

\section{Description}

This site is located to the southwest of 41LR194. The site appears to be a long but narrow scatter of cultural materials along the wooded banks of this drainage (Figure 2) in Whakana-Porum series loams

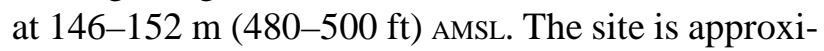
mately $20,954 \mathrm{~m}^{2}$ in size. The vegetation community consists of the Quercus stellata-Quercus marilandica(Carya texana) Woodland class, providing roughly five percent ground surface visibility.

\section{Excavations and Stratigraphy}

During the 1999-2000 site discovery and documentation phase, 18 shovel tests were excavated on site 


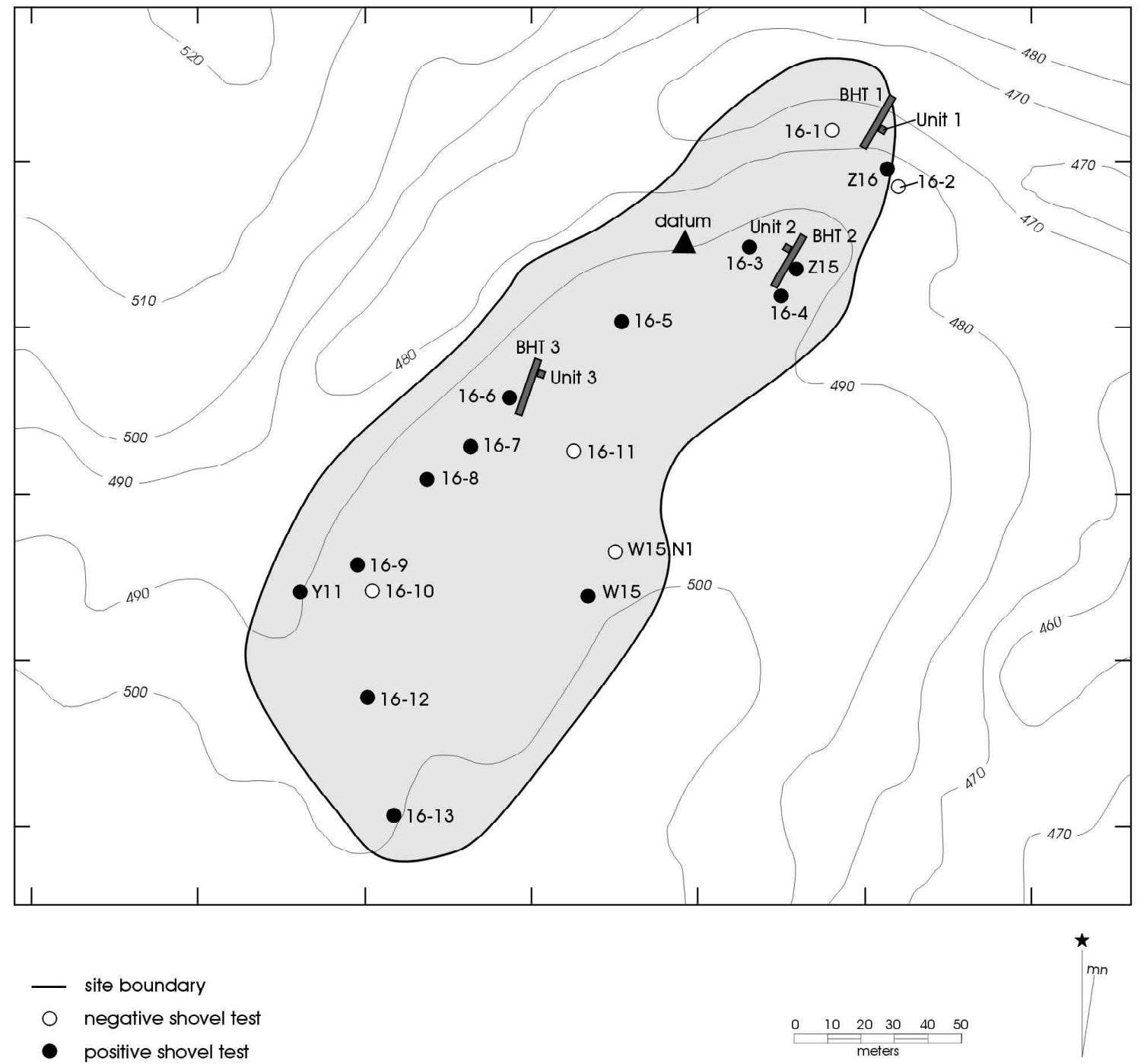

Figure 14. Site map of 41 LR196 showing the location of all units excavated on site.

(Figure 14). Of these, 13 yielded prehistoric materials to a depth of $100 \mathrm{~cm}$ bs. The artifacts are concentrated between $0-40 \mathrm{~cm}$ bs $(\mathrm{n}=19,37 \%)$ and $60-100$ $\mathrm{cm}$ bs $(\mathrm{n}=29,56 \%)$, with only five pieces of lithic debris in the $40-60 \mathrm{~cm}$ bs level. This distribution suggests that there may be two distinct components buried in the sandy sediments on the landform. The overall density of all prehistoric artifacts recovered during survey was 5.77 per positive shovel test.
During the 2001 site testing activities, three backhoe trenches and three 1 x 1-m test units were excavated on site (Figure 14). Test Units 1 and 2 were dug in the northeastern portion of the site adjacent to BHTs 1 and 2, respectively. Test Unit 3 was excavated adjacent to BHT 3, in the north-central portion of the site.

The terminal depths of the three hand-excavated units varied based on the depths of the red clay loam 
(Figure 15). The depth below surface of the red clay loam varied from about $52 \mathrm{~cm}$ bs in TU 1 , to about $130-148 \mathrm{~cm}$ bs in TU 2, and $112 \mathrm{~cm}$ bs in TU 3. The strata above this red clay loam zone consisted of the mottled yellow sand and red clay noted in other sites across Camp Maxey. The more massive stratum overlying this mottled transition zone is a yellowish-brown sandy loam present in all three units. A discernible thin humus layer is present only on top of TU 3 .

The three backhoe trenches were each five meters long and were excavated to a depth of between 143 (BHT 1) to $180 \mathrm{~cm}$ bs (BHT 3; Figure 16). A representative two-meter long section of the wall was profiled for documentation. The mechanical excavations were halted in or just below the mottled red clay and sandy loam transition zone that signals the relative proximity of the more homogeneous and sterile yellowishred clay loam that underlies cultural material-bearing stratum across the project area (Figure 16). In BHT 2, the thickest portion of the profile was the massive transitional yellow sandy loam stratum that ranged from $70-120 \mathrm{~cm}$ in thickness. In BHT 3, the mottled transition zone was the thickest stratum measuring approximately $120 \mathrm{~cm}$ in thickness. The transition zone of mottled red clay and sandy loam is relatively shallow in BHT 1 (45 cm bs).

\section{Artifacts Recovered}

A total of 490 artifacts was recovered from site discovery and test excavations at the site. Of these, 77 $(16 \%)$ came from survey and the remainder $(n=413$, $84 \%$ ) came from testing. Only prehistoric artifacts were found during both phases of work at the site. The prehistoric artifacts also include three charcoal samples from TU 1 ranging from $40-90 \mathrm{~cm}$ bs.

\section{Prehistoric Artifacts}

An overall total of 251 chipped lithic artifacts was recovered from the site during the two phases of work. The majority $(n=242,96 \%)$ consists of debitage, although two miscellaneous biface fragments and a miscellaneous uniface were also found at the site, in addition to two dart points. The remainder of the chipped lithic artifacts consists of four cores.

The second most common prehistoric artifact class found at 41LR196 consists of fire-cracked rock. A total of 239 fire-cracked rocks was recovered at the site.

\section{Chipped Lithics}

\section{Tools and Cores}

Two dart points were recovered during the test excavations at the site. The larger of the specimens (lot no. $312-1$; Figure $7 \mathrm{~g}$ ) is a Kent of the phalba variety (Johnson 1962:168) and has a narrow parallel stem and slightly convex base. The blade has straight edges and strong shoulders. It is made of heat-treated locally available fine-grained quartzite of dark gray color. It has a maximum length of $60 \mathrm{~mm}$, maximum blade width is $28 \mathrm{~mm}$, base width is $11.5 \mathrm{~mm}$, and neck width is $12.5 \mathrm{~mm}$. Its maximum thickness is 9 $\mathrm{mm}$. This specimen was recovered from the backdirt of BHT 3. The second dart point (lot no. 292-3; Figure $7 \mathrm{~h}$ ) is an untyped expanding stem, convex base specimen made of non-local greenish-gray finegrained chert. The specimen is deeply corner notched and has one complete and rather long barb. Both blade edges on both faces exhibit rejuvenation in the form of beveling. Morphologically, the specimen is reminiscent of Martindale points in thickness and blade and stem proportions and also has affinities in overall morphology to the "early corner notched" specimens of Early Archaic affiliation (Hester 1971). The specimen was recovered in TU 2 at a depth of between $100-110 \mathrm{~cm}$ bs. It has a maximum length of $49 \mathrm{~mm}$, maximum blade width is incomplete, base width is 22 $\mathrm{mm}$, and neck width is $18 \mathrm{~mm}$. It has a maximum thickness of $6.6 \mathrm{~mm}$.

The remaining three chipped lithic tools consist of a distal biface fragment, a miscellaneous biface edge fragment, and a miscellaneous uniface edge fragment. The distal biface fragment (lot no. 299-1) is a manufacture-broken dart point failure. It is made of black chert that is of probable non-local origin. It was found in TU 2 at $134 \mathrm{~cm}$ bs. The miscellaneous bifacial edge 

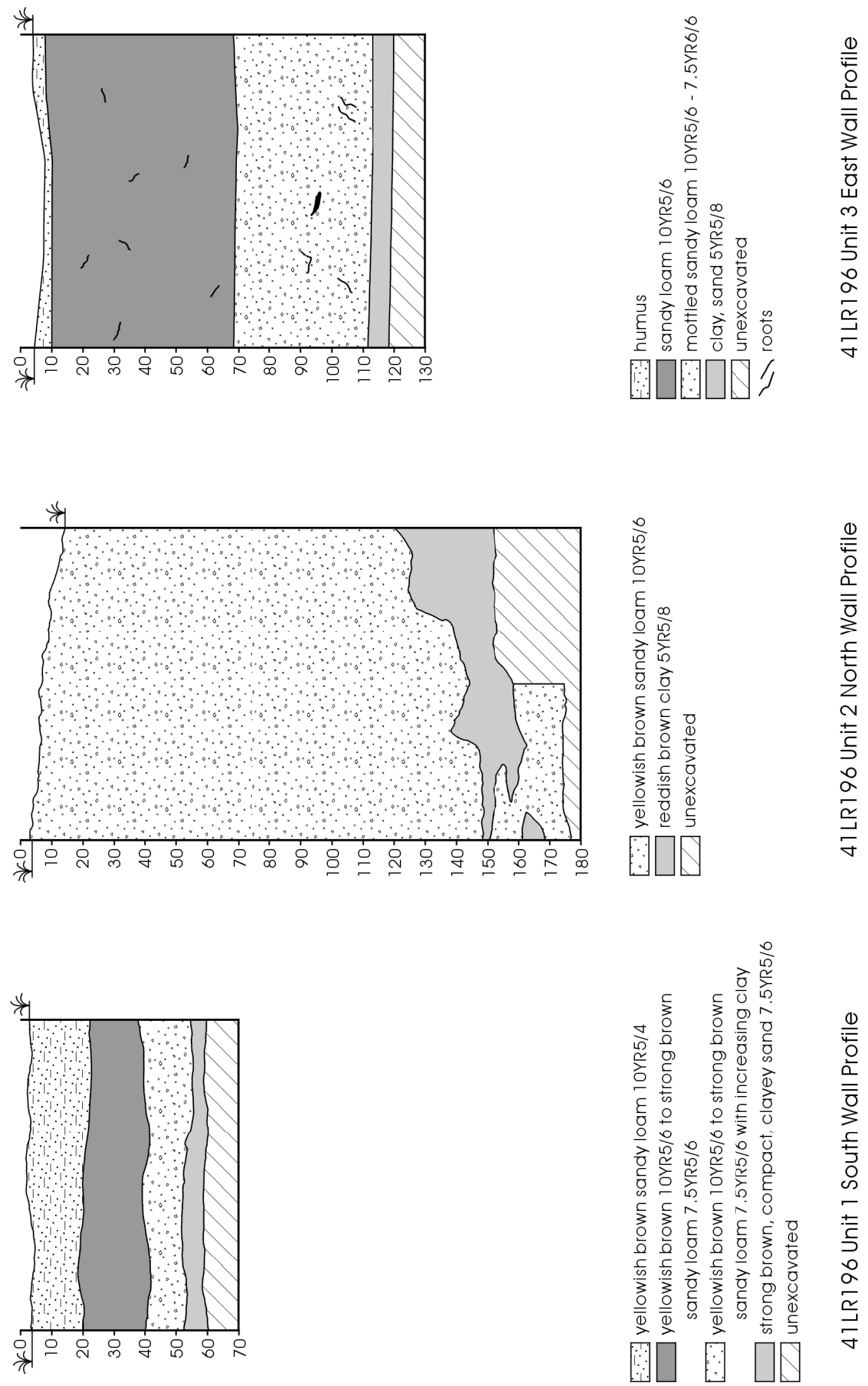

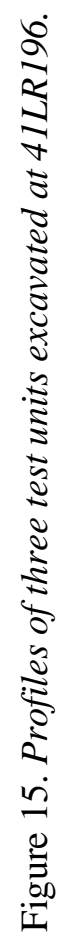



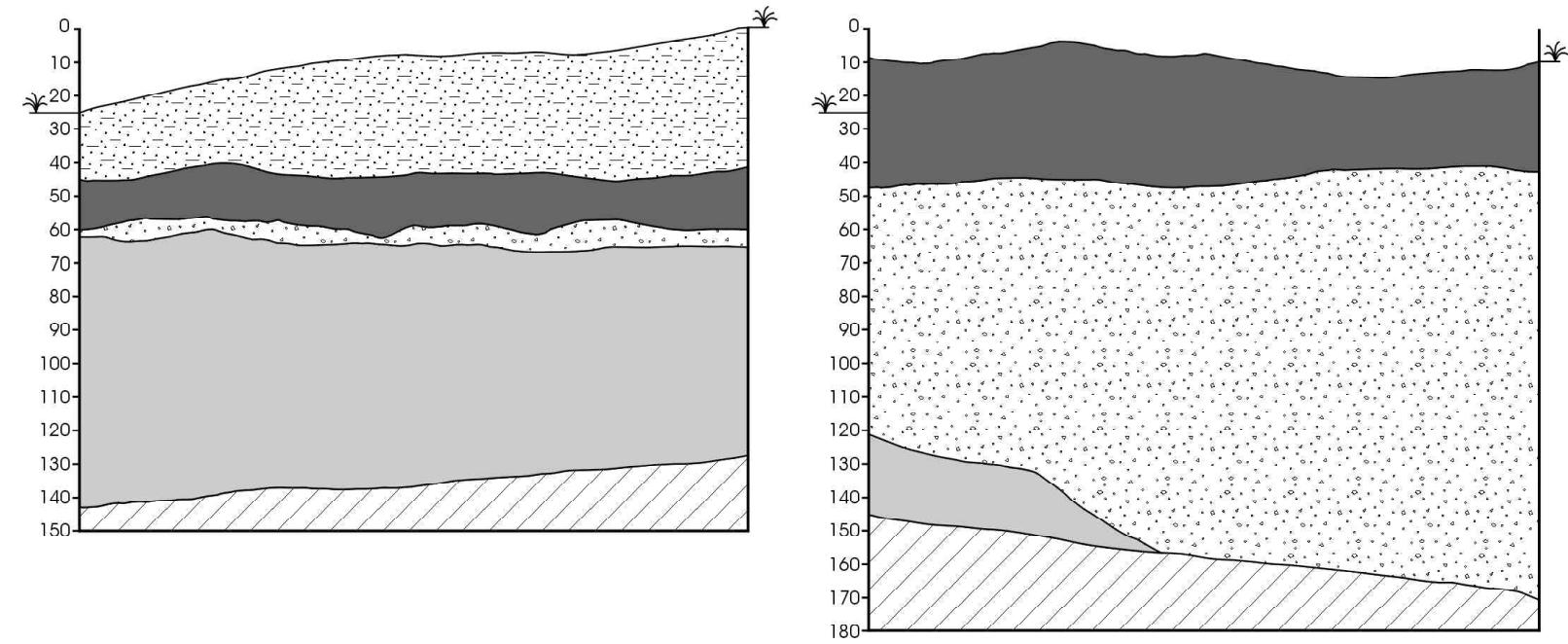

sandy loam 10YR5/6

red clay inclusions 10 YR5/6 to 7.5 YR $5 / 8$

strong brown to yellowish red 7.5 YR $5 / 8$ to 5 YR5/8

mottled gray red and brown clay, sand $5 Y R 5 / 8$

unexcavated

41 LR196 Backhoe Trench 1 East Wall Profile

sandy loam 10 YR $5 / 6$

sandy loam 10YR5/6 to red clay 7.5YR5/8 (transitional)

red and brown clay, sand 5 YR5/8

unexcavated

41LR196 Backhoe Trench 2 Wall Profile

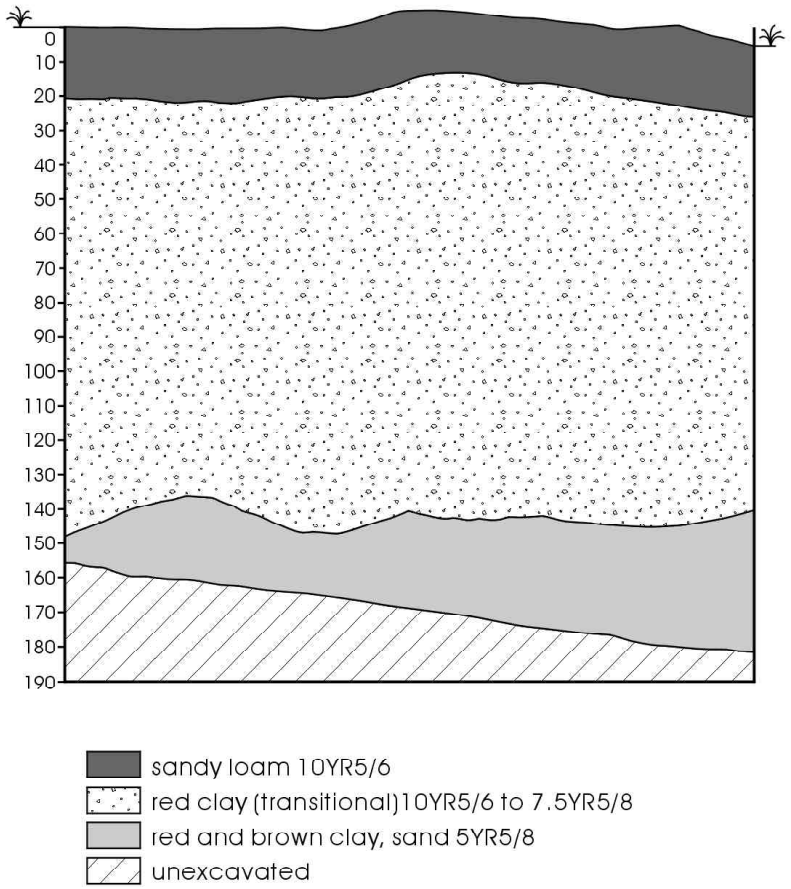

41 LR196 Backhoe Trench 3 West Wall Profile

Figure 16. Profiles of three backhoe trenches excavated at 41LR196. 
fragment (lot no. 305-3) is of local red chert and comes from TU 3, Level 6. The miscellaneous unifacial edge fragment (lot no. 308-2) is of locally available gray fine-grained quartzite. It is from TU 3, Level 9.

Three of the four cores from the site are of locally available gray fine-grained quartzite. Two may represent tested cobbles since they only have one and two flake scars, respectively. They measure 89 x 81 x 44 mm (lot no. 291-3), and 68 x 44 x 26 mm (lot no. 2914) and came from Level 10 of TU 2 . The third quartzite specimen is a core fragment (lot no. 288-4) with eight flake scars. It measures $51 \times 36 \times 23 \mathrm{~mm}$ and was found in Level 7 of TU 2. The final specimen (lot no. 295-3) also is a core fragment. It is of fine-grained chert of reddish-tan color. It measures 33 × 24 x 19 $\mathrm{mm}$ and comes from Level 14 of TU 2 .

\section{Debitage}

A total of 242 pieces of debitage was recovered from site 41LR196. Of these, 53 (22\%) are from the 1999 project survey (Lyle et al. 2001:83). Material types include three novaculite flakes, three silicified wood, four quartz, 93 chert, and 139 quartzite specimens. Chert and quartzite are present in overwhelmingly dominant numbers. The only non-local raw material used at 41LR196 was novaculite, found in the Ouachita Mountains of eastern Oklahoma and western Arkansas (Banks 1990). Heating is evident only in the chert and quartzite, a pattern common to all sites in this study. Six percent $(n=6)$ of the chert debitage is heated and twice as much $(n=16,12 \%)$ of the quartzite debitage has been heat treated. Heat-treating likely had a minor roll in stone tool manufacture at this site.

The chert breaks down into 57 decorticate flakes, 27 pieces with 1-50\% cortex, eight specimens with 5199\% cortex, and one primary flake. The mean thickness to length ratio is .21 . The quartzite debitage contains 67 decorticate flakes, 37 pieces with 1-50\% cortex, 22 specimens with 51-99\% cortex, and 13 primary flakes. The mean thickness to length ratio is .25. This indicates that middle stage reduction and tool manufacture were the primary activities at this site.
Flake types in the chert debitage include two angular debris, 10 biface manufacture flakes, four biface thinning flakes, 40 indeterminate flakes, one notching flake, 35 platform preparation flakes, and one uniface flake. The quartzite debitage consists of three angular debris, three biface thinning flakes, seven biface manufacture flakes, 80 platform preparation flakes, 44 indeterminate flakes, and one each of notching and uniface flakes.

Excavations recovered debitage from the surface to 170 $\mathrm{cm}$ bs. Within these levels there are three spikes in debitage density (Figure 17). The first density increase is at $10-20 \mathrm{~cm}$ bs accounting for only 10 percent $(\mathrm{n}=24)$ of the total debitage. The second is at $40-50 \mathrm{~cm}$ bs and is 15 percent $(n=36)$ of the total. The third $(70-80 \mathrm{~cm}$ bs) has the greatest density and makes up 31 percent $(n=75)$ of the total debitage. The artifact count per level drops off dramatically after $100 \mathrm{~cm}$ bs.

\section{Fire-cracked Rock}

Both heat spalls and FCR were encountered at the site during survey and site recording. During survey, thirteen heat spalls were found between $0-100 \mathrm{~cm}$ bs in six STs (W-24, Y-11, Z-16, 16-6, 16-7, and 16-9). Eleven FCR, with a total weight of $93.2 \mathrm{~g}$, were recovered from five STs (W-15, Z-15, Z-16, 16-3, and 16-4) between 0-100 cm bs.

The 215 pieces found during testing came from Levels 1 through 15 . Test Unit 1 only had two pieces (Level 3), while TU 2 had 197 pieces, and TU 3 had 16 pieces. All three units combined, the highest peaks in terms of FCR weight occur in Levels 8 (597.8 g, $\mathrm{n}=33$ ) and 10 (485.5 g, n=30), with smaller peaks in Levels 7 $(335.2 \mathrm{~g}, \mathrm{n}=21)$ and $12(401.5 \mathrm{~g}, \mathrm{n}=24)$.

\section{Charcoal Samples}

Three charcoal samples were recovered during testing. All three came from TU 2 and are from Levels 5, 7, and 9 at a depth of 50 to $90 \mathrm{~cm}$ bs. 


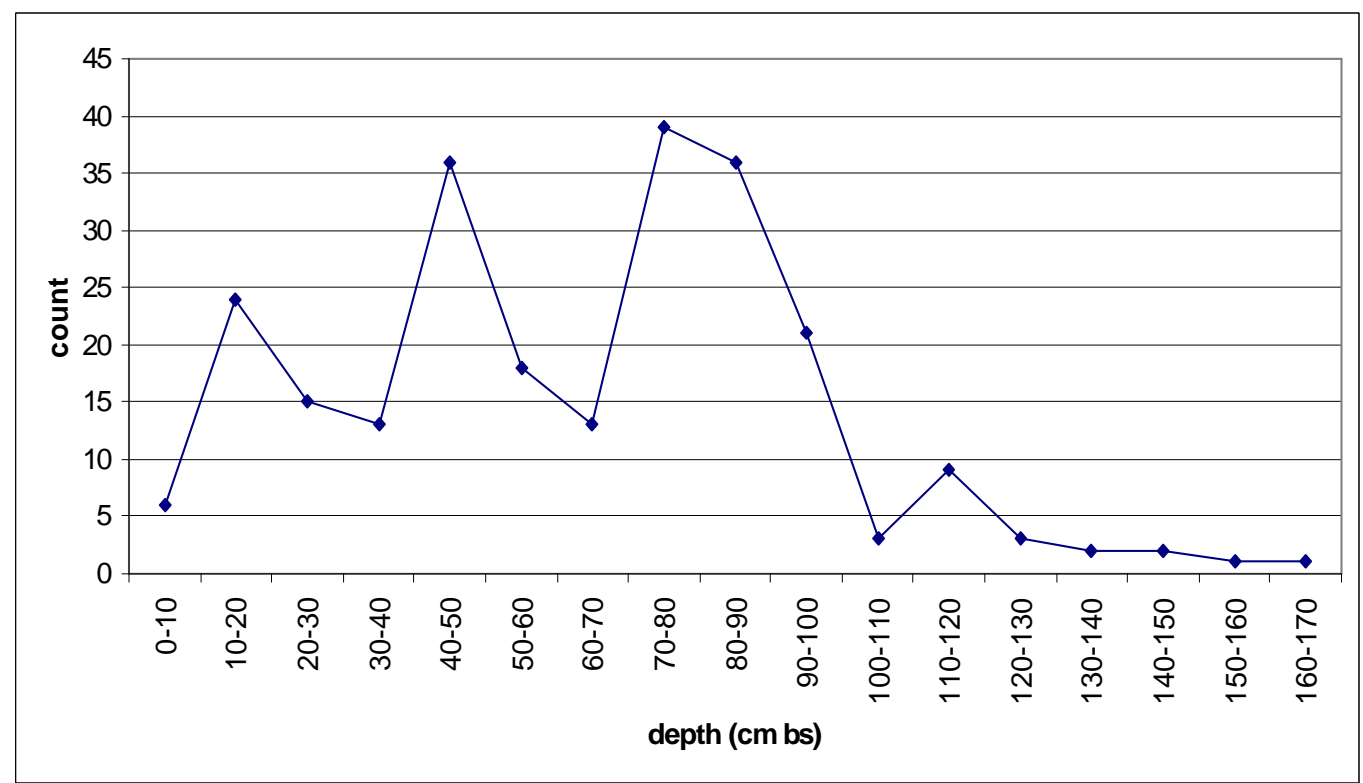

Figure 17. Unmodified debitage densities by depth, 41 LR196.

\section{LR200}

\section{Description}

This small site overlooks a moderate-sized drainage immediately to its north (Figure 2). The site is situated atop an upland landform of Whakana-Porum series loams at $152-155 \mathrm{~m}(500-510 \mathrm{ft})$ AMSL. The vegetation community consists of the Quercus stellata-Quercus marilandica-(Carya texana) Woodland class, providing roughly five percent ground surface visibility. The area was designated as having moderate probability. The site measures approximately $7,004 \mathrm{~m}^{2}$ in area.

\section{Excavations and Stratigraphy}

During the 1999-2000 site discovery and documentation phase, nine shovel tests were excavated on site (Figure 18). Of these, five shovel tests distributed along the center of the finger ridge yielded prehistoric cultural remains to depths of $100 \mathrm{~cm}$ bs. One of the shovel tests yielded only fire-cracked rock. Approximately 77 percent of the artifacts were concentrated between $0-40 \mathrm{~cm}$ bs. The overall density of prehistoric cultural materials recovered during testing was 3.8 per positive shovel test.
During the 2001 site testing activities three backhoe trenches and three $1 \mathrm{x} 1-\mathrm{m}$ test units were excavated on site (Figure 18). TU 1 was dug on the east-central portion of the site adjacent to BHT 1, while TU 2 was excavated in the south-central part of the site adjacent to BHT 2. TU 3 was excavated near the center of the site adjoining BHT 3 .

The terminal depths of the three hand-excavated units varied based on the depths of the mottled yellow and reddish-brown sand and red clay loam that mark the top of the sterile substrate (Figure 19). The depth below surface of the mottled sandy clay loam varied from about $95 \mathrm{~cm}$ bs (TU 1), to about $138 \mathrm{~cm}$ bs in TU 2, and $110 \mathrm{~cm}$ bs in TU 3 . The stratum above this mottled zone was a relatively massive undifferentiated yellowish-brown sandy loam. None of the units were excavated to the depth at which the more homogenous red clay loam was to be encountered. A thin humus layer capped TU 3, while a thicker fine sand stratum was present at the top of TU 1 . No humus layer was noted on top of TU 2.

The three backhoe trenches were each five meters long and were excavated to a depth of between 125 (BHT 3) to $190 \mathrm{~cm}$ (BHT 2; Figure 20). A representative two-meter long section of the wall was profiled for documentation. In BHT 1, the excavation was 


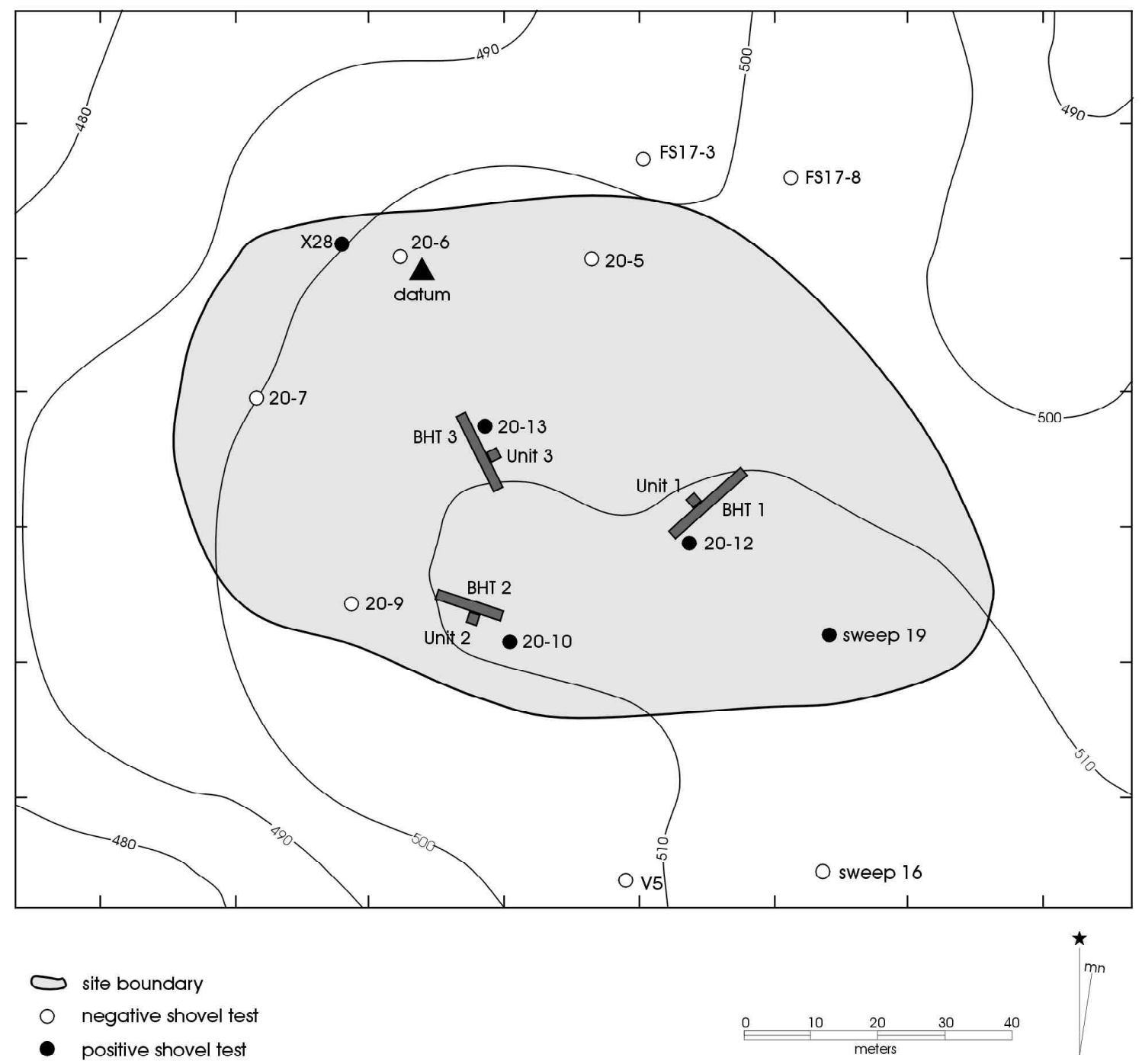

Figure 18. Site map of 41LR200 showing the location of all units excavated on site.

terminated in the sterile relatively homogenous brown clayey sand that underlies much of the region. Above this zone, a thin transitional stratum of mottled reddish brown clay and sand was noted. In BHTs 2 and 3, the mechanical excavations were halted in the mottled yellowish-red sandy clay loam that overlies the homogenous red clay. The thickest portion of all three BHTs is the massive undifferentiated yellowish-brown sandy loam stratum that ranged from roughly 90 (BHT 1) to $150 \mathrm{~cm}$ (BHT 2) in thickness. A thin dark brown humus stratum caps BHT 3, but is missing or was not discerned at the top of the other two BHTs.

\section{Artifacts Recovered}

A total of 341 artifacts was recovered from site discovery and testing excavations at the site. Of these, $17(5 \%)$ came from survey and the remainder $(n=324$, 95\%) came from testing. With the exception of a single military bullet, all others are prehistoric artifacts. Also 

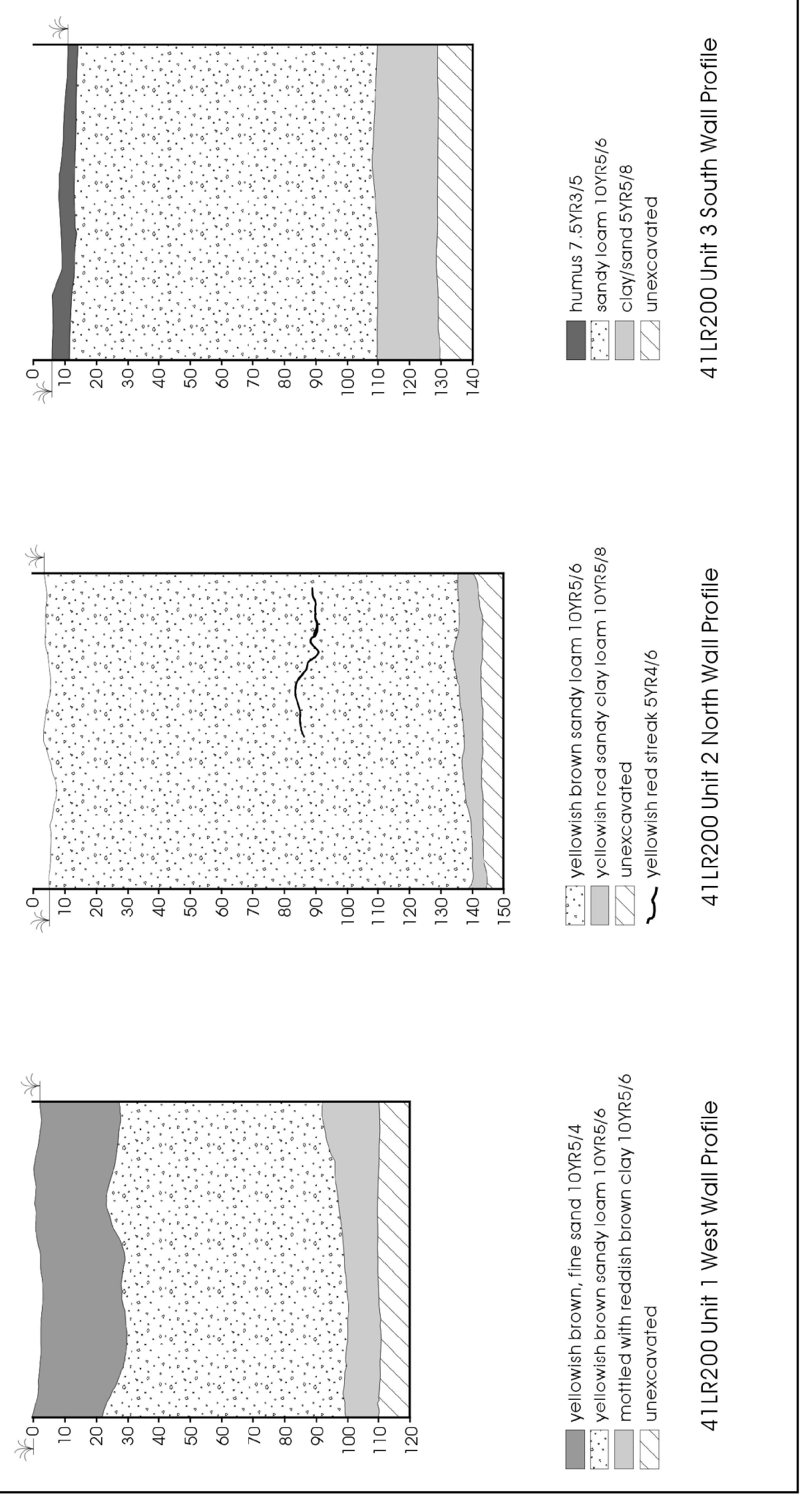

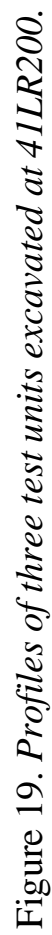



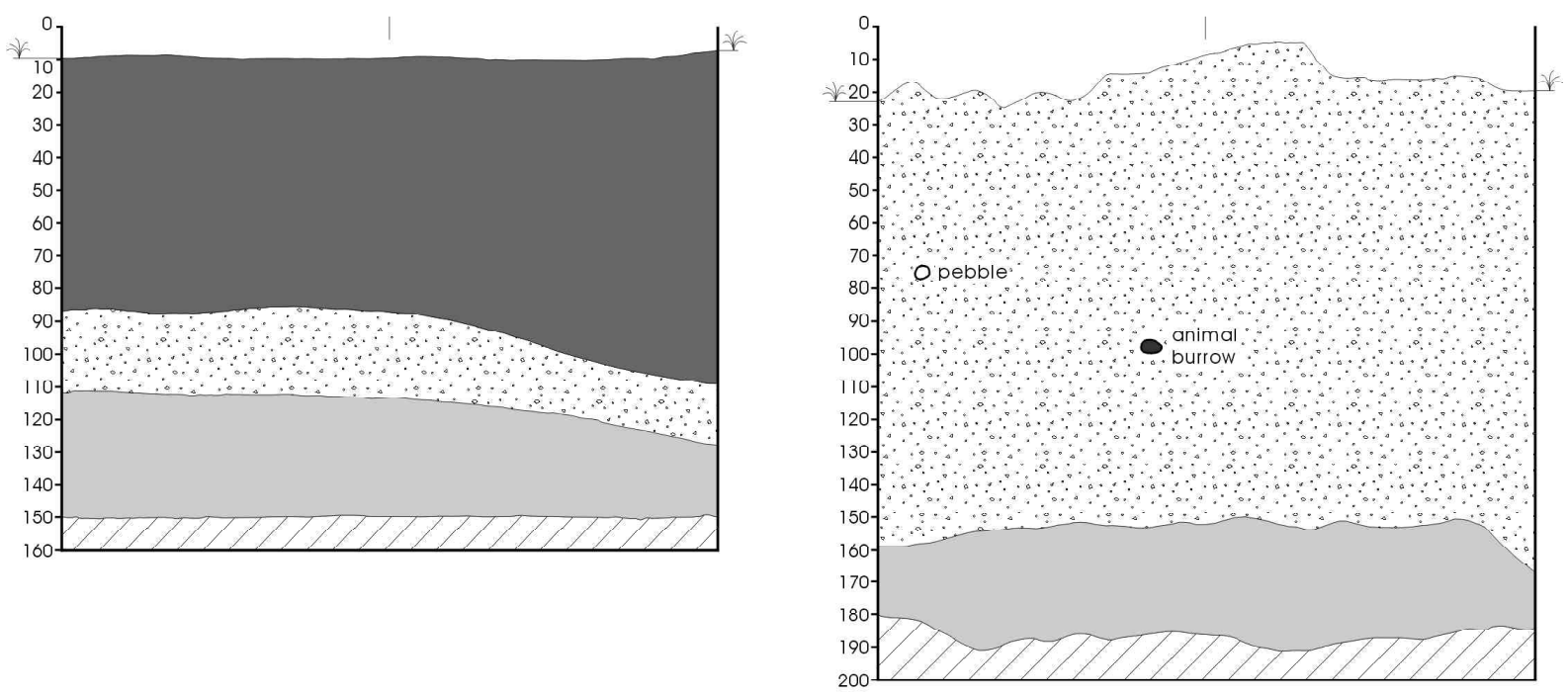

yellowish brown 1 OYR5/6

1OYR5/6 mottled with reddish brown clay

strong brown clayey sand 7.5 YR $5 / 8$

7 unexcavated

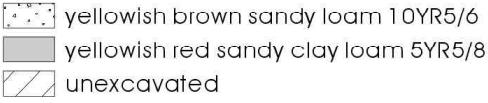

41 LR200 Backhoe Trench 2 North Wall Profile

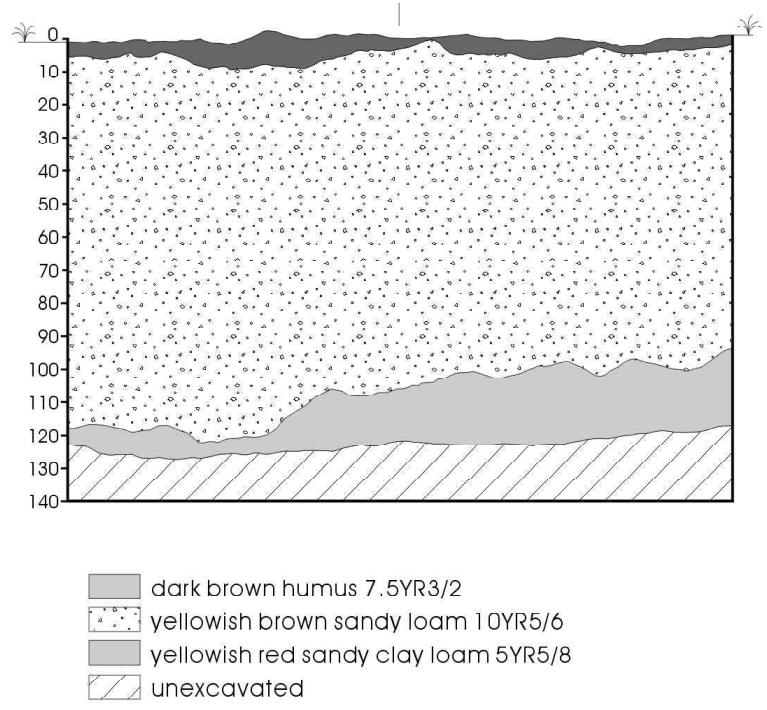

41LR200 Backhoe Trench 3 North Wall Profile

Figure 20. Profiles of three backhoe trenches excavated at 41LR200. 
among the artifacts is a single weathered piece of bone recovered from TU 1 , from a depth of $90-100 \mathrm{~cm}$ bs. The bullet is from TU 3, Level 3 and it likely does not represent a historic component at the site. Rather it is an isolated find and therefore no historic component is defined at 41LR200.

In addition to these artifacts, 16 charcoal samples were recovered from the site. Two of these came from site recording during survey (Lyle et al. 2001:235) while the additional 14 are from testing.

\section{Prehistoric Artifacts}

An overall total of 169 chipped lithic artifacts was recovered from the site during the two phases of work. The majority $(n=168,99 \%)$ consists of debitage and only one non-debitage artifact, a core, was found at the site.

Almost as many pieces of fire-cracked rock were recovered from the site as chipped lithics. A total of 170 fire-cracked rocks was recovered. No burned rock features were recognized in the excavation units.

\section{Chipped Lithics}

\section{Tools and Cores}

No chipped lithic tools were recovered from the site. However, a single multidirectional novaculite core was found in TU 3, Level 8 (70-80 cm bs). The core measures $35 \times 25 \times 21 \mathrm{~mm}$ and has six removal scars.

\section{Debitage}

During the two phases of work at site 41LR200 a total of 168 debitage was recovered, 11 (7\%) of these came from site discovery (Lyle et al. 2001:84), the remain$\operatorname{der}(\mathrm{n}=157,93 \%)$ came from testing. The raw materials are one chalcedony, one novaculite, two silicified sandstone, two silicified wood, three quartz, 78 chert, and 81 quartzite. The novaculite found is a non-local raw material from east Oklahoma and west Arkansas (Banks 1990). Heating is evident on only five percent $(n=4)$ of the chert and two percent $(n=2)$ of the quartzite. This indicates that thermal alteration of raw materials was infrequent at 41LR200.
The chert debitage consists of 48 decorticate flakes, 20 pieces with $1-50 \%$ cortex, eight specimens with $51-99 \%$ cortex, and two primary flakes $(100 \%$ cortex). The chert debitage mean thickness to length ratio is .22. The 81 quartzite debitage includes 34 decorticate flakes, 29 pieces with $1-50 \%$ cortex, 15 specimens with $51-99 \%$ cortex, and three primary flakes. The quartzite debitage have a mean thickness to length ratio of .28. As with site 41LR194, the chert debitage data indicates middle stage reduction and tool manufacture, while the quartzite debitage reflects the predominance of the early stage of reduction.

The breakdown of the chert flake types shows that there are four angular debris, one biface manufacture flake, six biface thinning flakes, one blade, 31 indeterminate types, one notching flake, and 34 platform preparation flakes. The quartzite debitage contains two biface manufacture flakes, two biface thinning flakes, 37 indeterminate types, and 40 platform preparation flakes. These comparisons support lithic activities involving the early and middle stages of biface reduction and tool production.

Debitage at 41LR200 was recovered from the surface down to $130 \mathrm{~cm}$ bs. There is a bimodal distribution in debitage densities (Figure 21). The first peak occurs between $20-60 \mathrm{~cm}$ bs. This accounts for 37 percent $(n=62)$ of the debitage recovered from 41LR200. The second peak is found between $70-100 \mathrm{~cm}$ bs and represents about 38 percent $(n=63)$ of the total debitage recovered. Below $100 \mathrm{~cm}$ bs, debitage density decreases gradually.

\section{Fire-cracked Rock}

During site discovery and recording, six FCR from four STs (20-10 [n=2], 20-12 [n=2], 20-13 [n=1], and Sweep 19 [ $\mathrm{n}=1]$ ), all from $80-100 \mathrm{~cm}$, were recovered with a total weight of $65.5 \mathrm{~g}$. The 164 pieces of burned rock recovered during testing came from the three test units. TU 1 contained the smallest number $(\mathrm{n}=11)$ and lowest weight $(38.6 \mathrm{~g})$ of FCR. On the other hand, TU 2 contained both the highest number $(\mathrm{n}=123)$ and weight $(771.1 \mathrm{~g})$ of FCR from the site. TU 3 yielded fewer numbers $(n=30)$ of FCR weighing a total of $434 \mathrm{~g}$. In TU 1, peaks in FCR weight occur in Levels 3 and 6, while peaks are found in 


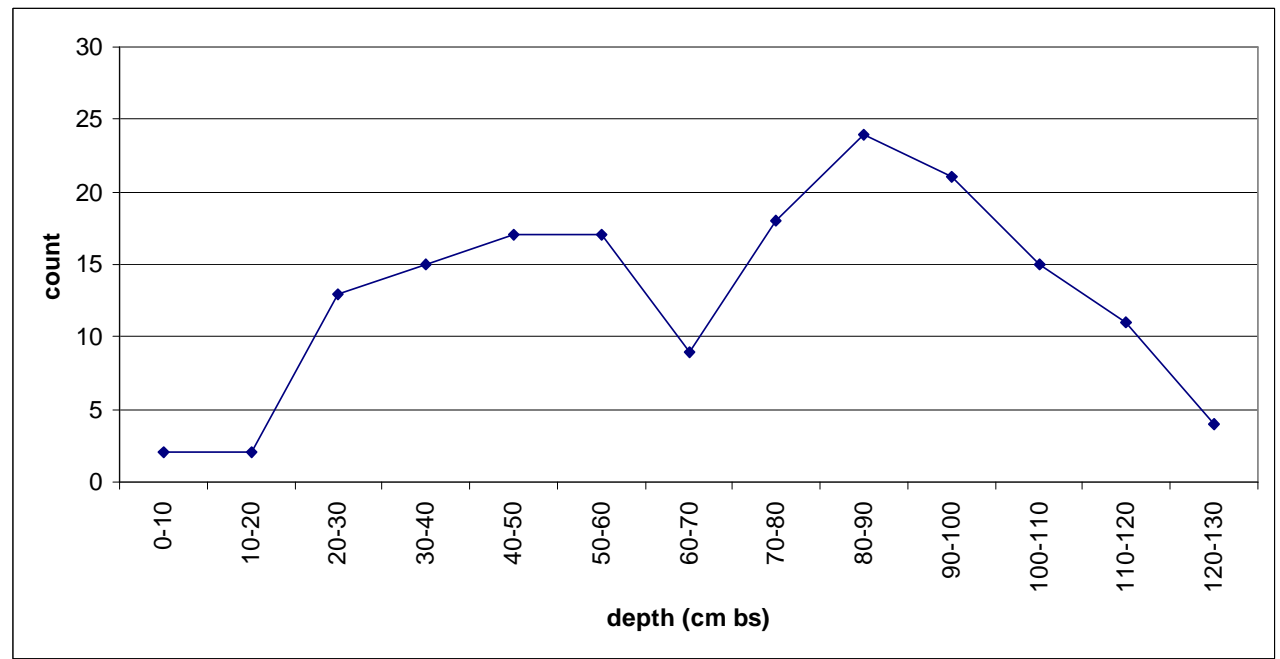

Figure 21. Unmodified debitage densities by depth, 41LR200.

Levels 7 and 11 of TU 2. Peaks in FCR weight are found in Levels 8 and 10 of TU 3.

\section{Charcoal Samples}

During site recording (Lyle et al. 2001) two pieces of charcoal were collected between $60-80 \mathrm{~cm}$ bs in ST 20-10. Fourteen additional samples were obtained during testing. Of these 14, two are from TU 1 (Levels 3 and 4), seven are from TU 2 (Levels 4-6 and 811), and five are from TU 3 (Levels 1-4, and 6). These charcoal samples are the only macrobotanical samples from 41LR200.

\section{Mass Specific Soil Susceptibility}

Thirty sediment samples from TU 2 of 41LR200 were analyzed for magnetic soil susceptibility signatures. Appendix A presents these raw data. Figure 22 presents the MS values for TU 2 by depth. Overall, the samples ranged from a low of 12.38 to a high of 22.49 . An examination of the figure suggests that three distinct peaks are present, with the first occurring at around $92.5 \mathrm{~cm}$ bs in Level 10, a second around 107.5 $\mathrm{cm}$ bs (Level 11), and a third at $142.5 \mathrm{~cm}$ bs (Level 15). A possible fourth peak, at $67.5 \mathrm{~cm}$ bs (Level 7), is probably not significant given the gradual nature of the changes above and below that point in the profile. It is probable, then, that three buried surfaces may be present in the unit.

Less than 80 pieces of debitage were recovered from TU 2 during excavation. Debitage was present from Level 3 through Level 13. An examination of the distribution suggests little vertical patterning, with slight increases in Levels $5(n=11), 9(n=10)$, and Level 11 $(\mathrm{n}=10)$. Only the Level 11 increase corresponds with the MS values. A total weight of only $771.1 \mathrm{~g}$ of firecracked rock was recovered from the unit. An examination of the vertical distribution of the fire-cracked rock suggests that Levels 7,10 , and 11 contain just over 50 percent of the material by weight $(390.7 \mathrm{~g})$. As with the debitage, the correlation with the increased MS values is weak, with two of the peak weights, in Levels 10 and 11, showing some relationship to MS peaks.

Unlike TU 5 in 41LR190, the MS values for TU 2 at 41LR200 show only a weak relationship with either the distribution of debitage or the weight of firecracked rock. The lack of any strong patterning suggests that while stable surfaces may be present in this unit, the surfaces are only weakly associated with human occupation. 


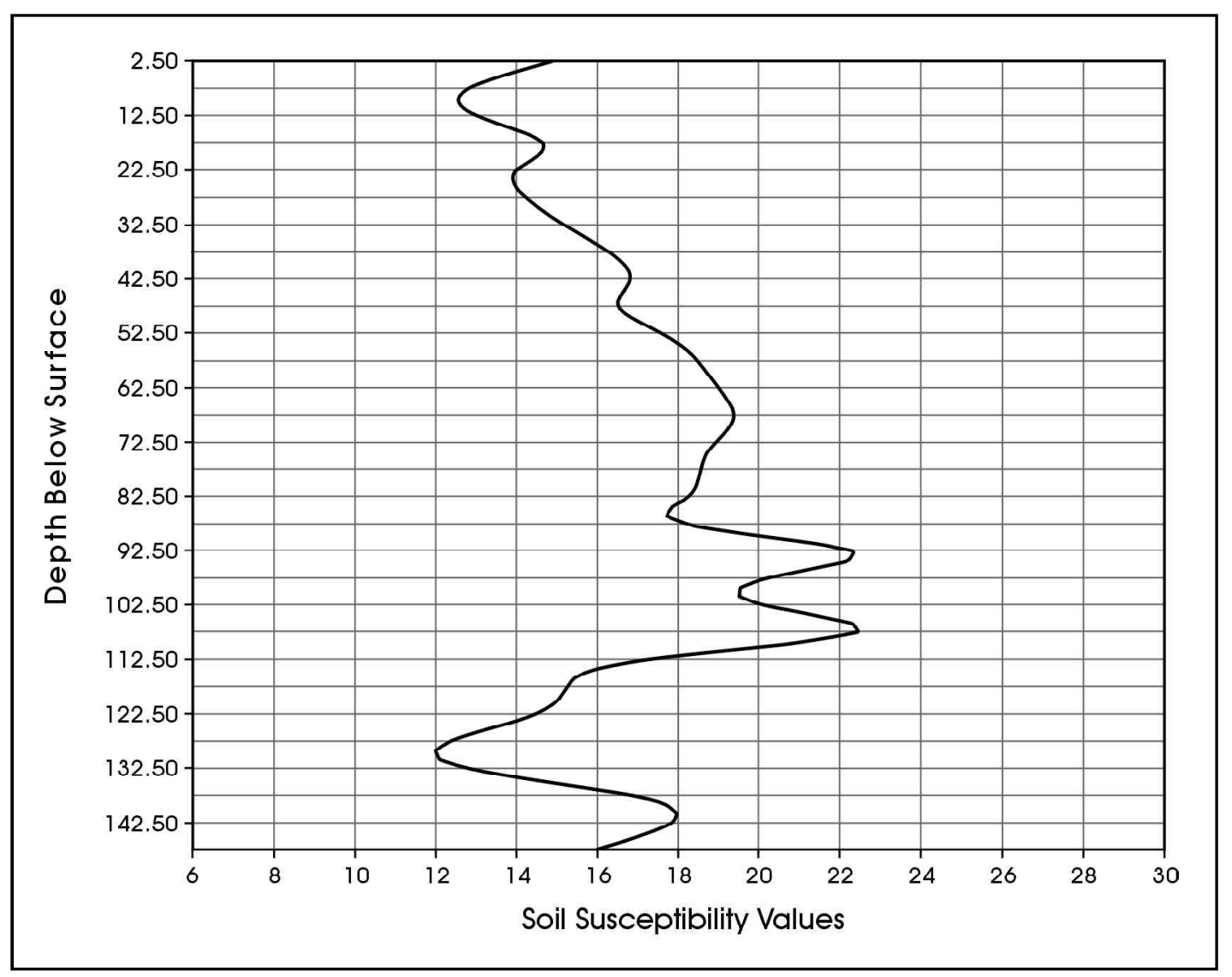

Figure 22. Plot of mass specific sediment susceptibility values for Test Unit 2, 41LR200.

\section{LR258}

\section{Description}

This prehistoric site is on a high probability landform at the confluence of two unnamed tributaries of Sanders Creek (Figure 2) in the northern portion of the facility. The site is situated atop an upland landform of Whakana-Porum series loams at 152-155 m (500-510 $\mathrm{ft}$ ) AMSL. This relatively large finger ridge has a toeslope that extends off the northwest point. The vegetation community consists of the Quercus stellataQuercus marilandica-(Carya texana) Woodland class. The datum was placed on a large oak tree near the point where the toeslope juts off the main landform.
This upland landform has medium- and large-sized oak and hickory trees. Surface visibility in the wooded areas was zero percent due to the leaf debris, and was less than 10 percent in the open grassy areas. This site is approximately $50,903 \mathrm{~m}^{2}$ in area. An open field to the south of the datum contained thick, dry grass with large clumps of sumac and brush. This field appears to have been moderately disturbed at some point in the past, and farther south of the field is a large, heavily disturbed area of artificial mounds. These mounds were used as target practice bunkers during and after WWII operations at Camp Maxey (Maj. Diltz, personal communication). Erosion along the creek banks, historic or military use of the open field, and the presence of the nearby bunkers impacted an estimated 50 percent of the landform. 


\section{Excavations and Stratigraphy}

During the 1999-2000 fieldwork, the site was tested with a total of 30 shovel tests (Figure 23). Prehistoric cultural materials were recovered from 21 STs. Of these 21 STs, 20 different shovel tests on the landform contained prehistoric lithic artifacts, four shovel tests (A-6, A-7, A-10, and B-5) on the eastern part of the landform (with an artifact density of 1.0), four other shovel tests (E-1, G-2, H-1, and I-2) at the southern end of the landform in an open field (with an artifact density of 1.33), and the remaining 12 shovel tests on the northern and western parts of the site. The prehistoric chipped lithic artifacts were found from 0-120 $\mathrm{cm}$ bs. The overall density of prehistoric artifacts recovered during testing was 2.9 per positive shovel test.

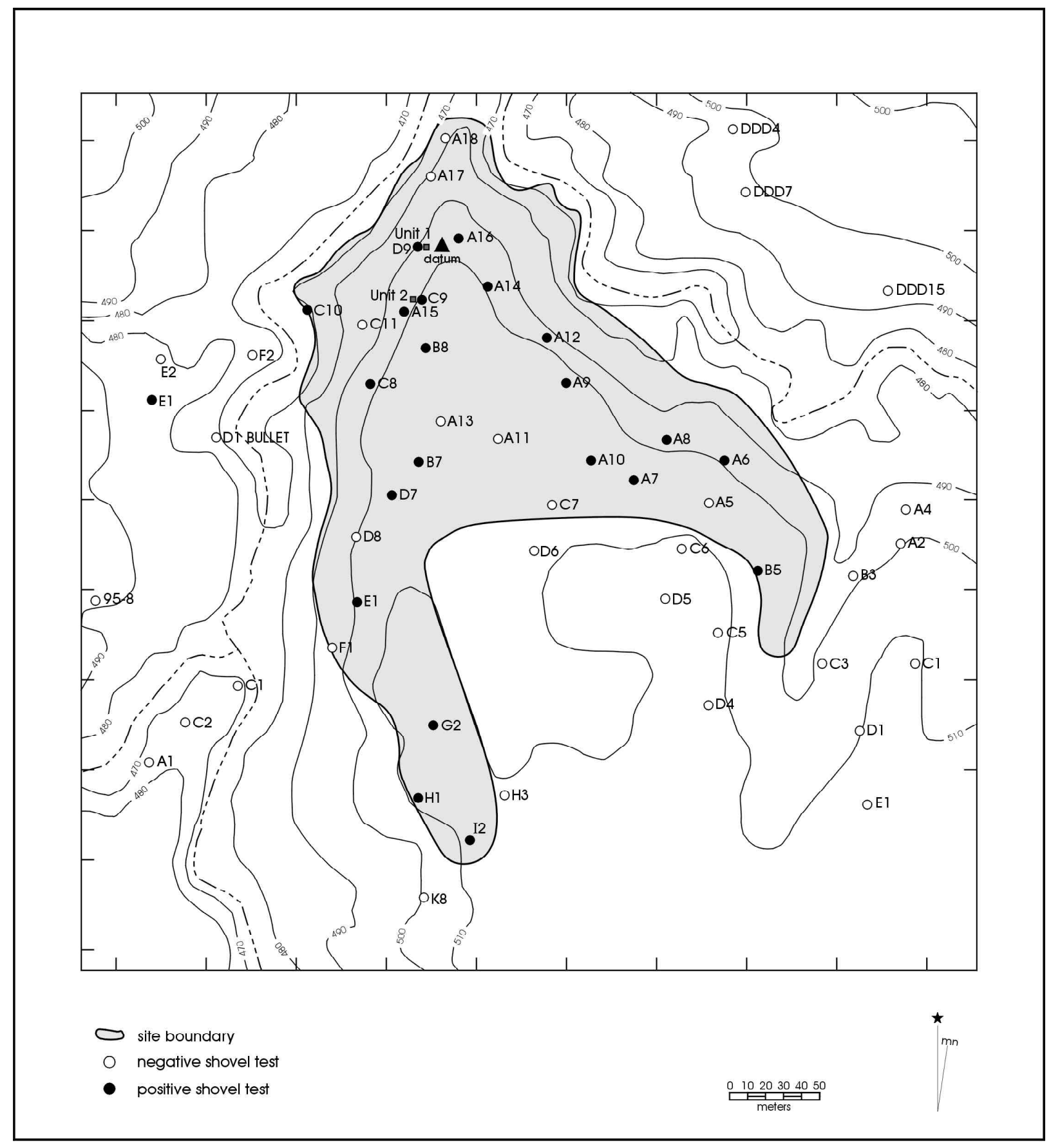

Figure 23. Site map of $41 L R 258$ showing the location of all units excavated on site. 
Three positive STs (I-2, H-1, and A-8) contained military artifacts.

Soils were generally deep with the average thickness of the sandy mantle at between 80 and $120 \mathrm{~cm}$ bs. Soil data from several STs indicate that the sandy loam is at least $140 \mathrm{~cm}$ thick.

During testing at 41LR258 two $1 \mathrm{x} 1$-m test units were excavated (Figure 23) in the north-central portion of the site, adjacent two positive shovel tests dug during site recording. TU 1 was excavated to a depth of 150 $\mathrm{cm}$ bs into mottled red sandy clay (Figure 24). This stratum normally overlies the homogenous red clay substrate that extends over much of the project area. A $50 \times 50 \mathrm{~cm}$ portion of TU 2 was excavated to a depth of $140 \mathrm{~cm}$ bs. The remaining quarter of the unit was dug to a depth of $180 \mathrm{~cm}$ bs into mottled clay loam. Overlying the red sandy clay at the bottom of TU 1 were two yellowish-brown sandy loam strata with only a slight color difference between them. The clay loam at the bottom of TU 2 was overlain by yellow sand and a thick layer of sandy loam. Both units were capped by thin humus layers. No backhoe trenches were dug at the site due to difficulties in accessing the site with heavy equipment under rainy conditions.

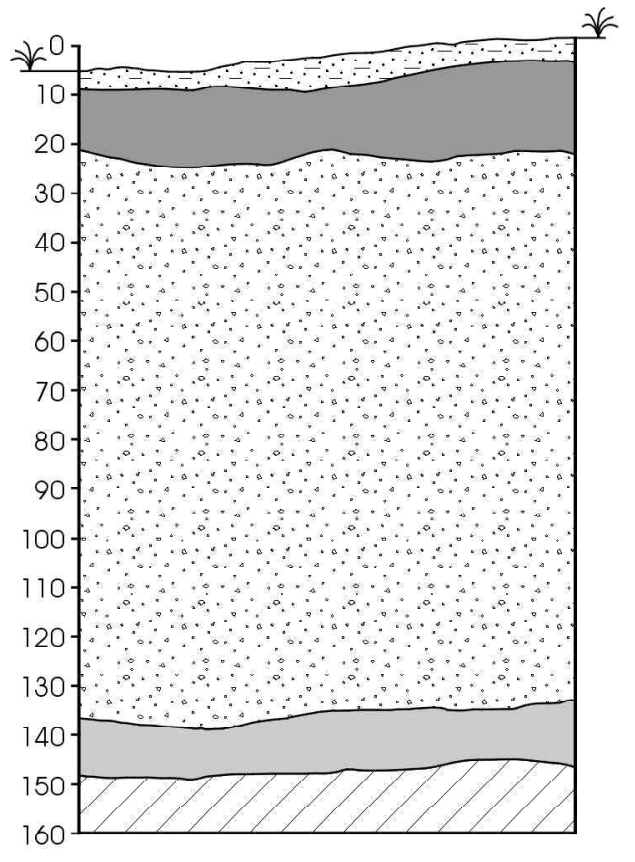

$\because \therefore$ dark brown humus soll 7.5 YR3/2
$\square$ light yellow brown sandy loam 10YR6/4
$\because \because$ yellowish brown sandy loam 10YR5/6
$\square$ red sandy clay 2.5 YR4/6
$\square$ unexcavated

41LR258 Unit 1 East Wall Profile

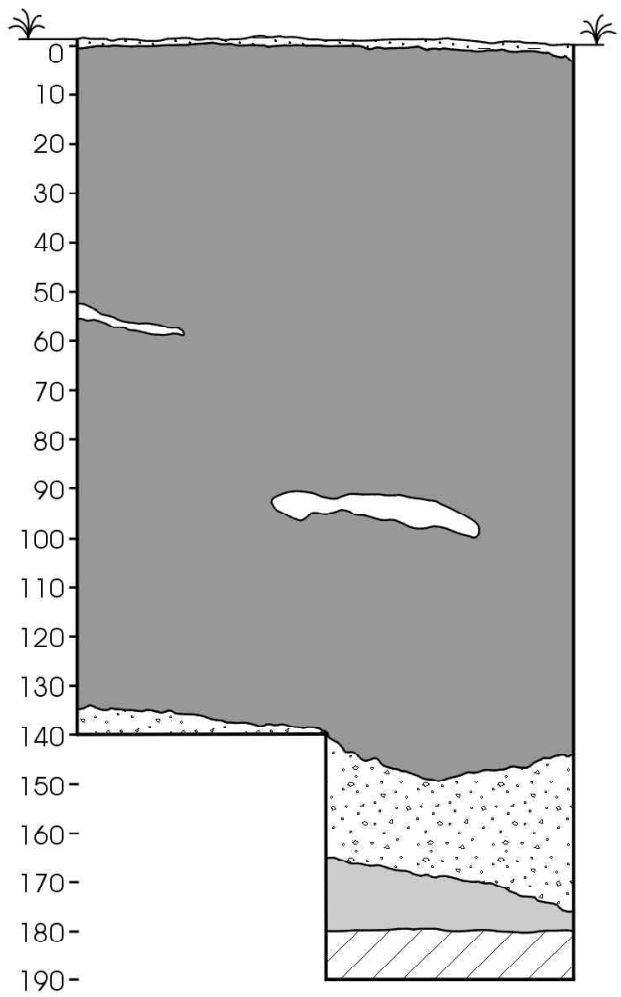

dark brown humus soil 7.5YR3/2 light yellow brown sandy loam 10YR6/4 yellowish brown sandy loam 10YR5/6 red sandy clay $2.5 Y R 4 / 6$ unexcavated

Figure 24. Profiles of two test units excavated at 41LR258. 


\section{Artifacts Recovered}

A total of 280 artifacts was recovered from excavations at the site. Of these, 65 (23\%) came from survey and the remainder $(\mathrm{n}=215,77 \%)$ came from testing efforts at the site. Prehistoric artifacts constitute the bulk of the collection $(n=275,98 \%)$. However, a total of five historic or modern artifacts was also recovered from the site. They consist of four military bullets and a shotgun shell. Military artifacts were recovered from three STs (H-1, I-2, and A-8). In two instances (A-8, $\mathrm{H}-1)$, the bullets were recovered in Level $1(0-20 \mathrm{~cm} \mathrm{bs})$. The specimen recovered from I-2 is from Level 5 ( $80-100 \mathrm{~cm} \mathrm{bs})$. It is likely this bullet fell in from above. The only bullet from testing came from TU 1, Level 2. Given that these five artifacts are probably the product of military activities on or in the vicinity of the site, no historic component was defined at 41LR258.

\section{Prehistoric Artifacts}

An overall total of 169 chipped lithic artifacts was recovered from the site during the two phases of work. The majority $(n=167,99 \%)$ consists of debitage. The remaining chipped lithic artifacts are two biface fragments. In addition, two native ceramic sherds were also found during testing of the site.

The second most common prehistoric artifact class consists of FCR. A total of 104 FCR was recovered. No burned rock features were identified during the work at the site.

\section{Chipped Lithics}

\section{Tools}

Shovel testing during site boundary definition at 41LR258 yielded one biface from $80-100 \mathrm{~cm}$ below the surface (ST D-9). It is made from a non-heat-treated Ogallala quartzite, and is $69 \times 52 \times 18 \mathrm{~mm}$ in length, width, and thickness. While well edged with all cortex removed, it is $18 \mathrm{~mm}$ thick. The biface is a roughly symmetrical ovate shape. There are no signs of wear to indicate use. A second biface fragment was recovered in TU 1, Level 9. It is a large proximal fragment of locally available gray fine-grained quartzite. It is made on a secondary flake core and was broken during the early stages of manufacture. The fragment measures $19 \mathrm{~mm}$ in maximum thickness.

\section{Debitage}

The site discovery and testing excavations at 41LR258 yielded 167 pieces of debitage, of these, $26(16 \%)$ came from the 1999-2000 site discovery work (Lyle et al. 2001:106). Raw material breakdowns are two quartz, three silicified wood, 50 quartzite, and 112 chert. Heat-treating is present only in five percent $(n=6)$ of the cherts, eight percent $(n=4)$ of the quartzite, and in none of the other material types. Such minor percentages show heat-treating to have been of low importance at 41LR258.

The chert debitage has 72 decorticate flakes, 25 specimens with $1-50 \%$ cortex, 10 pieces with $51-99 \%$ cortex, and five primary flakes. The mean thickness to length ratio is .18. The quartzite debitage consists of 24 decorticate flakes, 11 pieces with $1-50 \%$ cortex, seven specimens with 51-99\% cortex, and eight primary flakes. The mean thickness to length ratio of the quartzite is .23. These patterns in cortex and thickness to length ratio point to middle stage reduction and tool manufacture as the primary stone-working activity at 41LR258.

The flake types among the chert debitage include three angular debris, five biface manufacture flakes, 11 biface thinning flakes, two blades, 47 indeterminate types, one notching flake, 42 platform preparation flakes, and one uniface flake. The quartzite debitage consists of three biface manufacture flakes, three biface thinning flakes, 22 indeterminate, and 22 platform preparation flakes. The flake type data supports tool production as the primary activity at this site.

Debitage was encountered from the surface to $140 \mathrm{~cm}$ bs, and then from 150 to $180 \mathrm{~cm}$ bs where excavation was terminated (Figure 25). Debitage density is greatest between 40 and $80 \mathrm{~cm}$ bs containing 46 percent $(n=78)$ of the total. 


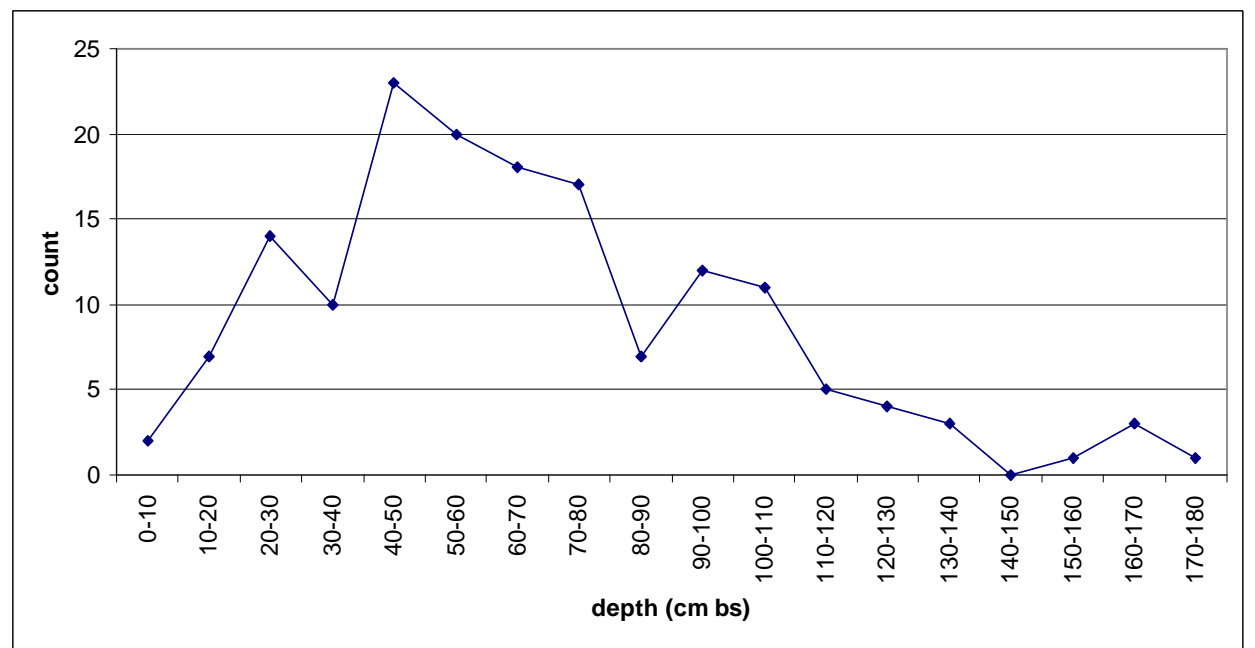

Figure 25 . Unmodified debitage densities by depth, 41 LR258.

\section{Native Ceramics}

Two ceramic sherds were recovered during the testing of the site. They were recovered from Level 3 (20$30 \mathrm{~cm} \mathrm{bs}$ ) of TU 1. Both appear to be undecorated body sherds made with a sandy paste containing no additional visible temper. Both sherds appear to be from vessels fired in an oxidized firing atmosphere. The two pieces are 8 and $6 \mathrm{~mm}$ in maximum thickness, and are only 14 and $9 \mathrm{~mm}$ in maximum dimension.

\section{Fire-cracked Rock}

Both heat spalls and FCR were encountered during survey and site recording. Two heat spalls came from STs A-16 and D-9, 20-40 cm bs. Thirteen STs (A-6, A-9, A-10, A-12, A-15, B-7, B-8, C-8, C-9, C-10, D-9, E-1, and I-2) contained 32 FCR weighing $237.4 \mathrm{~g}$. These FCR were distributed at all levels between 0 $130 \mathrm{~cm}$ bs. The 70 FCR pieces from testing are from both test units. TU 1 contained a total of 16 pieces weighing $53.4 \mathrm{~g}$. The only distributional peak, in terms of weight, occurs in Level 2 (49.4 g). TU 2 contained 54 pieces weighing $607.7 \mathrm{~g}$. Level $6(107 \mathrm{~g})$ and Level $14(146.4 \mathrm{~g})$ contained the only peaks in terms of FCR weight.

\section{Charcoal Samples}

Three samples were obtained during testing. All three are from TU 1 (Levels 4, 9, and 10). These charcoal samples are the only macrobotanical samples from 41LR258.

\section{Mass Specific Soil Susceptibility}

Thirty-six sediment samples from Test Unit 2 were analyzed for magnetic soil susceptibility signatures. Appendix A presents these raw data. Figure 26 presents the MS values for TU 2 by depth. Overall, the samples ranged from a low of 6.84 to a high of 19.59 . An examination of the figure suggests that four distinct peaks are present, all occurring below one meter in depth. A total of 69 pieces of debitage was recovered from this unit, which was excavated to $180 \mathrm{~cm}$ bs. However, only 15 items were recovered from below one meter. Given the small number of items $(n=15)$ spread between 100 and $180 \mathrm{~cm}$ bs, it is difficult to develop any relationship between the peaks in the MS values and the distribution of artifacts. The total weight of fire-cracked rock recovered from the excavation amounted to only $607.7 \mathrm{~g}$. However, 24 percent of this weight (146.4 g) was present in Level 14 (130$140 \mathrm{~cm} \mathrm{bs}$ ). This peak in fire-cracked rock weight 


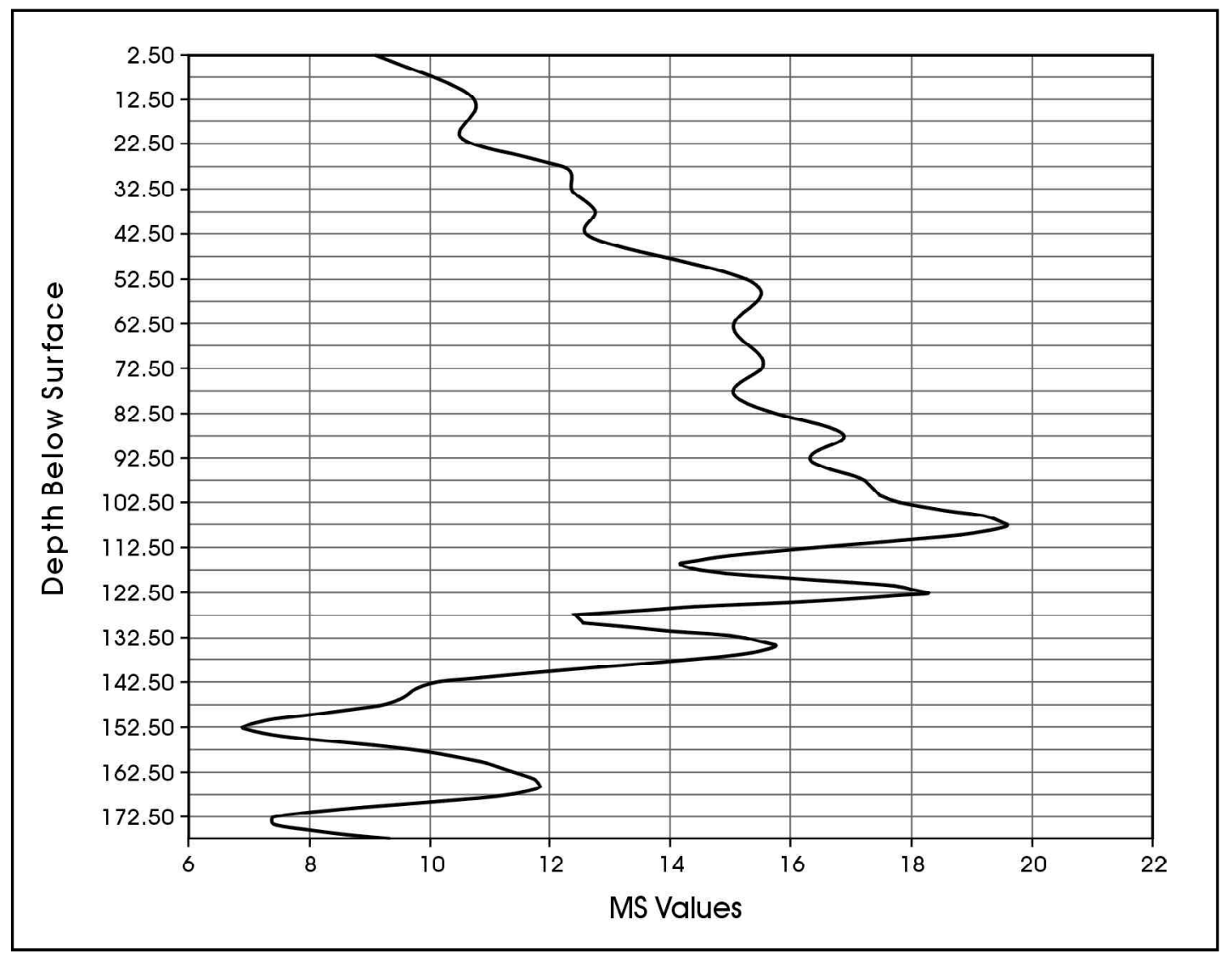

Figure 26. Plot of mass specific sediment susceptibility values for Test Unit 2, 41LR258.

seems to correlate with the MS peak at roughly 137.5 $\mathrm{cm}$ bs. No other significant relationships between the MS value peaks and either chipped stone artifacts or fire-cracked rock weights are present. The overall pattern, then, is one that suggests stable surfaces are present below one meter in depth, but occupation associated with those surfaces was minimal.

\section{LR259}

\section{Description}

This prehistoric site was recorded on a moderate probability upland landform with an adjacent high probability peninsula at the northern tip. Two unnamed creeks join at a confluence just off the northern tip of the landform, and eventually drain into Pat Mayse Reservoir approximately $400 \mathrm{~m}$ to the north. A dry gully borders the site to the west (Figure 2). The site is situated atop a landform of Whakana-Porum series loams at $149-155 \mathrm{~m}(490-510 \mathrm{ft})$ AMSL. This landform contains mixed oaks, Dogwood trees, and a stand of pines. Little bluestem grasses and leaf clutter prohibited surface visibility. The vegetation community consists of the Quercus stellata-Quercus marilandica(Carya texana) Woodland class. Military training in the area was documented. Hand grenade fragments were recovered from two shovel tests and observed along the tank track road leading into this area. Erosion along the eastern creek bank, which has a six to eight meter high cutbank that slumps at the base, is endangering the integrity of the already impacted site. The site is approximately $16,241 \mathrm{~m}^{2}$ in area.

\section{Excavations and Stratigraphy}

During the 1999-2000 fieldwork, the site was tested with a total of 14 shovel tests (Figure 27). Of these, nine were positive containing prehistoric and historic 


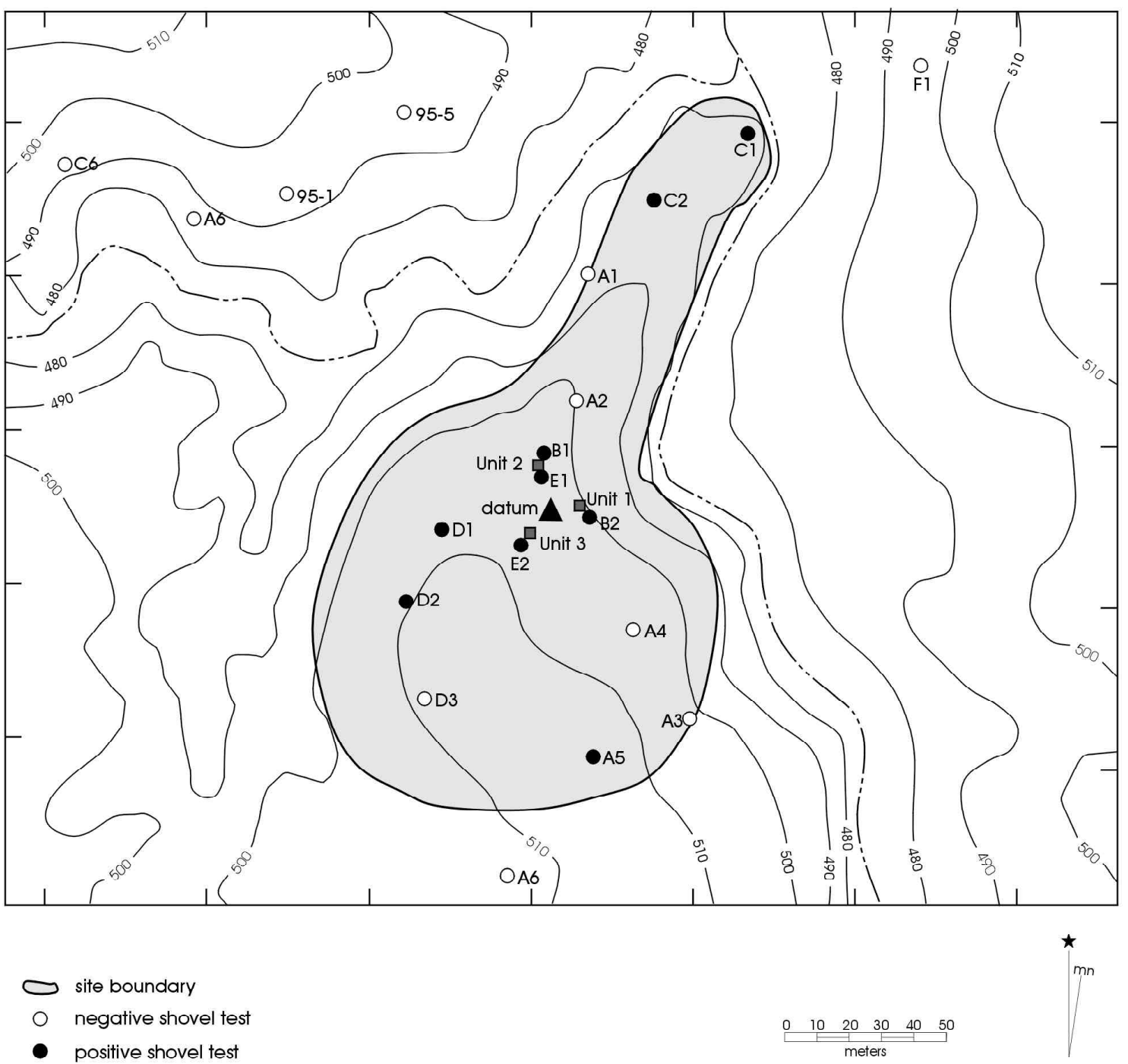

Figure 27. Site map of 41LR259 showing the location of all units excavated on site.

artifacts. Five of the nine shovel tests had prehistoric chipped lithic and/or ceramic artifacts $(n=2)$ between $0-120 \mathrm{~cm}$ bs; while one of the other four (ST D-1) contained only a grenade fragment, and the other three (C-1, B-2, and D-2) contained only fire-cracked rock. Slightly more than half $(58 \%)$ of the artifacts are from $80-120 \mathrm{~cm}$ bs. Depths to clay in the positive tests were at least $90 \mathrm{~cm}$ bs.
During the 2001 site testing activities three 1 x $1-\mathrm{m}$ test units were excavated on site (Figure 27). All three were dug in the central portion of the site adjacent positive shovel tests excavated during site recording. The terminal depths of the three hand-excavated units varied based on the depths of the mottled yellow and reddish-brown sand and red clay loam that marked the top of the sterile substrate (Figure 28). TU 1 was 
dug to a depth of $110 \mathrm{~cm}$ bs and about $10 \mathrm{~cm}$ into the sterile basal red clay. TUs 2 and 3 were excavated to 133 and $125 \mathrm{~cm}$ bs, respectively, into reddish-yellow sandy clay loam. In all three units, the basal stratum was overlain by a mottled yellowish-brown sandy loam with red clay mottles and inclusions. Yellowish-brown sandy loam constitutes the thickest stratum in each unit and a humus layer caps all three.

\section{Artifacts Recovered}

A total of 197 artifacts was recovered from excavations at the site. Of these, 39 (20\%) came from survey and the remainder $(\mathrm{n}=158,80 \%)$ came from testing efforts at the site. Prehistoric artifacts constitute the bulk of the collection $(n=188,95 \%)$, although a few metal artifacts were also recovered $(n=9,5 \%)$. In addition to these artifacts, a single mussel shell from ST B-1 (Level 2, 20-40 cm bs) was recovered during site recording. Finally, three charcoal samples were collected from the site.

The metal artifacts consist of three grenade fragments (ST A-5, Level 1; ST D-1, Level 3; and ST E-2, Level 1), and six .22-caliber bullets from ST E-1 (Level 1), and TU 3 (Levels 2, 3 [n=2], 5, and 11). Since all of these artifacts represent military activities at the location, no historic component was defined at 41LR259.

\section{Prehistoric Artifacts}

An overall total of 112 chipped lithic artifacts was recovered from the site during the two phases of work. The majority $(n=103,92 \%)$ consist of unmodified debitage. The remainder of the lithic artifacts consist of projectile points $(n=2)$, cores $(n=2)$, miscellaneous bifaces $(n=2)$, expedient scrapers $(n=2)$, and a miscellaneous uniface. In addition, nine prehistoric ceramics were recovered from the site; two during survey and seven during testing.

The second most common prehistoric artifact class is fire-cracked rock. A total of 67 fire-cracked rocks was recovered with 24 (36\%) found during survey. No burned rock features were identified at the site.

\section{Chipped Lithics}

\section{Tools and Cores}

Two projectile points were recovered during the two phases of work at the site. Both points appear to be unfinished preforms. The first of the points (lot no. 62; Figure 7i) is a lanceolate specimen recovered from Level 7 of TU 1. It has a concave base, a rather broad $(28 \mathrm{~mm})$ stem with parallel sides, and convex blade edges. The blade exhibits well-executed parallel "ribbon flaking" characteristic of Plainview points. The blade is alternately left-beveled but this feature is not a result of resharpening. No grinding is evident on the base or stem edges, and on one face of the stem there are three parallel basal thinning flake scars, the longest of which extends to a distance of $15 \mathrm{~mm}$ above the base. The opposite face has four shorter thinning scars that only reach to a distance of $9.5 \mathrm{~mm}$. The point is made on brownish-yellow chert that is locally available. In overall morphology, flaking pattern, and dimensions the point appears to fit into the general late Paleoindian group and it may represent a possible Plainview preform. The point measures $51 \mathrm{~mm}$ in maximum length, $28 \mathrm{~mm}$ in maximum width, it is 25 $\mathrm{mm}$ wide at the base, and has a maximum thickness of $7 \mathrm{~mm}$.

The second dart point, a parallel stem specimen, is also a preform (lot no. 9-2; Figure 7j). It was recovered from Level 10 of TU 1 . It has a short $(9 \mathrm{~mm})$ parallel to slightly contracting stem and straight to slightly convex base. The blade edges are not well formed and the blade is shouldered only on one edge. Numerous step fractured thinning flakes have prevented the thinning of one face of the specimen and led to the discard of the preform. The point is made on reddish-gray medium-grained quartzite that is of local origin. Although it is an unfinished specimen, sufficient shaping has occurred to suggest that the specimen was intended as a Kent type, quinlan variety (Johnson 1962:167-168). The point measures 50 $\mathrm{mm}$ in maximum length, has a maximum blade width of $26 \mathrm{~mm}$, a neck width of $17 \mathrm{~mm}$, and a base width of $13 \mathrm{~mm}$. The maximum thickness is $8 \mathrm{~mm}$.

The two bifaces recovered from the site consist of a proximal fragment (lot no. 27-3) made on a brownish-yellow fine-grained chert, and a large complete 

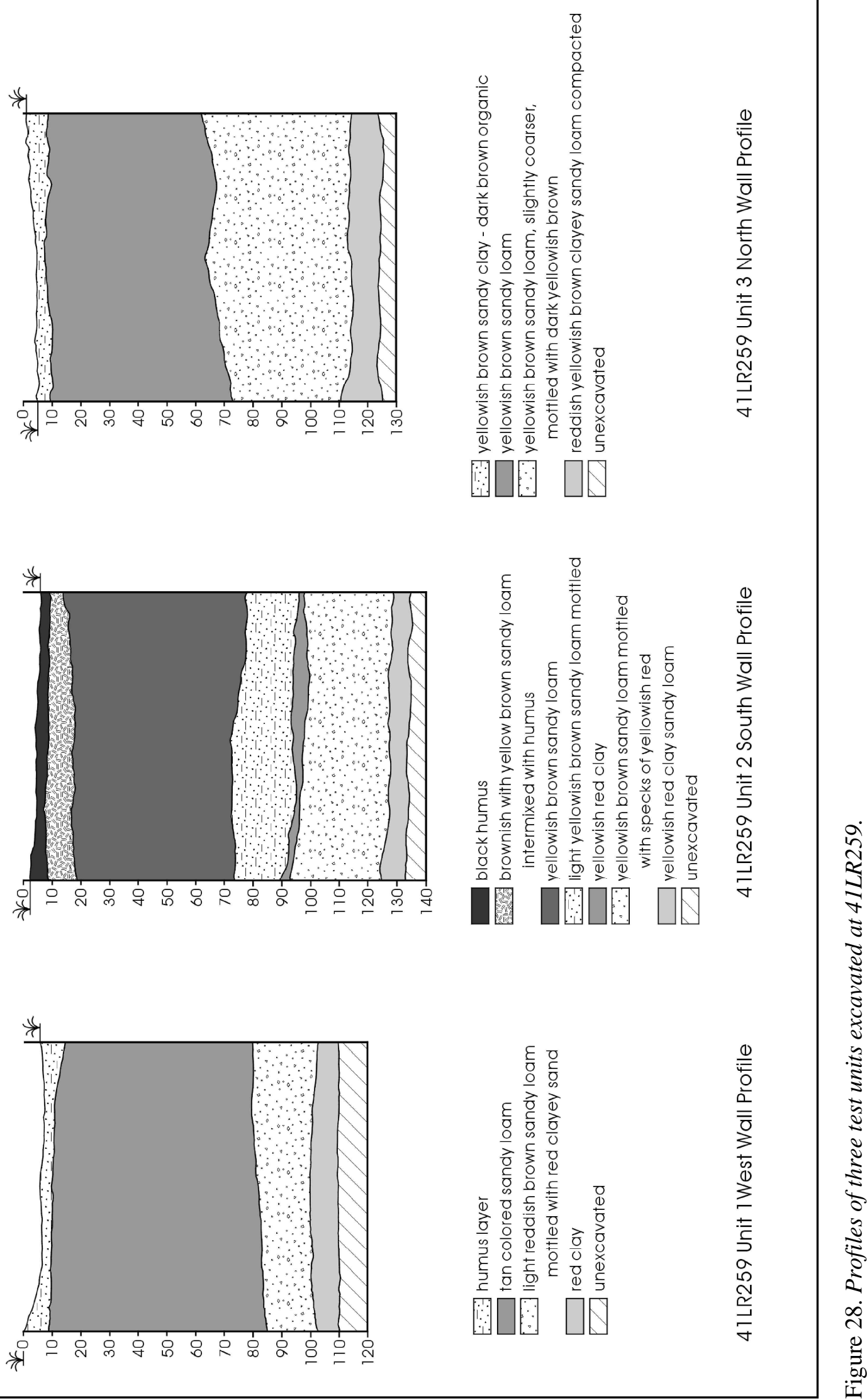
specimen (lot no. 15-1) made of mottled reddish-gray fine-grained quartzite. Both are locally available raw materials and both represent early reduction stage discards. The chert specimen was broken as a result of an imbedded fracture line while the quartzite specimen was not thinned properly due to numerous stepfractured flake removals. The complete specimen measures $85 \times 63 \times 36 \mathrm{~mm}$ and approximately 80 percent of its surface is cortex covered. The proximal fragment measures $34 \mathrm{~mm}$ in maximum width and 8 $\mathrm{mm}$ in maximum thickness.

The two expedient scrapers consist of an end scraper (lot no. 24-3) and a combination end/side scraper (lot no. $17-2)$. The end scraper is a small $(18 \mathrm{~mm})$ secondary flake of silicified wood with micro-flaking along its distal end. The use-wear stretches over $13 \mathrm{~mm}$ of the edge. The combination end/side scraper is a small (38 mm) secondary chert flake with $1-1.5 \mathrm{~mm}$ microscarring resulting from use along the lateral and distal margins. Micro-scarring is distributed over $23 \mathrm{~mm}$ of its edge. The flake blank used as an expedient tool has a corticated platform and approximately 35 percent of its dorsal face retains cortex. The fine-grained chert has a yellow, gray, and red mottled appearance and is of local origin.

The single miscellaneous uniface (lot no. 21-3) has use-related micro-flaking on alternate faces of two edges. This wear pattern is similar to that caused by the use of a pointed tip as an expedient drill. However, the fragment is too small to establish this usehistory with confidence.

The two cores recovered from the site include a large fine-grained quartzite specimen (lot no. 10-2) and a small chert core fragment (lot no. 9-3). The quartzite core has a single platform face and five unidirectional flake removals. The core measures 84 × 62 × $54 \mathrm{~mm}$ in maximum length, width, and thickness. The small chert fragment ( $40 \times 26 \times 15 \mathrm{~mm}$ ) has three flake removals and has a mottled gray and reddish appearance. The material is of local origin.

\section{Debitage}

Site 41LR259 yielded 103 pieces of debitage, of these, only nine were recovered during site survey (Lyle et al. 2001:107). The raw material types include one chalcedony, two quartz, seven novaculite, 28 quartzite, and
65 chert specimens. The novaculite found at the site likely has its origins in the Ouachita Mountains of eastern Oklahoma and western Arkansas (Banks 1990). Heating has affected three percent $(n=2)$ of the chert flakes and a single (4\%) quartzite flake. Heating, as a means to improve the workability of raw materials, was of low importance at this site.

Among the chert debitage there are 42 decorticate flakes, 16 with $1-50 \%$ cortex, six with $51-99 \%$ cortex, and one primary flake. The mean thickness to length ratio of the chert is .20 . The quartzite debitage has 13 decorticate flakes, nine flakes with $1-50 \%$ cortex, three specimens with 51-99\% cortex, and three primary flakes. The mean thickness to length ratio is .44. The chert debitage indicates that middle reduction stage tool manufacture was the main lithic activity at this site while the quartzite indicates the predominance of early reduction stage activities. This pattern has shown up in three of the six sites in this study. One of the likely explanations for this pattern is that the reduction of the two raw material types does not result in identical finished products. That is, because of its finer-grained quality, chert can be reduced more effectively into late reduction stage and finished tool forms than the relatively coarse-grained quartzite. Therefore, the quartzite debitage samples will always be dominated by higher percentages of corticated flakes.

The flake types among the chert debitage include three angular debris, nine biface thinning, one bipolar, 22 indeterminate, and 30 platform preparation flakes. The quartzite debitage collection consists of one biface manufacture, nine indeterminate, and 18 platform preparation flakes.

Debitage was encountered from the surface to $110 \mathrm{~cm}$ bs. The debitage density rises steadily and is greatest at $30-40 \mathrm{~cm}$ bs accounting for 22 percent $(\mathrm{n}=23)$ of the total (Figure 29). Following a significant drop in Level 5, the density remains fairly constant from 50 $100 \mathrm{~cm}$ bs and drops markedly again in Level 11 .

\section{Fire-cracked Rock}

Two heat spalls (from STs B-2 and E-1, 0-40 cm bs) and 22 FCR were collected during site discovery from 


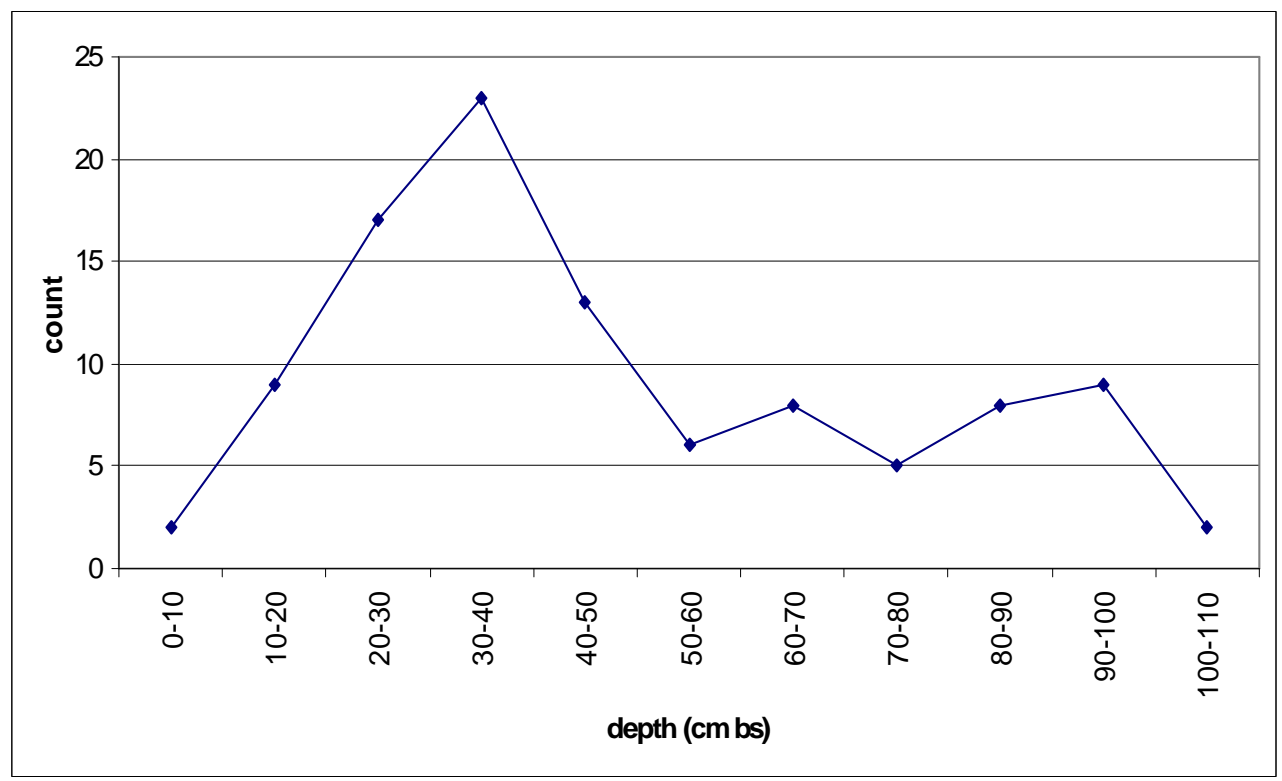

Figure 29. Unmodified debitage by depth, 41LR259.

41LR259 between $20-120 \mathrm{~cm}$ bs. The FCR came from six STs (B-2, C-1, C-2, D-2, E-1, and E-2) and weighed $319.5 \mathrm{~g}$. The $43 \mathrm{FCR}$ pieces from testing are from all three of the test units. TU 1 contained a total of eight pieces weighing $148 \mathrm{~g}$. The only distributional peak, in terms of weight, occurs in Level 8 (85.5 g). TU 2 contained 13 pieces weighing $420.1 \mathrm{~g}$. Level 7 (128.2 g) and Level 10 (136.2 g) contain the only peaks in terms of FCR weight. TU 3 contained 22 pieces weighing only $35 \mathrm{~g}$, no real peaks were present in the distribution.

\section{Native Ceramics}

The two ceramic sherds recovered during survey were from ST B-1 $(20-40 \mathrm{~cm}$ bs) and ST E-2 (81-100 cm bs) on the crest of the landform. The first sherd (in two pieces) is a grog-tempered body sherd from a bottle; the bottle had been reduced during firing, but cooled in a high oxygen environment (cf. Teltser 1993:Figure 2G). The specimen from ST E-2 is a plain body sherd ( $8.9 \mathrm{~mm}$ in thickness) tempered with grog, and is from a vessel that was oxidized during firing.

Seven additional ceramic sherds were recovered from the site during testing. Three of them came from TU 1 ,
Levels $4(30-40 \mathrm{~cm}$ bs, $\mathrm{n}=2)$ and $5(40-50 \mathrm{~cm} \mathrm{bs}$, $\mathrm{n}=1)$. The remaining four are from TU 2, Levels 3 $(20-30 \mathrm{~cm} \mathrm{bs}, \mathrm{n}=2), 7(60-70 \mathrm{~cm}$ bs, $\mathrm{n}=1)$, and 8 (70$80 \mathrm{~cm} \mathrm{bs}, \mathrm{n}=1)$. Two of the fragments refit so that only a sample of six will be discussed. No decorated sherds are present in the collection and only one small rim sherd from a bowl with an everted rim section of $5 \mathrm{~mm}$ is present. All the sherds appear to be from bowls based on surface treatment; however, only three can be confidently termed bowls. The determination of firing conditions is divided into fully oxidized, fully reduced, and those that are zoned with oxidized and reduced bands. The sherds have all undergone heavy erosion making the estimation of their original surface treatments difficult. At the very least the vessels were smoothed; some of the sherds still retain remnants of polishing. Two interiors are highly polished, reduced surfaces and may have been intentionally smudged. All the clay bodies are sandy paste with varying temper types. It is possible that the break surfaces examined on these particular sherds are not representative of the tempering agents present as there was no visible temper. However, the majority of the sherd assemblage exhibited grog-bone/shell, or bone/ shell temper. The largest sherd recently broke along a $3 \mathrm{~mm}$ sized piece of ferruginous material, possibly an iron concretion. No other temper was seen in this sherd. 


\section{Charcoal Samples}

Three charcoal samples were obtained during testing. Of these, one is from TU 1 (Level 5), and the other two are from TU 3 (Levels 4 and 7). These charcoal samples are the only macrobotanical samples from 41LR259.

\section{Mass Specific Soil Susceptibility}

Twenty-six sediment samples from TU 2 were analyzed for magnetic soil susceptibility signatures. Appendix A presents these raw data. Figure 30 presents the MS values for TU 2 by depth. Overall, the samples ranged from a low of 8.79 to a high of 26.86 . An examination of the figure suggests that three distinct peaks are present at depths of 77.5 (Level 7), 87.5
(Level 8), and 127.5 (Level 13). Unfortunately, only 10 pieces of debitage were recovered from the excavation of TU 2, making any detailed comparison between the artifacts and MS values difficult. Nevertheless, a consideration of the distribution of the 10 items of debitage clearly shows no relationships with the MS peaks. Four pieces of debitage were recovered in Level 3, one in Level 5, three in Level 10, and two in Level 11.

The total weight of fire-cracked rock recovered from excavation amounted to only 420.1 grams, with just over 95 percent of this total concentrated in Levels 5 , 7 , and 10. The only relationship between the firecracked rock weights and the MS peaks, then, occurred in Level 7. The overall pattern is one that suggests several stable surfaces with minimal occupation.

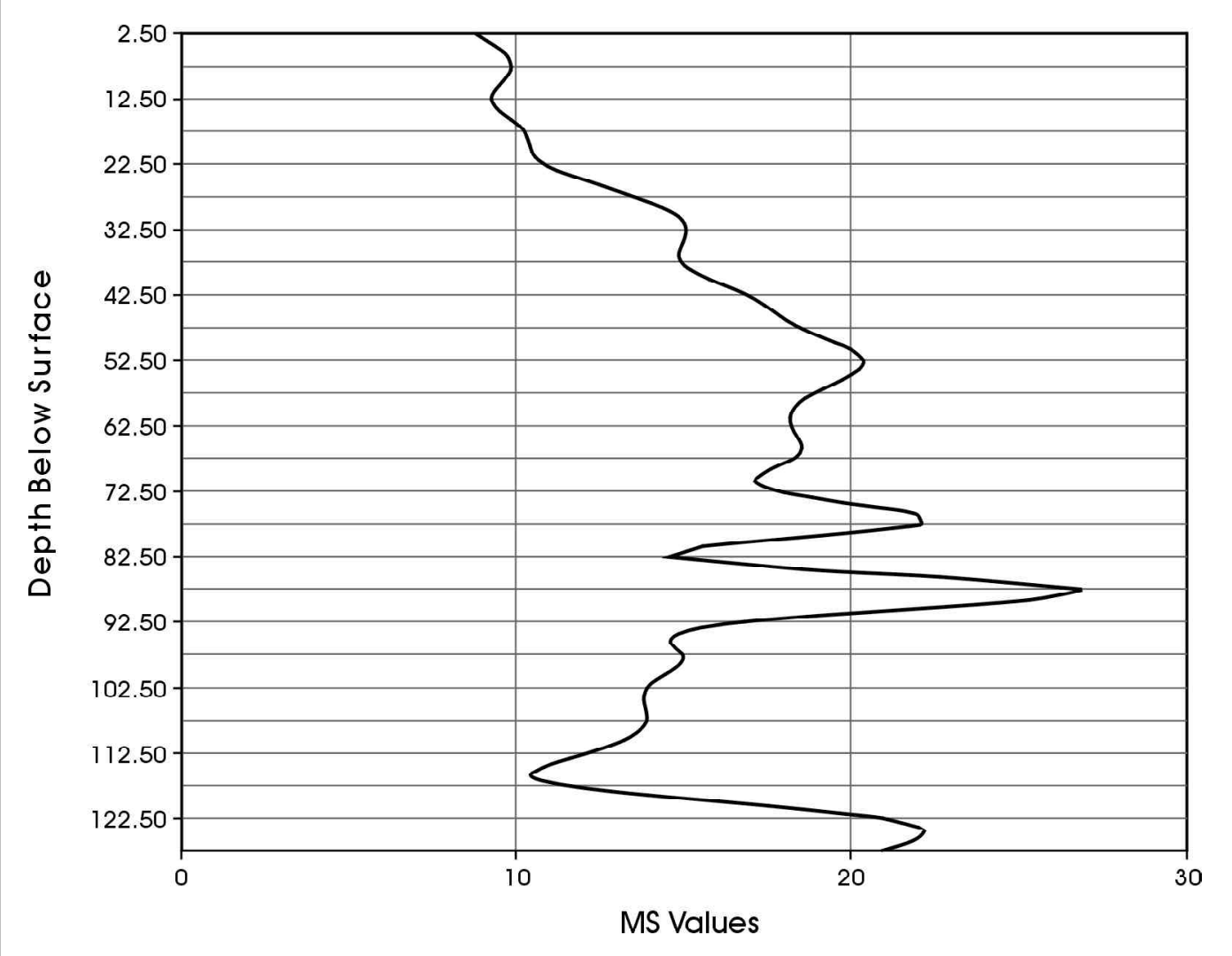

Figure 30. Plot of mass specific sediment susceptibility values for Test Unit 2, 41LR259. 



\section{Chapter 7: Summary and Recommendations}

The purpose of this testing project is to provide the Adjutant General's Office with the NRHP eligibility status of six previously recorded prehistoric archaeological sites located within the TXARNG Camp Maxey training facility. These investigations were performed in light of the proposed development of roads, firebreaks, and general training areas within the facility. Through excavation of backhoe trenches and manually excavated test units, the depositional integrity of each site was evaluated. With subsequent analyses of recovered artifacts and ecofacts, the temporal integrity of each site was similarly evaluated. The results of these evaluations were then combined in order to determine site significance. The following sections provide a brief summary of each site.

\section{LR190}

During the 1999-2000 site discovery and documentation phase, 20 shovel tests were dug on site. In addition, during the 2001 testing phase, three backhoe trenches and five $1 \times 1-\mathrm{m}$ test units were excavated. A total of 1,494 artifacts was recovered including six Late Archaic/Transitional Archaic projectile points (Kent $[\mathrm{n}=3]$ and Gary [n=3]). A few $(\mathrm{n}=35)$ historic artifacts were found during both phases of work at the site. The majority of the historic artifacts occur in the top portion of the profile. Cultural materials extend to a depth of about $120 \mathrm{~cm}$ bs. Peaks in material culture and magnetic soil susceptibility suggest the presence of at least two and perhaps three depositional/occupation surfaces. The presence of three burned rock features and the correspondence of the burned rock zone (Levels 7-10) with one of the magnetic susceptibility peaks lends further support to the presence of a buried occupation surface.

\section{LR194}

During the 1999-2000 site discovery and documentation phase, a total of 13 shovel tests was excavated. In addition, three backhoe trenches and three $1 \times 1-\mathrm{m}$ test units were excavated on site during testing. A total of 284 artifacts was recovered. An unidentified piece of metal and three military bullets are the only historic artifacts recovered from the site. The recovery context of some of the metal artifacts (TU 2, Levels $7[n=1]$ and $8[n=2])$ in deep deposits suggests a considerable degree of disturbance. The lack of temporal diagnostics and lithic tools, and the absence of intact features limits the research potential of the site.

\section{LR196}

During the 1999-2000 site discovery and documentation phase, 18 shovel tests were excavated on site. In addition, three backhoe trenches and three $1 \times 1-\mathrm{m}$ test units were excavated during testing. A total of 490 artifacts was recovered from site discovery and test excavations at the site. Artifacts were recovered to a depth of $170 \mathrm{~cm}$ bs. A possible Early Archaic dart point was recovered from 100-110 $\mathrm{cm}$ bs (TU 2). Although three peaks (Levels 8, 10,12) in burned rock distribution can be noted within TU 2, the unit with the highest number and greatest weight of FCR, no burned rock features could be defined. No magnetic soil susceptibility samples were recovered to investigate the presence of buried surfaces.

\section{LR200}

During the 1999-2000 site discovery and documentation phase, nine shovel tests were excavated on site. In addition, three backhoe trenches and three $1 \times 1-\mathrm{m}$ test units were excavated to test the site. A total of 341 artifacts was recovered although they do not include temporal diagnostics or tools. Artifacts were recovered to a depth of $130 \mathrm{~cm}$ below surface. Two peaks appear to be present in debitage distribution. The first peak occurs between $20-60 \mathrm{~cm}$ bs, the second peak is found between 70-100 cm bs. In terms of burned rock distributions, TU 2 contained both the highest number 
$(\mathrm{n}=123)$ and greatest weight $(771.1 \mathrm{~g})$ of FCR from the site. However, the correlation with the patterns in magnetic susceptibility values of the sediments is weak, with two of the peak weights, in Levels 10 and 11, showing some relationship to MS peaks. The lack of any strong patterning with either the debitage or the burned rock distributions suggests that while stable surfaces may be present in this unit, the surfaces are only weakly associated with human occupation. No intact features were identified at the site.

\section{LR258}

During the 1999-2000 fieldwork, the site was tested with a total of 30 shovel tests. An additional two $1 \mathrm{x}$ $1-\mathrm{m}$ test units were excavated during testing. A total of 280 artifacts was recovered from these excavations. No temporally diagnostic lithic artifacts were encountered. However, two undecorated ceramic body sherds were recovered in Level 3 of TU 1. In addition, five military artifacts were also recovered from the site, the majority of these came from the upper $20 \mathrm{~cm}$ of the deposits. Debitage was encountered from the surface to $180 \mathrm{~cm} \mathrm{bs}$, the highest densities occur between 40 and $80 \mathrm{~cm}$ bs. No intact features were noted at the site. The comparison of FCR patterning with the magnetic soil susceptibility patterns suggests that stable surfaces are present at the site below one meter in depth, but occupation associated with those surfaces was minimal.

\section{LR259}

During the 1999-2000 fieldwork, the site was tested with a total of 14 shovel tests. An additional three $1 \mathrm{x}$ 1 -m test units were dug at the site in 2001. A total of 197 artifacts was recovered including nine military artifacts. These artifacts were distributed from Level 1 through Level 11 and suggest a considerable degree of disturbance of the deposits. Two dart points were recovered during testing. One is a Kent preform (TU 1, Level 10) and the other is a probable Plainview preform (TU 1, Level 7). In addition, nine plain ceramic sherds were also recovered, distributed between $20-100 \mathrm{~cm}$ bs. Debitage was encountered from the surface to $110 \mathrm{~cm}$ bs. The debitage density is greatest at $30-40 \mathrm{~cm}$ bs and between $50-100 \mathrm{~cm}$ bs. No intact burned rock features were encountered. The patterning in magnetic soil susceptibility and artifact distributions indicates only a weak relationship between the two.

The significance of a prehistoric site under the National Historic Preservation Act is based on the site having yielded information important in history or prehistory or on it having the potential to yield such information in the future (36 CFR 60.4 Criterion (d)). Based on the more detailed presentation put forth in Chapter Six and the summary presented above, the following tabular summation (Table 1) provides CAR's recommendations for NRHP eligibility for each of the six sites.

Table 1. Potential to address research issues and NRHP eligibility of tested sites at Camp Maxey

\begin{tabular}{|c|c|c|c|c|c|c|}
\hline Site & Integrity & Chronology & Technology & Subsistence & Site Structure & NRHP Eligibility \\
\hline 41LR190 & Moderate & High & High & Moderate & High & Eligible \\
\hline 41LR194 & Low & Low & Low & Low & Low & Not Eligible \\
\hline 41LR196 & Moderate-Low & Moderate & Low & Low & Low & Not Eligible \\
\hline 41LR200 & Low-Moderate & Low & Low & Low & Low-Moderate & Not Eligible \\
\hline 41LR258 & Low-Moderate & Low & Low & Low & Low-Moderate & Not Eligible \\
\hline 41LR259 & Low-Moderate & Low & Low & Low & Low & Not Eligible \\
\hline
\end{tabular}


The five sites lacking criteria necessary for inclusion in the NRHP have been adequately tested and no further archaeological investigations are recommended for these sites. Proposed development within these areas of potential impact should be permitted to proceed. Site 41LR190, recommended by CAR for NRHP eligibility should, minimally, be avoided during the proposed developments within the facility. If avoidance for this significant site is not possible under the proposed plan of work, then mitigative efforts, in the form of data recovery, should be implemented prior to development.

Mitigation for 41LR190 should consist of the controlled hand excavation of a $50 \mathrm{~m}^{2}$ block. The southern portion of the block should investigate the deposits in the vicinity of TU 5. The goal should be to define the living surface associated with Feature 3 and the FCR zone evident in the BHT profile, and obtain representative ecofactual and subsistence-related artifacts associated with burned rock features. The northern portion of the block should be positioned in the vicinity of TUs 2 and 4 where additional burned rock features were identified during testing. The goals of the excavations should be the same as in the case of the southern portion of the block. The block may also provide information related to site structure. Special analyses (i.e., paleomagnetic orientation of burned rocks, macrobotanical analyses, and magnetic soil susceptibility) should be pursued to address the issues of feature integrity, living/occupation surface definition, and the gathering of subsistence-related data. 


\section{References Cited}

Adjutant General's Department of Texas (AGD)

1993 Archeological Survey Report, October 4, 1993. Letter Report. Adjutant General's Department of Texas, Austin.

1997 Archeological Survey Report, July 1, 1997. Letter Report. Adjutant General's Department of Texas, Austin.

Banks, L. D.

1990 From Mountain Peaks to Alligator Stomachs: A Review of Lithic Sources in Trans Mississippi South, Southern Plains and Adjacent Southwest. Oklahoma Anthropological Society Memoir \#4, pp. 33-34.

Bousman, C. B.

1998 Paleoenvironmental Change in Central Texas: The Palynological Evidence. Plains Anthropologist 43(164):201-219.

Brown, J. A.

1996 The Spiro Ceremonial Center: The Archaeology of Arkansas Valley Caddoan Culture in Eastern Oklahoma. 2 vols. Memoirs No. 29. Museum of Anthropology, University of Michigan, Ann Arbor.

Collins, M. B.

1995 Forty Years of Archeology in Central Texas. Bulletin of the Texas Archeological Society 66:361-400.

Corbin, J. E.

1992 Archaeological Survey of a Proposed Raw Water Line (EDA, B4) for the City of Paris, Lamar County, Texas. Nacogdoches, Texas.

Dillehay, T. D.

1974 Late Quaternary Bison Population Changes on the Southern Plains. Plains Anthropologist 19(65):180196.

Fox, D.

1979 An Archaeological Reconnaissance of Proposed Sewage Improvements for the City of Reno, Lamar County, Texas. C-48-1316. Texas Department of Water Resources.

1981 An Archaeological Reconnaissance of Proposed Sewage Treatment Facilities for the City of Reno, Lamar County, Texas. C-48-1316. Texas Department of Water Resources.

Girard, J. S.

2000 National Register Testing at the Conly Site (16BI19). In Regional Archaeology Program, Management Unit 1, Eleventh Annual Report, edited by J. S. Girard, pp. 11-64. Louisiana Regional Archaeology Program, Natchitoches.

Harris, R. K., I. M. Harris, J. C. Blaine, and J. Blaine

1965 A Preliminary Archeological and Documentary Study of the Womack Site, Lamar County, Texas. Bulletin of the Texas Archeological Society 36:287-363. 
Hester, T.

1971 Archeological Investigations at the La Jita Site, Uvalde County, Texas. Bulletin of the Texas Archeological Society 42:51-148.

Hyatt, R., and H. Mosca

1972 Survey of Cultural Resources of the Proposed Big Pine Lake, Lamar and Red River Counties, Texas. Produced for the United States Army Corps of Engineers, Tulsa District. Southern Methodist University.

Jackson, A. T., M. S. Goldstein, and A. D. Krieger

2000 The 1931 Excavations at the Sanders Site, Lamar County, Texas. Archival Series 2. Texas Archeological Research Laboratory, The University of Texas at Austin.

Johnson, L.

1962[1961] The Yarbrough and Miller Sites of Northeastern Texas, with a Preliminary Definition of the La Harpe Aspect. Bulletin of the Texas Archeological Society 32:141-284.

1989 Great Plains Interlopers in the Eastern Woodlands during Late Paleo-Indian Times. Office of the State Archeologist Report 36. Texas Historical Commission, Austin.

1995 Past Cultures and Climates at Jonas Terrace: 41ME29, Medina County, Texas. Office of the State Archeologist Report 40. Texas Historical Commission, Austin.

Johnson, L., and G. T. Goode

1994 A New Try at Dating and Characterizing Holocene Climates, as well as Archeological Periods, on the Eastern Edward's Plateau. Bulletin of the Texas Archeological Society 65:1-51.

Kenmotsu, N. A., and T. K. Perttula

1993 Archeology in the Eastern Planning Region, Texas: A Planning Document. Cultural Resources Management Report 3. Department of Antiquities Protection, Texas Historical Commission, Austin.

Lorrain, D., and N. Hoffrichter

1968 Archeological Survey and Excavation at Pat Mayse Reservoir, Texas. Archeological Salvage Project, Southern Methodist University, Dallas.

Luke, C.

1978 Initial Testing Report for 41LR58, Lamar County, Texas. State Department of Highways and Public Transportation.

Lyle, A. S., T. K. Perttula, S. A. Tomka

2001 Camp Maxey II, A 5,000 Acre Survey of Camp Maxey, Lamar County, Texas. Archaeological Survey Report, No. 312. Center for Archaeological Research, The University of Texas at San Antonio.

Mahoney, R. B., and S. A. Tomka

2001 National Register Eligibility Testing of 41 MM340 and 41 MM341 along Little River, Milam County, Texas. Archaeological Survey Report, No. 303, Center for Archaeological Research, The University of Texas at San Antonio; Archeological Studies Program, Report No. 30, Environmental Affairs Division, Texas Department of Transportation, Austin. 
Nickels, D. L, L. C. Nordt, T. K. Perttula, C. B. Bousman, and K. Miller

1998 Archaeological Survey of Southwest Block and Selected Roads and Firebreaks at Camp Maxey, Lamar County, Texas. Archaeological Survey Report, No. 290. Center for Archaeological Research, The University of Texas at San Antonio.

Perttula, T. K. (editor)

1999 The Hurricane Hill Site (41HP106): The Archaeology of a Late Archaic/Early Ceramic and EarlyMiddle Caddoan Settlement in Northeast Texas. 2 vols. Special Publication No. 4. Friends of Northeast Texas Archaeology, Pittsburgh and Austin.

Perttula, T. K., and R. Nathan

1988 Cultural Resources Survey of the Natural Gas Pipeline Company of America Southern Interconnect Pipeline, Lamar, Red River, Franklin, Morris, and Cass Counties, Texas. Institute of Applied Sciences, North Texas State University.

Prewitt, E. R.

1981 Cultural Chronology in Central Texas. Bulletin of the Texas Archeological Society 52:65-89.

1985 From Circleville to Toyah: Comments on Central Texas Chronology. Bulletin of the Texas Archeological Society 54:201-238.

Ressel, D.

1979 Soil Survey of Lamar and Delta Counties. United States Department of Agriculture, Soil Conservation Service, Washington, D.C.

Reynolds, R. L., and J. W. King

1995 Magnetic Records of Climate Change. U.S. National Report to I.U.G.G., 1991-1994. American Geophysical Union. <http://www.agu.ong/revgeophys/reyno100/reyno100.html> Accessed April 2001.

Rice, P. M.

1987 Pottery Analysis: A Sourcebook. University of Chicago Press, Chicago.

Robinson, D. G., T. M. Meade, L. H. Kay, L. Gassaway, and D. Kay

2001 An Archaeological Inventory of Camp Swift, Bastrop County, Texas. Archaeological Survey Report, No. 316. Center for Archaeological Research, The University of Texas at San Antonio.

Schambach, F. F.

1998 Pre-Caddoan Cultures of the Trans-Mississippi South. Arkansas Archeological Survey Research Series 53, Fayetteville.

Shafer, H. J.

1965 Archeological Surveys of Honea, Pat Mayse, and Halsell Reservoirs, Texas. Survey Report No. 1. Texas Archeological Salvage Project.

Story, D. A.

1990 Cultural History of the Native Americans. In The Archeology and Bioarcheology of the Gulf Coastal Plain, by D. A. Story, J. A. Guy, B. A. Burnett, M. D. Freeman, J. C. Rose, D. G. Steele, B. W. Olive, and K. J. Reinhard, pp. 163-366. Research Series No. 38. 2 vols. Arkansas Archeological Survey, Fayetteville. 
Stuvier, M., and P. J. Reimer

1993 Extended ${ }^{14} \mathrm{C}$ Database and Revised CALIB Radiocarbon Calibration Program. Radiocarbon 35:215230.

Sullo, D. M., and S. C. Stringer

1998 Cultural Resource Investigations for Minor Construction Projects, Camp Maxey, Lamar County, Texas. Adjutant General's Department of Texas, Austin.

Teltser, P. A.

1993 An Analytic Strategy for Studying Assemblage-Scale Ceramic Variation: A Case Study from Southeast Missouri. American Antiquity 58(3):530-543.

Wood, W. R.

1998 Archaeology on the Great Plains. The University Press of Kansas, Lawrence.

Wyckoff, D. G.

1984 The Foragers: Eastern Oklahoma. In Prehistory of Oklahoma, edited by R. E. Bell, pp. 119-160. Academic Press.

Young, W. C.

1984 Archeological Testing of Site 41LR92, Lamar County, Texas. State Department of Highways and Public Transportation. 



\section{Appendix A}

Magnetic Sediment Susceptibility Testing

by

Raymond P. Mauldin 


\section{Introduction}

The magnetic susceptibility (MS) of a given sediment sample can be thought of as a measure of how easily that sample can be magnetized (Dearing 1999; Gose and Nickels 2001). At low magnetic field strengths, this measure is primarily related to the concentration and grain size of ferro and ferromagnetic minerals in the sample (Gose and Nickels 2001). A number of processes can result in an increase in MS values in a sediment sample. Of these processes, those that are of concern here are related to an increase in the organic constitutes or changes in the mineralogy of sediments in a given sample (see Collins et al. 1994; McClean and Kean 1993; Singer and Fine 1989). Sediments with higher organic content tend to have higher magnetic susceptibility values, probably as a result of the production of maghemite, an iron oxide, during organic decay (Reynolds and King 1995). Pedogenic processes, such as soil formation and weathering, can result in the concentration of organic material, as well as alterations in the mineralogy of a given zone. These processes can significantly impact susceptibility readings. Cultural processes, such as the concentration of ash, charcoal, and refuse, would also produce higher MS readings. A measure of the magnetic susceptibility of a sediment sample, then, may provide information on both the presence of surfaces, as well as a measure of the concentration of cultural activity upon those surfaces.

\section{Collection Procedures and Laboratory Methods}

A total of 116 samples were processed for magnetic sediment susceptibility from four sites (41LR- 190, 200, 258, and 259) at Camp Maxey. All samples were collected at $5-\mathrm{cm}$ intervals along a given vertical stretch of an excavation unit. All sediment samples were air dried on a non-metal surface. After drying, the samples were then ground to a uniform grain size using a ceramic mortar and pestle. This was done to standardize particle size and make the material both easier to handle and pack into sample containers. After each sample was ground, the mortar and pestle was washed with tap water and wiped dry with a paper towel to avoid cross-sample contamination. The ground sample was then poured into a sample container consisting of a plastic cube with external dimensions of $2.54 \times 2.54 \times 1.94 \mathrm{~cm}$. The cubes have an average weight of 4.83 grams. The sediment filled cube was then weighed, and the weight of the sample calculated by subtracting the empty cube weight. This was done to correct for differences in mass. Assuming that sample volume and material are constant, larger samples should have higher susceptibility values simply as a function of greater mass.

The cube was then placed into a MS2B Dual Frequency Sensor that, in conjunction with a MS2 Magnetic Susceptibility Meter, provided a measure of the magnetic susceptibility of the sample (see Dearing 1999). For each cube, three distinct readings were taken using the SI (standard international) scale. These were averaged to provide a single reading. The value, referred to as volume specific susceptibility and noted with the symbol $K_{\text {. }}$ (Kappa), is recorded on a scale of $10^{-5}$, though there are no units associated with the value. That is, the value is dimensionless (Dearing 1999).

In order to correct for differences in sample weight, and provide units to the value $K$, the mass specific susceptibility value (X) was calculated using the formula,

$$
X=\left(K_{0} / p\right)
$$

where $\mathrm{p}$ is the sample bulk density expressed in $\mathrm{kg} \mathrm{m}^{-3}$. The bulk density is determined by dividing the sample mass by volume. However, as all samples were measured in identical cubes, and all cubes were full, the sample volume is assumed to be constant. Only the mass of the sample varied. Mass specific susceptibility can be determined by,

$$
\mathrm{X}=(\mathrm{K} * \text { calibrated mass }) / \text { sample mass }
$$

where sample mass is determined by subtracting the cube weight from the total sample weight (Dearing 1999). Calibrated mass is assumed to be 10 grams.

While the resulting values now have both a scale and associated units, the critical element for the current discussion is related to relative differences between 
X sample values within a given profile or site, rather than absolute differences. That is, the principal interest is in rapid changes in the mass specific susceptibility values along a profile. This change may signal either a buried surface and/or cultural activity at that location. Comparisons of absolute values between samples from different areas, especially when the parent material of the soils is different, are of limited utility given our current goals.

This can be seen in Table A-1, which lists a variety of examples of mass specific susceptibility values for several different materials. In all cases, the analysis was performed following the procedures outlined previously. Note that the values differ widely, from a low of -1.47 for tap water, to a high of 97.62 for sediments collected from a burned rock midden. Samples 5 and
6 are of two different clays from the same general setting, far northern Lamar County in north Texas. The mass specific susceptibility is different for these samples, probably as a function of different frequencies of trace elements that, though small in absolute quantity, can dramatically impact the susceptibility values.

The potential impacts of cultural processes on susceptibility values can be seen by considering a data set collected from an archaeological site located in Brown County, 41BR473. A total of 279 sediment susceptibility samples were collected from each level of over 50 shovel tests placed at this site. In all cases, the analytical procedures followed those outlined previously. Table A-2 presents summary data on all 279 cases, along with susceptibility scores for those

Table A-1. Magnetic sediment susceptibility data for a variety of substances

\begin{tabular}{|l|c|c|c|c|c|c|c|}
\hline \multicolumn{1}{|c|}{ Sample Type } & $\begin{array}{c}\text { Total } \\
\text { Wt. (gr.) }\end{array}$ & $\begin{array}{c}\text { Sample } \\
\text { Wt. (gr.) }\end{array}$ & $\begin{array}{c}\text { Reading } \\
\mathbf{1}(\mathbf{k})\end{array}$ & $\begin{array}{c}\text { Reading } \\
\mathbf{2}(\mathbf{k})\end{array}$ & $\begin{array}{c}\text { Reading } \\
\mathbf{3}(\mathbf{k})\end{array}$ & $\begin{array}{c}\text { Average } \\
\text { K }\end{array}$ & $\begin{array}{c}\text { Corrected } \\
\text { Mass (X) }\end{array}$ \\
\hline $\begin{array}{l}\text { 1) Sandy sediment } \\
\text { with organics }\end{array}$ & 13.7 & 8.85 & 27.9 & 28 & 28.1 & 28.00 & 31.64 \\
\hline $\begin{array}{l}\text { 2) Modern mesquite } \\
\text { charcoal and sediment }\end{array}$ & 9.4 & 4.55 & 10.7 & 10.8 & 10.7 & 10.73 & 23.59 \\
\hline $\begin{array}{l}\text { 3) Modern oak } \\
\text { wood ash }\end{array}$ & 7.5 & 2.65 & 16.1 & 16.2 & 16.2 & 16.17 & 61.01 \\
\hline $\begin{array}{l}\text { 4) Sediment from } \\
\text { burned rock midden }\end{array}$ & 11.3 & 6.45 & 62.9 & 63 & 63 & 62.97 & 97.62 \\
\hline $\begin{array}{l}\text { 5) Grey clay - no } \\
\text { human occupation }\end{array}$ & 12.6 & 7.75 & 10.4 & 10.3 & 10.4 & 10.37 & 13.38 \\
\hline $\begin{array}{l}\text { 6) Red clay - no } \\
\text { human occupation }\end{array}$ & 10.8 & 5.95 & 11.9 & 12 & 12 & 11.97 & 20.11 \\
\hline 7) Sandstone & 14.7 & 9.85 & 6.9 & 7 & 7.1 & 7.00 & 7.11 \\
\hline 8) Limestone & 12.7 & 7.85 & -0.5 & -0.5 & -0.5 & -0.50 & -0.64 \\
\hline 9) Tap water & 10.5 & 5.65 & -0.8 & -0.8 & -0.9 & -0.83 & -1.47 \\
\hline
\end{tabular}

Table A-2. Presence/absence of cultural material and mass specific sediment susceptibility scores for shovel tests at 41BR473

\begin{tabular}{|c|c|c|c|c|c|}
\hline & All Cases & $\begin{array}{c}\text { FCR } \\
\text { Present }\end{array}$ & $\begin{array}{c}\text { FCR } \\
\text { Absent }\end{array}$ & $\begin{array}{c}\text { Chipped Stone } \\
\text { Present }\end{array}$ & $\begin{array}{c}\text { Chipped Stone } \\
\text { Absent }\end{array}$ \\
\hline $\begin{array}{c}\text { Number } \\
\text { of Samples }\end{array}$ & 279 & 84 & 195 & 38 & 241 \\
\hline Mean Value & 48.3 & 56.9 & 44.6 & 55.2 & 47.2 \\
\hline $\begin{array}{c}\text { Standard } \\
\text { Deviation }\end{array}$ & 17.2 & 17.7 & 15.6 & 16.1 & 17.1 \\
\hline
\end{tabular}


settings that had fire-cracked rock (FCR) or chipped stone present. If cultural inputs result in higher susceptibility values, then it should be the case that significantly higher susceptibility values will be present in levels that have cultural material.

An examination of Table A-2 will demonstrate that this is indeed the case. Levels that have FCR present do have higher scores relative to those that lack FCR. Similarly, those levels that have chipped stone present have a higher average mass specific susceptibility score relative to those that lack chipped stone. As the distribution is approximately normal, a t-test was used to test the overall significance of these differences. In both the FCR and chipped stone comparisons, the test confirms that those levels with cultural material have significantly higher scores than those without cultural material (FCR t-statistic $=5.804, \mathrm{df}=277, \mathrm{p}<.001$; chipped stone t-statistic $=2.674, \mathrm{df}=277, \mathrm{p}=.008$ ). Our preliminary investigations, then, coupled with the previous work, clearly suggest that an analysis of the magnetic susceptibility of sediment can provide additional information on both the presence of buried surfaces, as well as the impact of cultural material on those surfaces.

Table A-3 presents the raw data for the 116 samples from the four sites at Camp Maxey. A site-by-site discussion of the specific results is provided in Chapter 6. 
Table A-3. Sediment susceptibility data for four sites at Camp Maxey

\begin{tabular}{|c|c|c|c|c|c|c|c|}
\hline Site- Unit & Depth & Weight (g) & Reading 1 & Reading 2 & Reading 3 & Average & MSS Value \\
\hline LR 200- Test Unit 2 & 2.5 & 14.2 & 13.6 & 14.0 & 14.1 & 13.90 & 14.82 \\
\hline LR 200- Test Unit 2 & 7.5 & 14.5 & 12.0 & 12.6 & 12.5 & 12.37 & 12.78 \\
\hline LR 200- Test Unit 2 & 12.5 & 14.9 & 13.0 & 13.2 & 13.2 & 13.13 & 13.03 \\
\hline LR 200- Test Unit 2 & 17.5 & 14.6 & 14.3 & 14.4 & 14.4 & 14.37 & 14.69 \\
\hline LR 200- Test Unit 2 & 22.5 & 14.9 & 14.1 & 14.2 & 14.0 & 14.10 & 13.99 \\
\hline LR 200- Test Unit 2 & 27.5 & 14.5 & 13.8 & 13.9 & 13.7 & 13.80 & 14.26 \\
\hline LR 200- Test Unit 2 & 32.5 & 14.8 & 15.1 & 15.2 & 15.3 & 15.20 & 15.23 \\
\hline LR 200- Test Unit 2 & 37.5 & 14.9 & 16.6 & 16.3 & 16.5 & 16.47 & 16.34 \\
\hline LR 200- Test Unit 2 & 42.5 & 14.5 & 16.9 & 16.1 & 15.9 & 16.30 & 16.84 \\
\hline LR 200- Test Unit 2 & 47.5 & 14.3 & 15.6 & 15.6 & 15.8 & 15.67 & 16.53 \\
\hline LR 200- Test Unit 2 & 52.5 & 14.3 & 16.8 & 16.7 & 16.7 & 16.73 & 17.65 \\
\hline LR 200- Test Unit 2 & 57.5 & 14.7 & 18.3 & 18.4 & 18.2 & 18.30 & 18.52 \\
\hline LR 200- Test Unit 2 & 62.5 & 14.6 & 18.5 & 18.6 & 18.6 & 18.57 & 18.98 \\
\hline LR 200- Test Unit 2 & 67.5 & 14.3 & 18.4 & 18.4 & 18.4 & 18.40 & 19.41 \\
\hline LR 200- Test Unit 2 & 72.5 & 14.9 & 19.2 & 19.0 & 19.0 & 19.07 & 18.92 \\
\hline LR 200- Test Unit 2 & 77.5 & 14.7 & 18.4 & 18.3 & 18.4 & 18.37 & 18.59 \\
\hline LR 200- Test Unit 2 & 82.5 & 14.8 & 18.2 & 18.3 & 18.2 & 18.23 & 18.27 \\
\hline LR 200- Test Unit 2 & 87.5 & 14.3 & 17.4 & 17.3 & 17.2 & 17.30 & 18.25 \\
\hline LR 200- Test Unit 2 & 92.5 & 14.8 & 22.3 & 22.3 & 22.4 & 22.33 & 22.38 \\
\hline LR 200- Test Unit 2 & 97.5 & 14.9 & 20.3 & 20.4 & 20.5 & 20.40 & 20.24 \\
\hline LR 200- Test Unit 2 & 102.5 & 14.7 & 19.7 & 19.9 & 20.0 & 19.87 & 20.11 \\
\hline LR 200- Test Unit 2 & 107.5 & 14.6 & 21.7 & 22.2 & 22.1 & 22.00 & 22.49 \\
\hline LR 200- Test Unit 2 & 112.5 & 14.4 & 16.3 & 16.5 & 16.5 & 16.43 & 17.15 \\
\hline LR 200- Test Unit 2 & 117.5 & 14.5 & 14.8 & 14.9 & 14.6 & 14.77 & 15.25 \\
\hline LR 200- Test Unit 2 & 122.5 & 14.7 & 14.2 & 14.3 & 14.4 & 14.30 & 14.47 \\
\hline LR 200- Test Unit 2 & 127.5 & 14.3 & 11.6 & 11.8 & 11.8 & 11.73 & 12.38 \\
\hline LR 200- Test Unit 2 & 132.5 & 14.7 & 12.5 & 12.7 & 12.5 & 12.57 & 12.72 \\
\hline LR 200- Test Unit 2 & 137.5 & 14.2 & 15.7 & 15.9 & 15.9 & 15.83 & 16.88 \\
\hline LR 200- Test Unit 2 & 142.5 & 14.3 & 16.7 & 17.0 & 17.1 & 16.93 & 17.86 \\
\hline LR 200- Test Unit 2 & 147.5 & 14.1 & 14.7 & 14.8 & 14.7 & 14.73 & 15.88 \\
\hline LR 190-Test Unit 5 & 2.5 & 12.7 & 13.9 & 13.9 & 13.9 & 13.90 & 17.66 \\
\hline LR 190-Test Unit 5 & 7.5 & 12.6 & 13.5 & 13.4 & 13.5 & 13.47 & 17.33 \\
\hline LR 190-Test Unit 5 & 12.5 & 13.4 & 16.2 & 16.4 & 16.3 & 16.30 & 19.02 \\
\hline LR 190-Test Unit 5 & 17.5 & 13.1 & 15.3 & 15.1 & 15.2 & 15.20 & 18.38 \\
\hline LR 190-Test Unit 5 & 22.5 & 12.7 & 15.1 & 15.1 & 15.1 & 15.10 & 19.19 \\
\hline LR 190-Test Unit 5 & 27.5 & 13.7 & 16.2 & 16.5 & 16.4 & 16.37 & 18.45 \\
\hline LR 190-Test Unit 5 & 32.5 & 13.3 & 16.9 & 17.2 & 16.8 & 16.97 & 20.03 \\
\hline LR 190-Test Unit 5 & 37.5 & 14.4 & 19.5 & 19.4 & 19.4 & 19.43 & 20.31 \\
\hline LR 190-Test Unit 5 & 42.5 & 14 & 20.1 & 20 & 20 & 20.03 & 21.85 \\
\hline LR 190-Test Unit 5 & 47.5 & 13.3 & 18.8 & 18.7 & 18.8 & 18.77 & 22.16 \\
\hline LR 190-Test Unit 5 & 52.5 & 13.5 & 18.8 & 18.7 & 18.7 & 18.73 & 21.61 \\
\hline LR 190-Test Unit 5 & 57.5 & 14.7 & 20.6 & 20.5 & 20.5 & 20.53 & 20.80 \\
\hline LR 190-Test Unit 5 & 62.5 & 13.5 & 19.8 & 19.8 & 19.9 & 19.83 & 22.88 \\
\hline LR 190-Test Unit 5 & 67.5 & 14 & 23.8 & 23.6 & 23.8 & 23.73 & 25.88 \\
\hline LR 190-Test Unit 5 & 72.5 & 14.2 & 23.4 & 23.5 & 23.5 & 23.47 & 25.04 \\
\hline
\end{tabular}


Table A-3. continued...

\begin{tabular}{|c|c|c|c|c|c|c|c|}
\hline Site- Unit & Depth & Weight (g) & Reading 1 & Reading 2 & Reading 3 & Average & MSS Value \\
\hline LR 190-Test Unit 5 & 77.5 & 13.5 & 19.4 & 19.4 & 19.4 & 19.40 & 22.38 \\
\hline LR 190-Test Unit 5 & 82.5 & 14.4 & 21.8 & 22 & 22 & 21.93 & 22.92 \\
\hline LR 190-Test Unit 5 & 87.5 & 14.6 & 19.4 & 19.4 & 19.4 & 19.40 & 19.86 \\
\hline LR 190-Test Unit 5 & 92.5 & 13.7 & 18.9 & 19 & 19.9 & 19.27 & 21.72 \\
\hline LR 190-Test Unit 5 & 97.5 & 12.9 & 28.4 & 28.4 & 28.4 & 28.40 & 35.19 \\
\hline LR 190-Test Unit 5 & 102.5 & 12.5 & 24.1 & 24.3 & 24.3 & 24.23 & 31.59 \\
\hline LR 190-Test Unit 5 & 107.5 & 12.3 & 23.2 & 23.1 & 23.1 & 23.13 & 30.97 \\
\hline LR 190-Test Unit 5 & 112.5 & 12.3 & 17.8 & 17.9 & 17.8 & 17.83 & 23.87 \\
\hline LR 190-Test Unit 5 & 117.5 & 12.3 & 15.6 & 15.9 & 15.7 & 15.73 & 21.06 \\
\hline LR 258- Test Unit 2 & 2.5 & 11.9 & 6.3 & 6.4 & 6.5 & 6.40 & 9.05 \\
\hline LR 258- Test Unit 2 & 7.5 & 11.2 & 6.4 & 6.5 & 6.4 & 6.43 & 10.10 \\
\hline LR 258- Test Unit 2 & 12.5 & 12.3 & 8 & 8.1 & 8 & 8.03 & 10.75 \\
\hline LR 258- Test Unit 2 & 17.5 & 13.4 & 9 & 9.1 & 9.2 & 9.10 & 10.62 \\
\hline LR 258- Test Unit 2 & 22.5 & 12.4 & 8.1 & 8.1 & 8.1 & 8.10 & 10.70 \\
\hline LR 258- Test Unit 2 & 27.5 & 12.3 & 9.1 & 9.2 & 9.1 & 9.13 & 12.23 \\
\hline LR 258- Test Unit 2 & 32.5 & 13 & 10 & 10.1 & 10.2 & 10.10 & 12.36 \\
\hline LR 258- Test Unit 2 & 37.5 & 13.8 & 11.4 & 11.5 & 11.5 & 11.47 & 12.78 \\
\hline LR 258- Test Unit 2 & 42.5 & 12 & 9 & 9.1 & 9 & 9.03 & 12.60 \\
\hline LR 258- Test Unit 2 & 47.5 & 13.8 & 12.5 & 12.5 & 12.5 & 12.50 & 13.94 \\
\hline LR 258- Test Unit 2 & 52.5 & 13.8 & 13.7 & 13.9 & 13.6 & 13.73 & 15.31 \\
\hline LR 258- Test Unit 2 & 57.5 & 14 & 14.2 & 14.1 & 14.2 & 14.17 & 15.45 \\
\hline LR 258- Test Unit 2 & 62.5 & 14 & 13.8 & 13.8 & 13.8 & 13.80 & 15.05 \\
\hline LR 258- Test Unit 2 & 67.5 & 14 & 14 & 14.1 & 14.1 & 14.07 & 15.34 \\
\hline LR 258- Test Unit 2 & 72.5 & 14.1 & 14.4 & 14.4 & 14.4 & 14.40 & 15.53 \\
\hline LR 258- Test Unit 2 & 77.5 & 12.5 & 11.5 & 11.6 & 11.5 & 11.53 & 15.04 \\
\hline LR 258- Test Unit 2 & 82.5 & 14 & 14.5 & 14.6 & 14.4 & 14.50 & 15.81 \\
\hline LR 258- Test Unit 2 & 87.5 & 13.9 & 15.3 & 15.4 & 15.3 & 15.33 & 16.91 \\
\hline LR 258- Test Unit 2 & 92.5 & 12.8 & 13 & 13 & 13 & 13.00 & 16.31 \\
\hline LR 258- Test Unit 2 & 97.5 & 14.1 & 15.9 & 16 & 16 & 15.97 & 17.22 \\
\hline LR 258- Test Unit 2 & 102.5 & 13.5 & 15.4 & 15.6 & 15.5 & 15.50 & 17.88 \\
\hline LR 258- Test Unit 2 & 107.5 & 12.4 & 14.8 & 14.9 & 14.8 & 14.83 & 19.59 \\
\hline LR 258- Test Unit 2 & 112.5 & 12 & 11.7 & 11.8 & 11.5 & 11.67 & 16.27 \\
\hline LR 258- Test Unit 2 & 117.5 & 13.3 & 12.3 & 12.3 & 12.3 & 12.30 & 14.52 \\
\hline LR 258- Test Unit 2 & 122.5 & 13.5 & 15.8 & 15.9 & 15.8 & 15.83 & 18.26 \\
\hline LR 258- Test Unit 2 & 127.5 & 13.3 & 10.5 & 10.6 & 10.5 & 10.53 & 12.44 \\
\hline LR 258- Test Unit 2 & 132.5 & 13.9 & 13.8 & 13.9 & 13.8 & 13.83 & 15.25 \\
\hline LR 258- Test Unit 2 & 137.5 & 12.6 & 11.1 & 11.2 & 11.1 & 11.13 & 14.33 \\
\hline LR 258- Test Unit 2 & 142.5 & 13.1 & 8.3 & 8.5 & 8.4 & 8.40 & 10.16 \\
\hline LR 258- Test Unit 2 & 147.5 & 13.6 & 8 & 8.2 & 8.1 & 8.10 & 9.24 \\
\hline LR 258- Test Unit 2 & 152.5 & 13.6 & 6 & 6 & 6 & 6.00 & 6.84 \\
\hline LR 258- Test Unit 2 & 157.5 & 12.5 & 7.5 & 7.4 & 7.5 & 7.47 & 9.73 \\
\hline LR 258- Test Unit 2 & 162.5 & 13.7 & 10.1 & 10.1 & 10.1 & 10.10 & 11.39 \\
\hline LR 258- Test Unit 2 & 167.5 & 14.4 & 10.8 & 10.9 & 10.8 & 10.83 & 11.32 \\
\hline LR 258- Test Unit 2 & 172.5 & 13.1 & 6 & 6.1 & 6.2 & 6.10 & 7.38 \\
\hline LR 258- Test Unit 2 & 177.5 & 13.3 & 8 & 8 & 8.1 & 8.03 & 9.48 \\
\hline
\end{tabular}


Table A-3. continued...

\begin{tabular}{|c|c|c|c|c|c|c|c|}
\hline Site- Unit & Depth & Weight (g) & Reading 1 & Reading 2 & Reading 3 & Average & MSS Value \\
\hline LR 259- Test Unit 2 & 2.5 & 12.3 & 6.4 & 6.6 & 6.7 & 6.57 & 8.79 \\
\hline LR 259- Test Unit 2 & 7.5 & 12.6 & 7.7 & 7.7 & 7.7 & 7.70 & 9.91 \\
\hline LR 259- Test Unit 2 & 12.5 & 12.6 & 7.2 & 7.2 & 7.2 & 7.20 & 9.27 \\
\hline LR 259- Test Unit 2 & 17.5 & 14.1 & 9.4 & 9.6 & 9.6 & 9.53 & 10.28 \\
\hline LR 259- Test Unit 2 & 22.5 & 13.5 & 9.4 & 9.4 & 9.4 & 9.40 & 10.84 \\
\hline LR 259- Test Unit 2 & 27.5 & 13.6 & 11.9 & 12 & 12.1 & 12.00 & 13.68 \\
\hline LR 259- Test Unit 2 & 32.5 & 13.6 & 13.3 & 13.3 & 13.3 & 13.30 & 15.17 \\
\hline LR 259- Test Unit 2 & 37.5 & 11.7 & 10.2 & 10.3 & 10.3 & 10.27 & 14.94 \\
\hline LR 259- Test Unit 2 & 42.5 & 13.1 & 14 & 14.1 & 14 & 14.03 & 16.97 \\
\hline LR 259- Test Unit 2 & 47.5 & 12.4 & 14 & 14 & 14 & 14.00 & 18.49 \\
\hline LR 259- Test Unit 2 & 52.5 & 13.3 & 17.2 & 17.3 & 17.4 & 17.30 & 20.43 \\
\hline LR 259- Test Unit 2 & 57.5 & 13.8 & 16.9 & 17 & 17 & 16.97 & 18.91 \\
\hline LR 259- Test Unit 2 & 62.5 & 12.9 & 14.7 & 14.7 & 14.7 & 14.70 & 18.22 \\
\hline LR 259- Test Unit 2 & 67.5 & 13.5 & 15.8 & 16.1 & 15.8 & 15.90 & 18.34 \\
\hline LR 259- Test Unit 2 & 72.5 & 13 & 14.4 & 14.6 & 14.5 & 14.50 & 17.75 \\
\hline LR 259- Test Unit 2 & 77.5 & 12.6 & 17.2 & 17.2 & 17.2 & 17.20 & 22.14 \\
\hline LR 259- Test Unit 2 & 82.5 & 13 & 11.9 & 11.9 & 11.9 & 11.90 & 14.57 \\
\hline LR 259- Test Unit 2 & 87.5 & 14.1 & 24.9 & 24.9 & 24.9 & 24.90 & 26.86 \\
\hline LR 259- Test Unit 2 & 92.5 & 13.9 & 15.1 & 15.2 & 15.1 & 15.13 & 16.69 \\
\hline LR 259- Test Unit 2 & 97.5 & 13 & 12.2 & 12.3 & 12.3 & 12.27 & 15.01 \\
\hline LR 259- Test Unit 2 & 102.5 & 13.5 & 12 & 12.2 & 12 & 12.07 & 13.92 \\
\hline LR 259- Test Unit 2 & 107.5 & 12.6 & 10.9 & 10.8 & 10.8 & 10.83 & 13.94 \\
\hline LR 259- Test Unit 2 & 112.5 & 14.8 & 12.1 & 12.2 & 12.1 & 12.13 & 12.17 \\
\hline LR 259- Test Unit 2 & 117.5 & 14 & 10.3 & 10.4 & 10.4 & 10.37 & 11.30 \\
\hline LR 259- Test Unit 2 & 122.5 & 12.9 & 16.9 & 17 & 17 & 16.97 & 21.02 \\
\hline LR 259- Test Unit 2 & 127.5 & 12.6 & 16.1 & 16.2 & 16.2 & 16.17 & 20.81 \\
\hline
\end{tabular}




\section{References Cited}

Collins, M. B., W. A. Gose, and S. Shaw

1994 Preliminary Geomorphological Findings at Dust and Nearby Caves. Journal of Alabama Archaeology 40:35-56.

Dearing, J.

1999 Environmental Magnetic Susceptibility. Chi Publishing, Kenilworth, England.

Gose, W. A., and D. L. Nickels

2001[1998] Archaeomagnetic and Magnetic Susceptibility Analyses. In Test Excavations at the Culebra Creek Site, 41BX126, Bexar County, Texas, by D. L. Nickels, C. B. Bousman, J. D. Leach, and D. A. Cargill, pp. 204-214. Archaeological Survey Report, No. 265, Center for Archaeological Research, University of Texas at San Antonio; Archeology Studies Program, Report 3, Environmental Affairs Division, Texas Department of Transportation, Austin.

McClean, R. G., and W. F. Kean

1993 Contributions of Wood Ash Magnetism to Archeomagnetic Properties of Fire Pits and Hearths. Earth and Planetary Science Letters 119:387-394.

Reynolds, R. L., and J. W. King

1995 Magnetic Records of Climate Change. U.S. National Report to I.U.G.G., 1991-1994. American Geophysical Union. <http://www.agu.ong/revgeophys/reyno100/reyno100.html> Accessed April 2001.

Singer, M. J., and P. Fine

1998 Pedogenic Factors Affecting Magnetic Susceptibility of Northern California Soils. Soil Science of America Journal 53:1119-1127. 